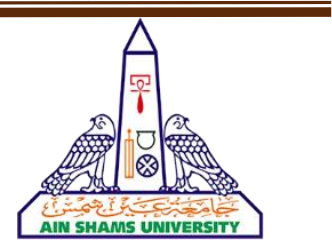

كلية التربية النوعية

قسم تكنولوجيا التعليم

أثثر استراتيجيتين للفصول المعكوسة التثاركية (التقدمية/الرجعية)

في تنمية مهارات تطوير المواقع التعليمية لدي طلاب الدراسات العليا

مستل من رسالة ماجستير مقدم من الباحثة

مني السيد العربي بيومي

معيدة بقسم تكنولوجيا التعليم-كلية التربية النوعية-جامعة عين شمس

استكمالا للحصول على درجة الماجستير في التربية النوعية

تخصص "تكنولوجيا التعليم"

\title{
تحت إشراف
}

د/ رضا إبراهيم عبد المعبود

مدرس تكنولوجيا التعليم

كلية التربية النوعية

جامعة عين شمس
أ.د/ وليد يوسف محمد

أستاذ تكنولوجيا التعليم

كلية التربية-جامعة حلوان

$$
\text { r. 19- ه 1 1 1 }
$$




\section{أثر استراتيجيتين للفصول المعكوسة التشاركية "التقدمية/الرجعية" أ.مني السيد العربي}

\section{مستخلص البحث}

يهدف البحث الحالي إلي تحديد البيئة الأنسب (الفصل المعكوس التشاركي

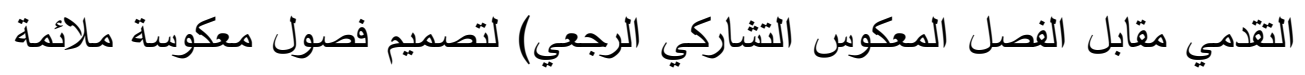

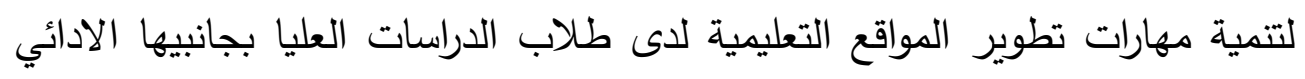

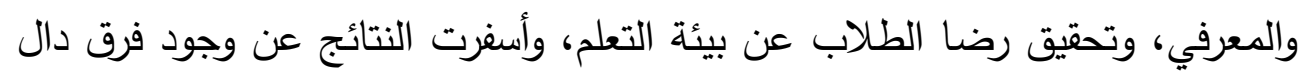

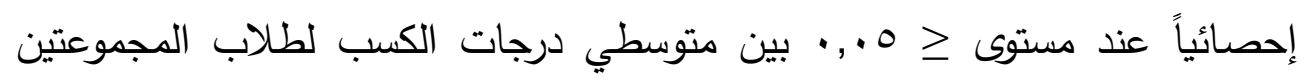

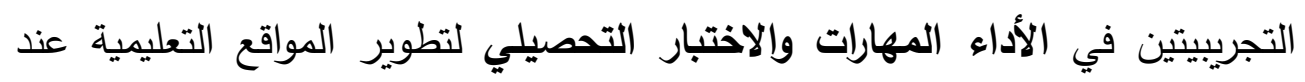

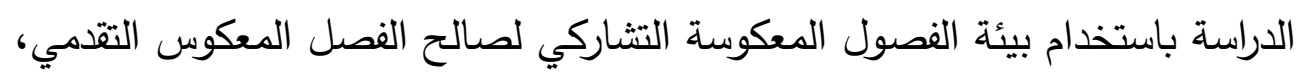

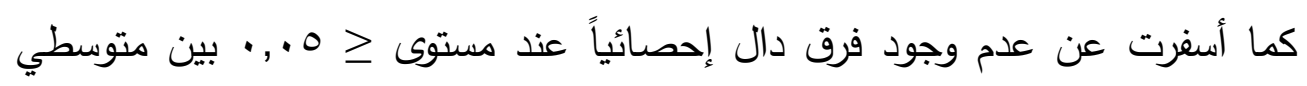

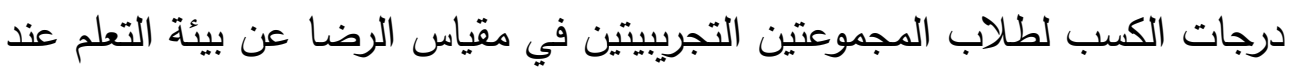

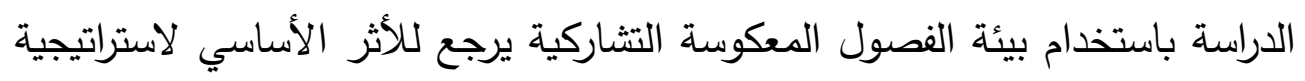

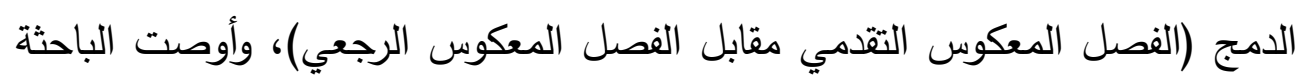

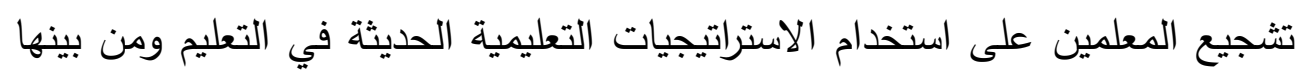
استراتيجية الفصول المعكوسة. 


\section{Summary of the research}

The present research aims to determine the most suitable environment (progressive reverse participatory versus retroactive participatory reverse chapter) to design appropriate reverse classes to develop the skills of developing educational sites for graduate students with both performance and cognitive aspects, and to achieve student satisfaction with the learning environment, and the results resulted in a statistically significant difference when The level of $\leq 0.05$ between the average scores of students of the two experimental groups in the performance skills and achievement test for the development of educational sites when studying using a participatory reverse classroom environment in favor of the progressive reverse classroom, also resulted in no difference Statistically at $\leq 0.05$ between the average scores of students of the two experimental groups in the satisfaction measure of the learning environment when studying using the participatory reverse classroom environment due to the basic impact of the integration strategy (progressive reverse versus retroactive reverse), the researcher recommended encouraging teachers to use modern educational strategies in Education, including the strategy of reverse classes 


\section{أثر استراتيجيتين للفصول المعكوسة التشاركية "التقدمية/الرجعية" أ.مني السيد العربي}

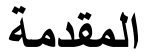

إن الاهتمام بتطوير النظم التعليمية هو حجر الأساس لتطور الدول المتقدمة في مختلف المجالات، ونظرًا للتطور التكنولوجي السريع في مناحي الحياة عامة، وفي التيا

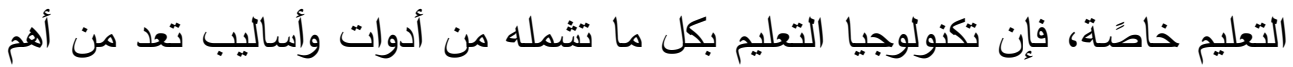
المستحدثات التكنولوجية الحديثة التي تزيد من كفاءة التعلم.

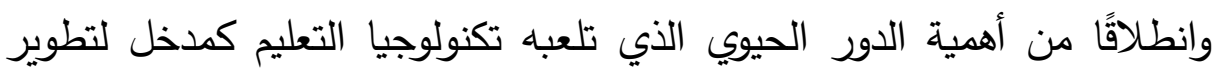

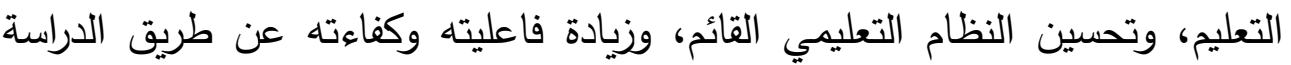
التحليلية الدقيقة والمتأنية والمنظمة للمنظومة التعليمية بأكملها، وما يشتمل عليه من وناهين

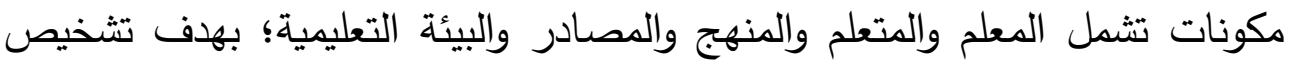
وتحديد مشكلاتها ومواطن الخلل فيها واقتراح أنسب الحلول لها، ثم تصميم هذه الحلول في شكل منتوجات تعليمية وتطويرها، وتتفيذها، وتقويمها بهدف تسهيل

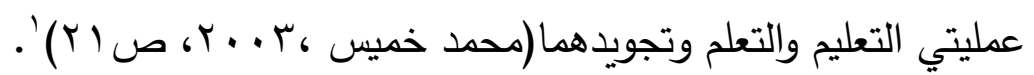
فإننا في حاجة إلى اختيار المستحثثات التكنولوجية الملائمة للتظلب على مشكلة

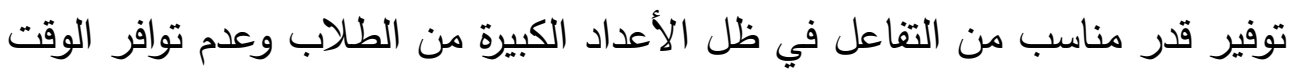
الكافي لإحداث التفاعل بين المعلم وطلابه، وبين الطلاب بعضهم البعض لممارسة مزيد من الأنشطة التعليمية المختلفة لتحقيق الأهداف المنشودة.

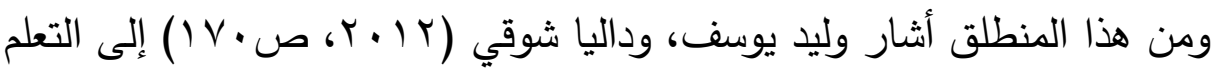
المدمج كأحد المستحدثات التكنولوجية المهمة التي يمكن أن تساهم في حل كثير من لئل المشكلات التي تواجه العملية التعليمية.

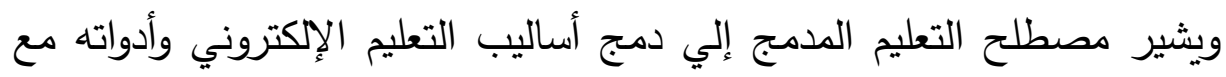
أساليب التعليم التقليدي وأدواته داخل القاعة الدراسية بالمؤسسة التعليمية، ومن ثم فهو تطبيق للاستراتيجيات التعليمية القديمة برؤية المستحدثات التكنولوجية الحديثة، فيتم الجمع بين مديزات التعلم التقليدي والآكتروني والمستحدثات التكنولوجية، وفيه يتحول بلية 
دور المعلم إلي مرشد وموجه للمتعلمين (الغريب زاهر إسماعيل،9 . . ب، ص19-

ولقد أشارت العديد من الدراسات إلى فاعلية التعليم المدمج في تحسين مخرجات

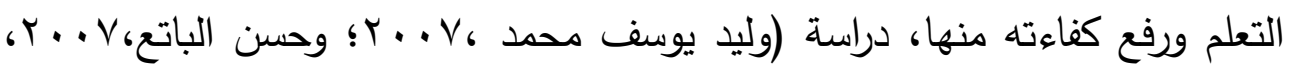

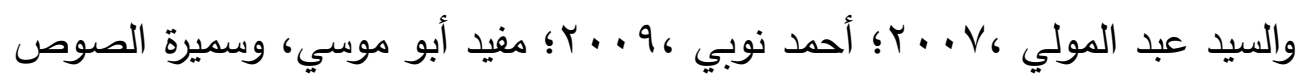

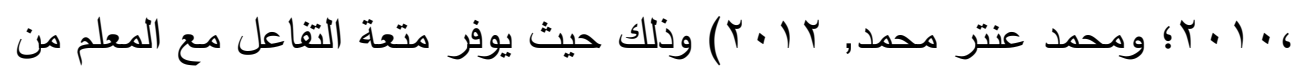
جانب، والتقاعل مع المواد التعليمية الرقمية من جانب آخر، وبالتالي يمكن تحقيق الأهداف التعليمية بوقت أقل بنسبة .0\% من الاستراتيجيات التقليدية (حمدي عز

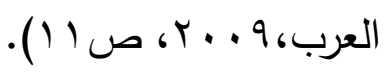

وقامت دراسة تايبنك وبوتيه (Tayebinik,Puteh,2012,pp103-108) بتحليل نتائج الدراسات والبحوث السابقة و توصل البحث إلى أن التعليم المدمج أكثر

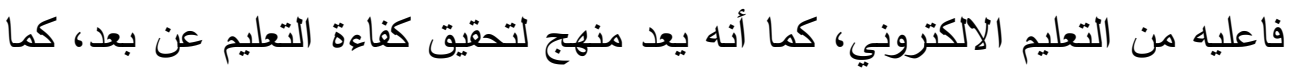
أكدا الباحثان علي أن التعليم المدمج سيكون هو النمط السائد في المستقبل. Bernatek, وفي هذا الإطار قامت دراسة كل من برنتك وآخرون (etal.,2012,pp5-13)، و دراسة والني (Walne, 2012, p3)، وكذلك دراسة هورن وستاكر (Horn\&Staker,2011,pp4-6) بتحليل معظم نماذج التعليم المدمج التي طبقت من خلال الدراسات والبحوث المختلفة، وذلك بهدف الخروج بتصنيف لأنماط التعليم المدمج، واتفقت نتائج هذه الدراسات أنه يعد من أكثر هذه الأنماط نجاحًا هو نمط الفصل الدراسي المعكوس Flipped-Classroom Style حيث يعتمد التعلم داخل هذا النمط على العملية التعليمية، فتتم دراسة المحتوي أولًا من خلال أساليب التعليم الإكتروني في المنزل، ثم القيام بالأنشطة المختلفة داخل البيئة التقليدية تحت إشراف المعلم . 


\section{أثر استراتيجيتين للفصول المعكوسة التشاركية "التقدمية/الرجعية" أ.مني السيد العربي}

ومن هذا المنطلق نجد أن الفصل المعكوس يجعل الطلاب أكثر استعدادًا للتعلم؛

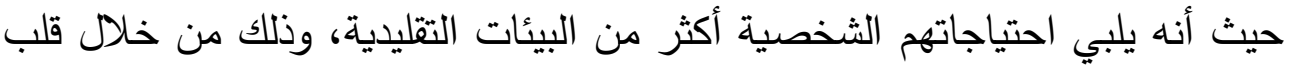
العملية التعليمية، حيث يزود المعلم المتعلمين بدصادر التعلم، ويطلب منهم دراستها

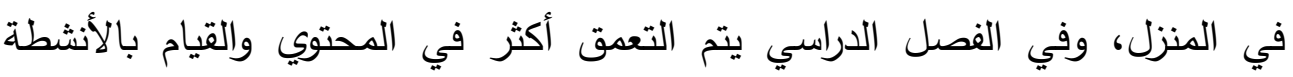

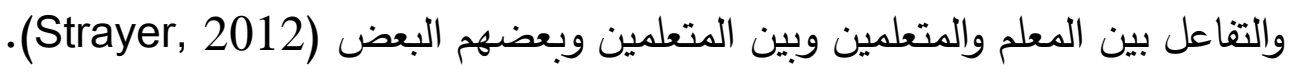

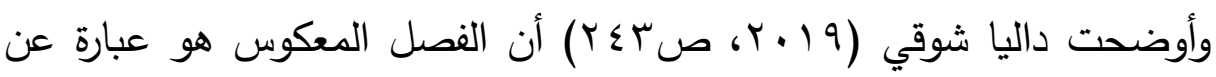

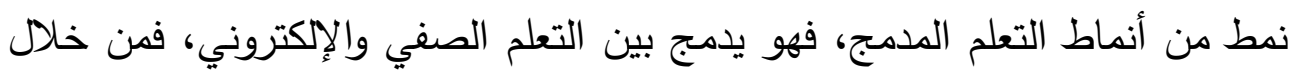
الفصل المعكوس يقوم الطالب بدراسة الموضوعات والمهارات العملية بتعمق وتركيز من خلال البيئة الإكترونية، وفي البيئة الصفية تتم الأنثطة والمناقثات تحت إثراف البرات

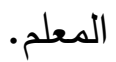

كنللك تثير نتائج عديد من الدراسات والبحوث إلي التأثير الفعال لبيئة الفصل

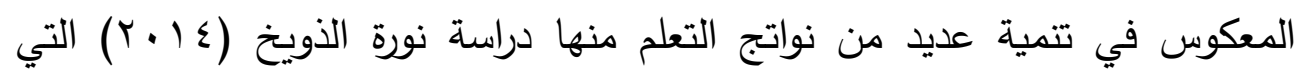
أظهرت نتائجها فاعلية الفصل المعكوس في تتمية مهارات التعلم الذاتي لدى الطلاب، وذلك من خلال تفوق الدجموعة التجريبية والتي استخدمت الفصل المعكوس على لفي

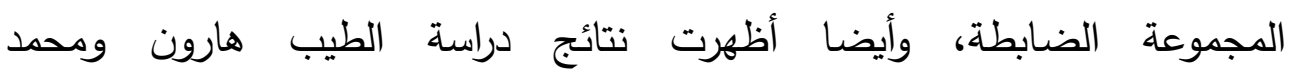

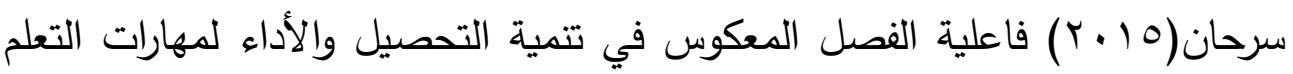

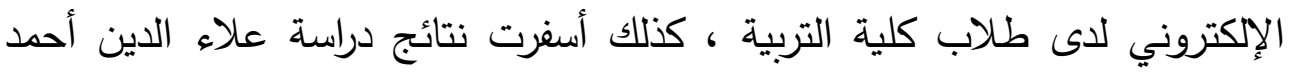

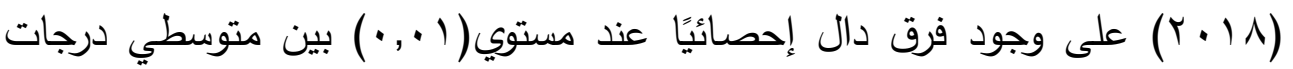
طلاب المجموعتين في التطبيق البعدي في اختبار مهارات التنكير التاريخي لصالح

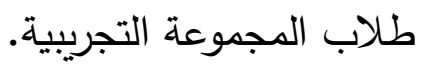
كما تثير عديد من نظريات التعلم إلى فاعلية الفصل المعكوس ومنها نظرية

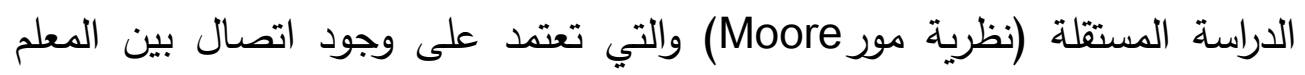

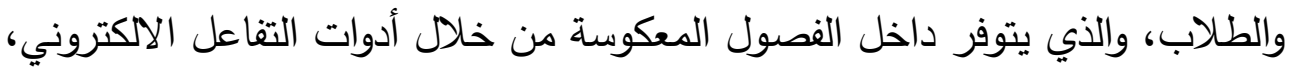


بالإضافة إلى التواصل الصفي بين المعلم والطلاب، كما تعتمد النظرية على استقلالية المتعلم، وضرورة هيكلة البرامج التعليمية بما يوفر فرصة للتعلم الذاتي، وذلك من خلال قيام المتعلم بمشاهدة الفيديوهات التعليمية في المنزل، بالإضافة للقيام بالأنشطة المنزلية، مما يوفر وقت الحصة للتفاعل والحوار بين المعلم

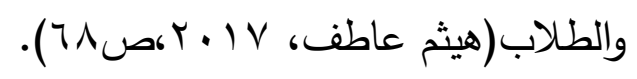

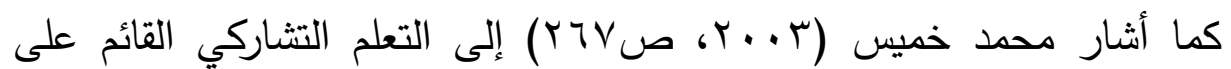
الويب على انه "نمط تعلم يعمل فيها المتعلمون معًا، في مجموعات صغيرة أو كبيرة، ويشاركون في إنجاز المهرة أو تحقيق أهداف تعليمية مشتركة، حيث يتت اكتساب المعرفة والمهارات أو الاتجاهات من خلال العمل الجماعي المشترك، ومن ثم فهو يركز على الجهود التعاونية التثاركية بين المتعلمين لتوليد المعرفة من خلال التفاعلات الاجتماعية والمعرفية، وهو تعلم ممركز حول المتعلم، وينظر إلى المتعلم كمشارك نشط في عملية التعلم". كما أشار (Edman, 2010,p101) إلى التعلم التشاركي بأنه نمط من أنماط التعلم القائم على التقاعل بين المتعلمين وبعضهم البعض، من خلال تكوين مجموعات صغيرة، تتشارك فيما بينها لإنجاز المهمة المطلوبة، وتحقيق الأهداف التعليمية المنشودة، فيصبح التعلم نظام متمركز حول المتعلم ويشارك في المعلم. وهناك عديد من الدراسات التي أجريت وأثتتت فاعلية التعلم التشاركي عبر

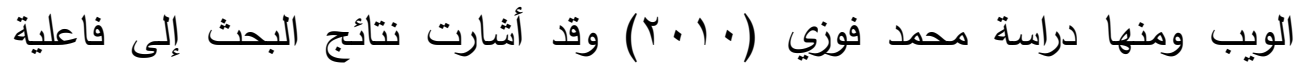
البرنامج التدربيي في تحسين الجوانب المعرفية والأدائية والوجدانية (اتجاهات المعلمين) لكفايات توظيف المعلمين لتكنولوجيا التعلم الإكتروني في التدري ، وأيضا

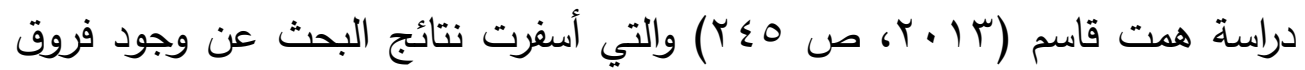
دالة بين متوسط درجات المجموعة التجريبية الأولى التي تستخدم (بيئة التعلم الإلكتروني) ومتوسط درجات المجموعة التجريبية الثانية التي تستخدم (بيئة التعلم 


\section{أثر استراتيجيتين للفصول المعكوسة التشاركية "التقدمية/الرجعية" أ.مني السيد العربي}

الإلكتروني التشاركي) في التطبيق البعدي لاختبار التحصيل ومقياس الاتجاه لصالح

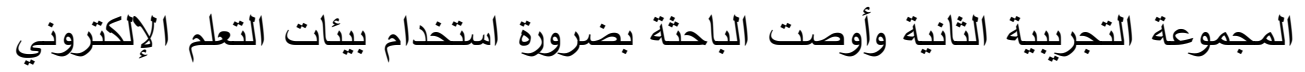
التثاركي في تدريس الكقررات التعليمية الدختلفة ، وأكدت دراسة حسام عبد الرحيم الرئية

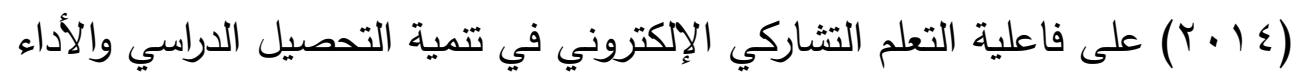
المهارى لدى طلاب الصف الثاني الثانوي الصناعي في مادة الحاسوب. و بذلك يعد الفصل المعكوس القائم على التعلم التثاركي، استراتيجية متكاملة لها

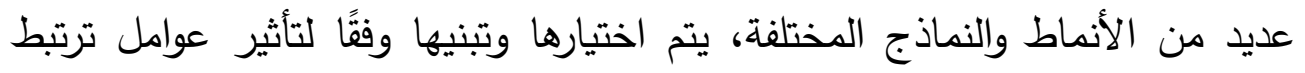
بطبيعة المؤسسة التي سوف تتبنى النظام والقيود التظيمية الخاصة بها، ونوعية

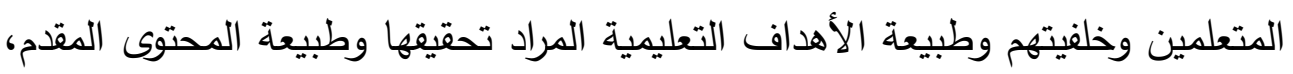

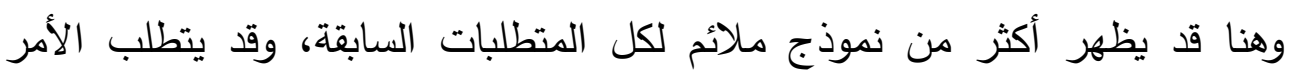
إخضاع هذه النماذج للتجريب من خلال بحوث كيفية وكمية وإجرائية تؤكد تفوق إحداهما على الأخرى في إطار بيئة تعليمية ذات محددات معينة.

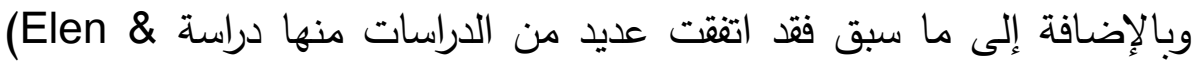
Aly, 2005) ضرورة إلقاء مسئولية التعلم على عاتق المتعلم، من خلال توفير بيئة تعليمية تتيح للمتعلم حرية اختيار نمط التعلم، وفرصة اختيار المحتوى العلمي الذي يناسب قدراته وميوله، ولكنها اختلفت في درجة التحكم التي يجب إعطاءها للمتعلم.

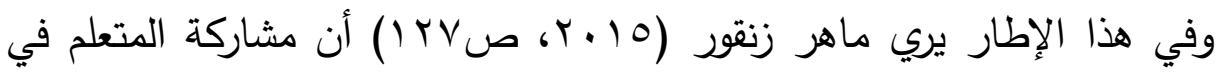
اتخاذ القرارات المتعلقة بعملية تعلمه الذاتي يساهم في زيادة ميوله واهتماماته الذاتية

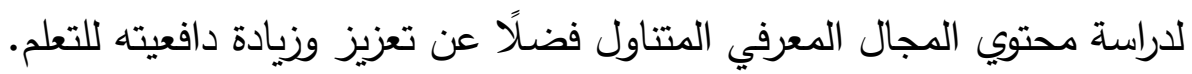

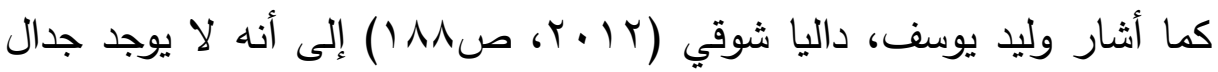

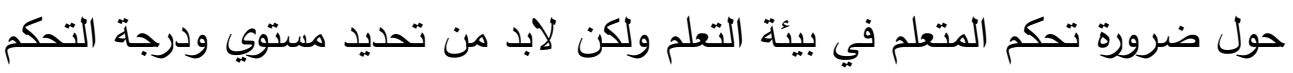
الذي يجب ان يمارسه المتعلم في هذه البيئة خاصة بيئة التعلم الدمدج حيث ان دلئ درجة 
تحكم المتعلم ترجع لعدد من المتغيرات منها (عمر المتعلم، الخبرات السابقة للمتعلم، خطوات التعلم، درجه تعقيد المادة التعليمية، ودرجة ألفة المتعلم مع المادة المقدمة. بالإضافة إلى أن هناك عديد من الدراسات والبحوث السابقة التي أظهرت نتائجها عدم وجود فرق دال إحصائيًا بين متوسطي درجات المجموعتين (تحكم البرنامج -

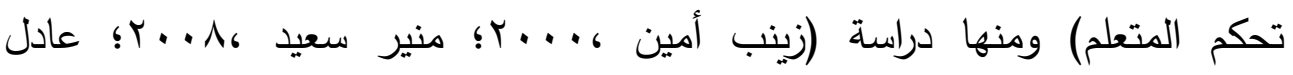

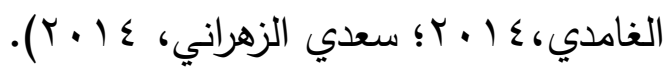
وانطلاقًا مما سبق نجد أن هناك أهمية كبري لتحكم المتعلم في تعلمه، ولكن إختلفت الآراء حول تحديد درجة تحكم المتعلم، كما إختلفت الدراسات والبحوث السابقة في تناول مصطلحي تحكم المتعلم مقابل تحكم البرنامج بمسميات مختلفة منها استراتيجية تحكم مرتفع واستراتيجية تحكم متوسط، واستراتيجية تحكم منخفض وهناك من يطلق عليه تحكم المتعلم بالبرنامج بدرجه كامله وتحكم البرنامج بدرجه جزئيه

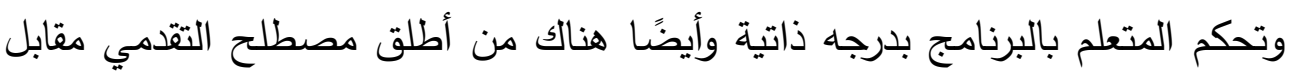

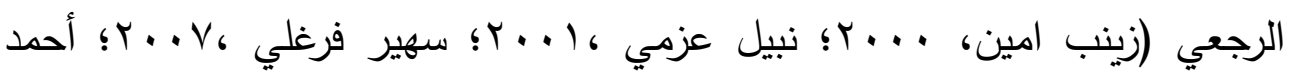

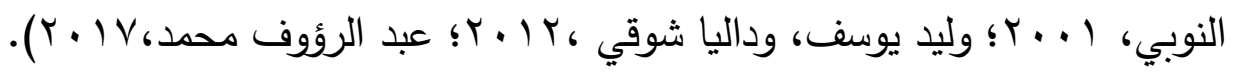
وقد تبنت الباحثة مصطلحي التقدمي مقابل الرجعي، حيث أشارت دراسة وليد

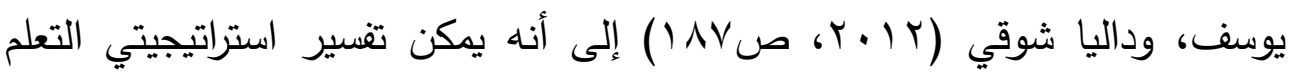
التقدمي مقابل الرجعي في ضوء أساليب التحكم على أساس أن استراتيجية التعلم المدمج التقدمي تمنح الطالب القدرة على التحكم في اختيار الأنشطة والتطبيقات بينما تعتمد استراتيجية التعلم المدمج الرجعي على تحكم المصمم التعليمي في إعداد خلطة محددة مسبقًا وفقًا لتحليل المحتوي وطبيعة الدارسين وقيود بيئة التعلم وخصائصها. ومن خلال ما سبق ولنظر لأهمية المتغيرين (التقدمي مقابل الرجعي) وارتباطهما بطبيعة بيئة الفصول المعكوسة فقد قامت الباحثة باختيار بيئة الفصل المعكوس التقدمي مقابل بيئة الفصل المعكوس الرجعي. 


\section{أثر استراتيجيتين للفصول المعكوسة التشاركية "التقدمية/الرجعية" أ.مني السيد العربي}

وفي هذا الإطار فنحن امام بيئتين للفصل المعكوس التشاركي هما: بيئة الفصل

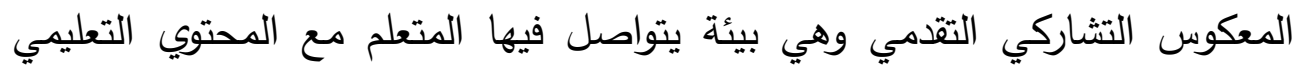
المقدم من قبل المعلم (المصمم التعليمي)، ثم يتم إتاحة الفرصة للمتعلمين لاختيار الأنثطة ونوعية المحتوى، والتحكم في توقيت التعلم لتحقيق الأهداف التعليمية المرجوة، بينما بيئة الفصل المعكوس التثاركي الرجعي هي عبارة عن بيئة يتواصل

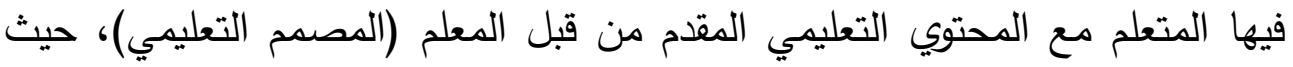
تتضمن البيئة لقطات الفيديو والأنثطة المحددة مسبقًا من قبل المعلم (المصمم التعليمي) وفقًا لتحليل المحتوي وخصائص المتعلمين وطبيعة بيئة التعلم. ومن ناحية أخرى يعد تعلم المهارات المعرفية "Cognitive Skills" بجانبيها

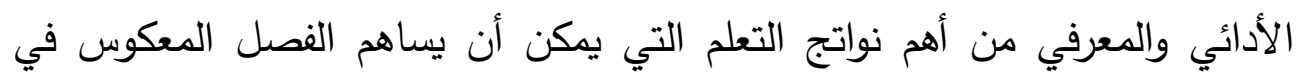

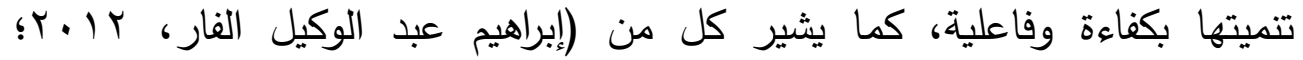

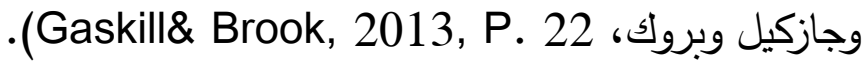

وفى هذا الإطار تعد مهارات تطوير المواقع التعليمية من أهم المهارات التي

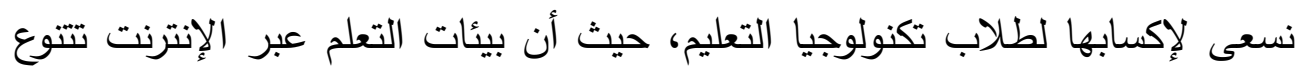
في تصميمها تتوعًا كبيرًا، ويظهر هذا التنوع في تصميم واجهات التفاعل وتتابع الصفحات ومدي التفاعل المتاح مع المتعلم وغيرها من المتغيرات التي تختلف وتتتوع

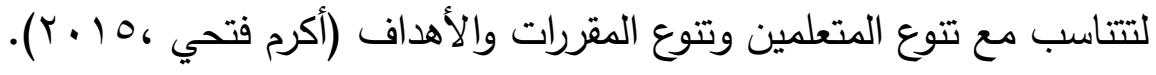

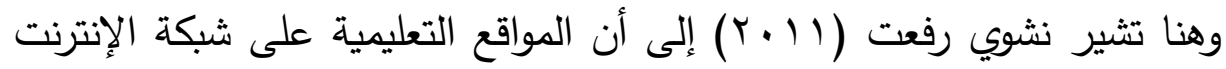
أصبحت وسيلة لنقل المعرفة والمعلومات في العصر الجديد مما يساعد المتعلمين

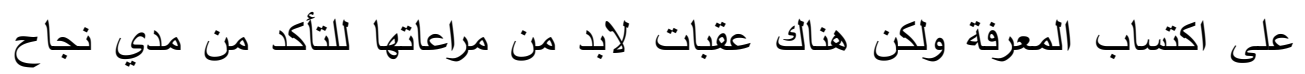

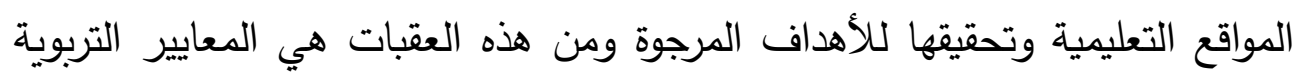

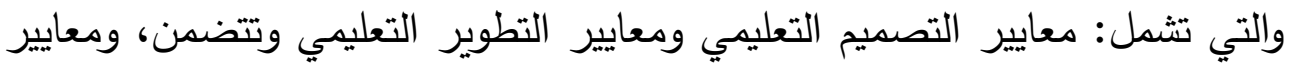

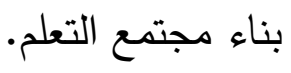


وكذلك يمكن الحكم على جودة البيئات التعليمية بدرجه قبولها من الفئات

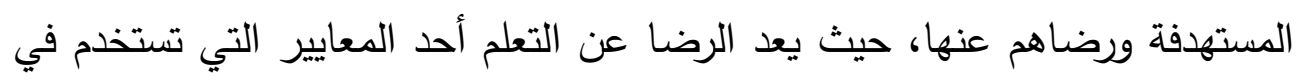
تحديد مدى نجاح البيئة التعليمية، وهو يعد أحد مؤشرات الجودة الشاملة للبيئة وهنا تشير غانوزي (Giannousi, et al, 2011) ان رضا المتعلمين يعد عامل مهم وحاسم في تحديد مدى فاعلية بيئة التعلم. ومن هذا المنطلق نجد أن هناك علاقة واضحة بين الرضا عن بيئة التعلم وتحقيق نواتج التعلم الاخرى، حيث يمثل الرضا عن بيئة التعلم بكل ما تشمله من عناصر ، أحد أهم العناصر الأساسية لتحقيق النجاح في استخدامها والإفادة منها. مشكلة البحث تمكنت الباحثة من بلورة مشكلة البحث الحالي، وتحديدها وصياغتها من خلال المحاور الاتية: - n - n أولًا: زيادة الاهتمام باستخدام بيئات التعلم المدمج بصفة عامة وبيئات التعلم المعكوس على وجه الخصوص، وذلك لما تتميز هذه البيئات من مميزات عديدة، وقد أثثتت البحوث والدراسات تأثيرها الفعال في تحقيق نواتج التعلم المختلفة، (كما أشارت الباحثة في مقدمة البحث) لذلك اتجه البحث نحو تحسين هذه البيئات وزيادة فاعليها من خلال دراسة متغيرات تصميمها، ومن هذه المتغيرات تحديد التصميم الأنسب لبيئة الفصل المعكوس التشاركية (التقدمية /الرجعية). ثانيًا: يوجد تصميمان أساسيان لبيئة الفصل المعكوس التشاركية فهما تصميمان يساعدان المتعمين على استخدام سهل لهذه البيئات وبالتالي تساهم بشكل أساسي في Proactive تحقيق نواتج التعلم المختلفة وهما بيئة الفصل المعكوس التقدمي Flipped Classroom

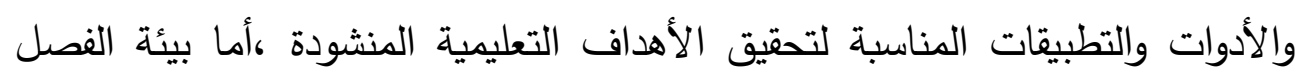




\section{أثر استراتيجيتين للفصول المعكوسة التشاركية "التقدمية/الرجعية" أ.مني السيد العربي}

المعكوس الرجعي Reactive Flipped Classroom فهي بيئة تقوم على إعداد

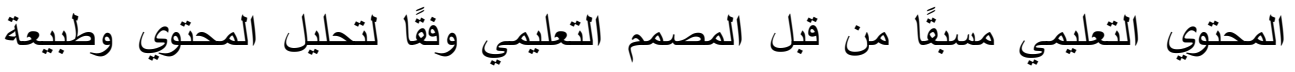
الدارسين وقيود بيئة التعلم وخصائصها ولكل من هذين التصميمين دعم نظري، وله

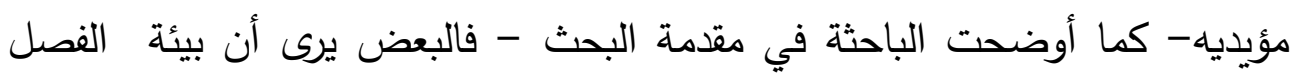

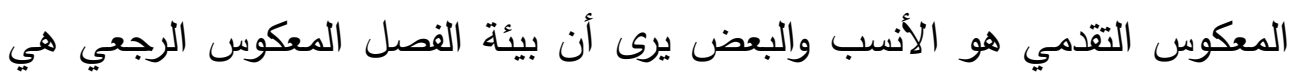
الانسب.

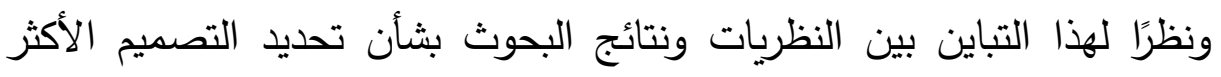

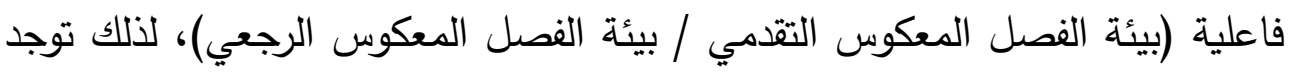

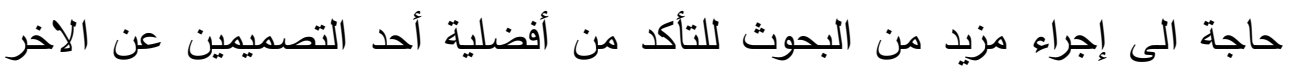
خاصة أن الدراسات والبحوث لم تتعرض بثكل مباشر لدراسة هذا المتغير ببيئات الفصل المعكوس القائمة على المحتوى المهارى وهو ما يهدف إليه البحث الحالي.

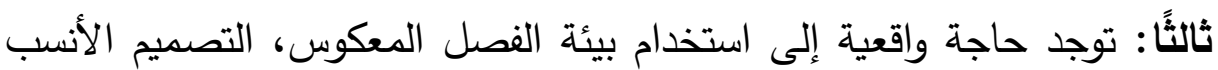

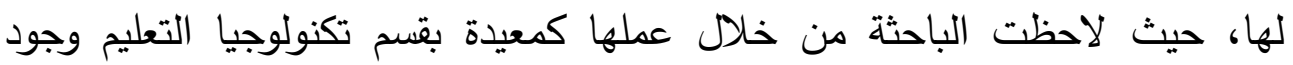
قصور لاى الطلاب في مهارات تطوير المواقع التعليمية ناتجة عن القصور في الطريقة التقليدية للتدريس لعدم مراعاتها الفروق الفردية بين المتعلمين وعدم استخدام المستحدثات التكنولوجية المختلفة في العملية التدريسية.

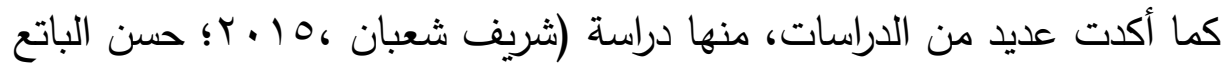

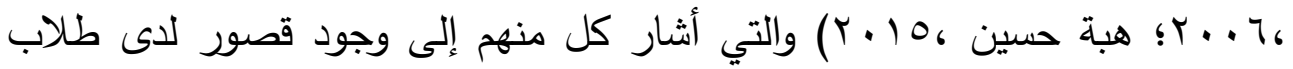
تكنولوجيا التعليم في مهارات تطوير المواقع التعليمية. وعلى ضوء ما سبق يمكن تحديد مشكلة البحث الحالي وصياغتها في العبارة التقريرية التالية "توجد حاجة إلى تحديد أنسب تصميم لبيئة الفصل المعكوس (بيئة

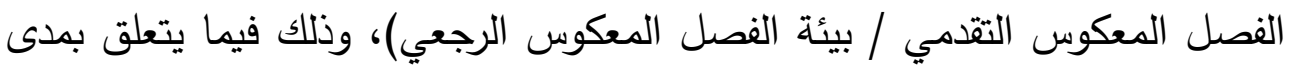


تأثيرهما علي تعلم المهارات بجانبيها الأدائي والمعرفي وتحقيق رضا الطلاب عن بيئة التعلم. وفى ضوء ما تقدم يمكن معالجة مشكلة البحث من خلال الإجابة على الأسئلة

ويحاول البحث الحالي الإجابة على السؤال الرئيس الاتي:

"كيف يمكن تصميم بيئة فصل معكوس تشاركية بنمطين مختلفين (التقدمي/الرجعي) لتنمية مهارات تطوير المواقع التعليمية لدى طلاب الدراسات العليا،

وتحقيق رضائهم عن هذه الفصول؟"

ويتفرع من هذا السؤال الرئيس الأسئلة الفرعية الاتية: ا. ما مهارات تطوير المواقع التعليمية الواجب توافرها لدى طلاب الدراسات

العليا؟

r. ما معايير تصميم بيئة الفصول المعكوسة التشاركية الملائمة لتنمية

مهارات تطوير المواقع التعليمية؟

r. ما صورة بيئة الفصل المعكوس بتصميميها (التقدمي/الرجعي) عند تطويرهما باستخدام نموذج التعلم المدمج (وليد يوسف، داليا شوقي، ب ا • Y) ع. ما أثر استراتيجيتي الفصول المعكوسة التشاركية (الفصل المعكوس التقدمي مقابل الفصل المعكوس الرجعي) على كل من:

مهارات تطوير المواقع التعليمية لاى طلاب الدراسات العليا؟

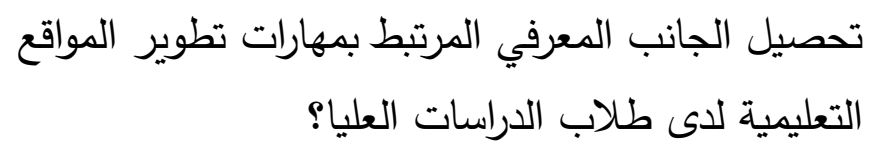
تحقيق رضا طلاب الدراسات العليا عن هذه الفصول؟ 
أثر استراتيجيتين للفصول المعكوسة التشاركية "التقدمية/الرجعية" أ.مني السيد العربي أهداف البحث

$$
\text { يسعي البحث الحالي إلى تحديد: }
$$

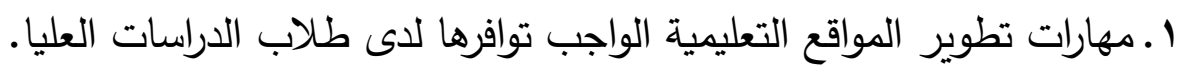

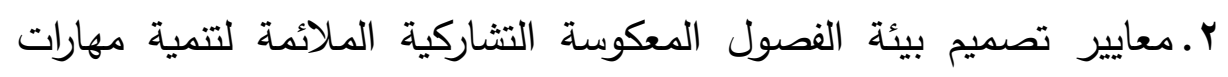
تطوير المواقع التعليمية. r. البيئة الأنسب (الفصل المعكوس التشاركي التقدمي مقابل الفصل المعكوس

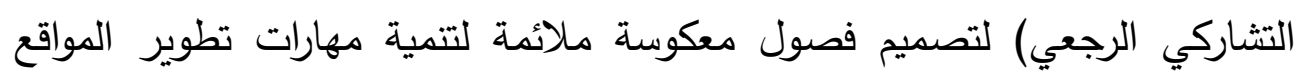

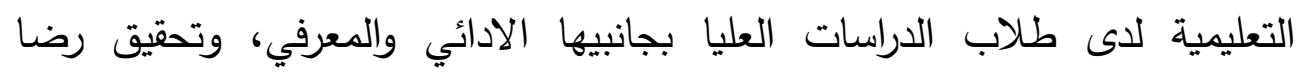

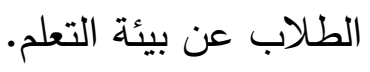

\section{أهمية البحث}

ا. قد تسهم نتائج البحث في تبني المؤسسات التعليمية المعنية استراتيجيات وأنماط

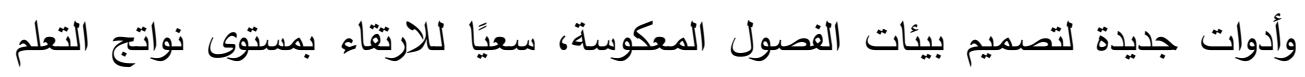

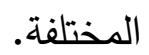

r. يقدم هذا البحث نموذجًا لبيئات الفصول المعكوسة المستخذمة في تعليم

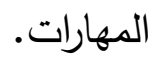

r. قد تسهم نتائج البحث في تعزيز الإفادة من إمكانيات بيئات الفصول المعكوسة

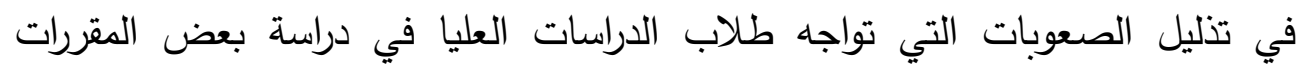

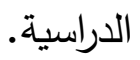

؛ ـ قد تسهم نتائج هذا البحث في تزويد مصدمي ومطوري بيئات التعليم الددمج

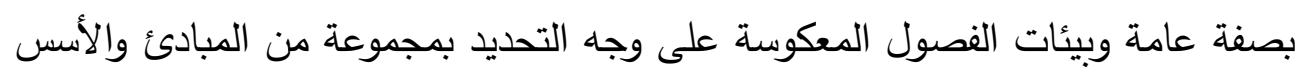

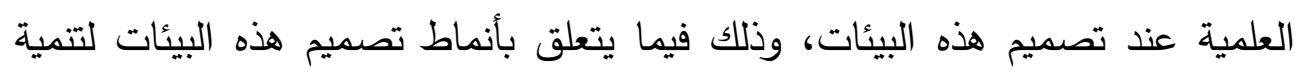

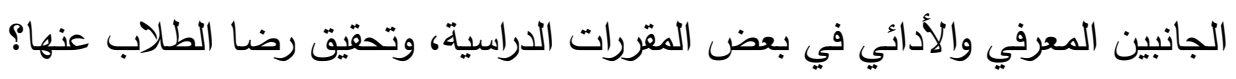


ه. قد تقيد نتائج هذا البحث في تقديم بعض الأسس والمبادئ العلمية المقننة في

تصميم بيئات الفصول المعكوسة المعدة للمقررات التي تتضمن جانبين معرفي وإدائي.

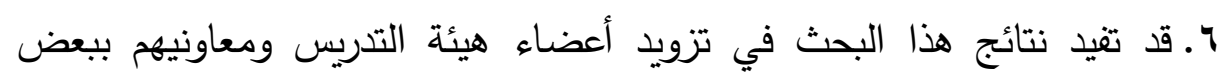
الارشادات العملية في تصميم، واختيار بيئات الفصول المعكوسة المعدة للمقررات التي فئي تتضمن مهارات عملية بجانبيها المعرفي والأدائي.

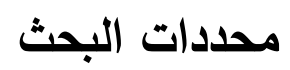

يقتصر البحث الحالي على:

ا .حد بشري: طلاب الدراسات العليا بقسم تكنولوجيا التعليم بكلية التربية النوعية

$$
\text { (جامعة عين شمس وجامعة بنها) }
$$

تنمية بعض مهارات تطوير المواقع التعليمية الواجب توافرها

$$
\text { لدى طلاب الدراسات العليا. }
$$

r..حد زماني: تم تطبيق تجربة البحث في الفصل الدراسي الثاني للعام الدراسي

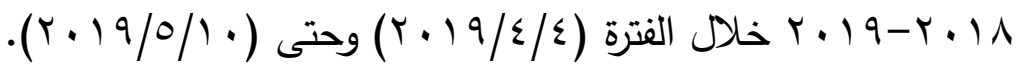

$$
\begin{aligned}
& \text { منهج البحث }
\end{aligned}
$$

ينتمي هذا البحث إلى فئة البحوث التطويرية التي تستخدم بعض مناهج الدراسات الوصفية في مرحلة الدراسة والتحليل والتصميم، والمنهج التجريبي عند قياس أثر المتغير المستقل للبحث على متغيراته التابعة في مرحلة التقويم.

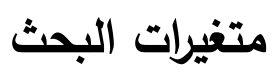

أولًا: المتغير المستقل اشتمل البحث على مُتغير مستقل هو:

ا- بيئة الفصول المعكوسة التشاركية بنمطيها:

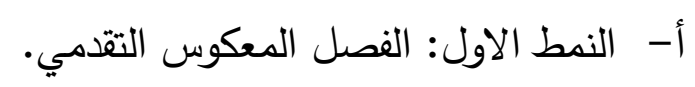




\section{أثر استراتيجيتين للفصول المعكوسة التشاركية "التقدمية/الرجعية" أ.مني السيد العربي}

ب- النمط الثاني: الفصل المعكوس الرجعي.

ثانيًا: المتغيرات التابعة اشتمل البحث على ثلاث متغيرات تابعة هي:

ا- التحصيل المعرفي المرتبط بتنمية مهارات تطوير المواقع التعليمية لدى طلاب

الدراسات العليا.

r- الأداء العملي لمهارات تطوير المواقع التعليمية الواجب توافرها لدى طلاب

الدراسات العليا.

r- رضا طلاب الدراسات العليا عن هذه الفصول.

\section{عينة البحث}

تم اختيار عينة البحث بصورة عشوائية من طلاب الدراسات العليا بقسم تكنولوجيا التعليم بكلية التربية النوعية (جامعة عين شمس وجامعة بنها) وتكونت العينة من ( • (0) طالب وطالبة، وتم تقسيم العينة إلى مجموعتين تجريبيتين (مجموعة تدرس من خلال الفصل المعكوس التقدمي وعددها (ro) ومجموعة تدرس من خلا الب الفصل

$$
\begin{aligned}
& \text { المعكوس الرجعي وعددها (Yo). } \\
& \text { أدوات القياس }
\end{aligned}
$$

ا- اختبار تحصيلي لقياس الجوانب المعرفية الخاصة بمهارات تطوير المواقع

التعليمية.

r- بطاقة تقييم المنتج النهائي لقياس الجوانب الأدائية الخاصة بمهارات تطوير

المواقع التعليمية.

r- مقياس رضا الطلاب عن الفصول المعكوسة. 


\section{فروض البحث}

يسعي البحث الحالي للتأكد من صحة الفروض التالية:

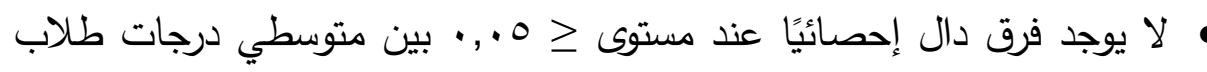
المجموعتين التجريبيتين في أداء مهارات تطوير المواقع التعليمية عند الدراسة باستخدام بيئة الفصول المعكوسة التشاركية يرجع للأثر الأساسي لاستراتيجية الدمج (الفصل فئلئل المعكوس التقدمي مقابل الفصل المعكوس الرجعي).

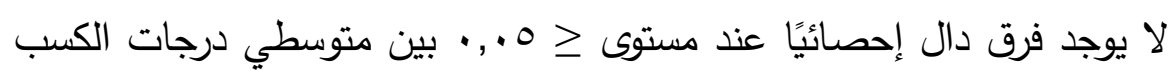
لطلاب المجموعتين التجربيتين في اختبار التحصيل المعرفي المرتبط بمهارات تطوير المواقع التعليمية عند الدراسة باستخدام بيئة الفصول المعكوسة التشاركية يرجع للأثر الأساسي لاستراتيجية الدمج (الفصل المعكوس التقدمي مقابل الفصل المعكوس الرجعي).

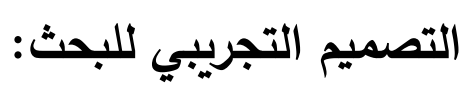
على ضوء المتغير المستقل موضع البحث الحالي وأنماطه، استخدم الباحث في هذا البحث امتداد التصميم التجريبي ذو المجموعة الواحدة، واختبار قبلي واختبار بعديExtended One Group Pre-Test, Post-Test Design في معالجتين مختلفتين (المجموعتين التجريبيتين للبحث) ويوضح الجدول التالي التصميم التجريبي

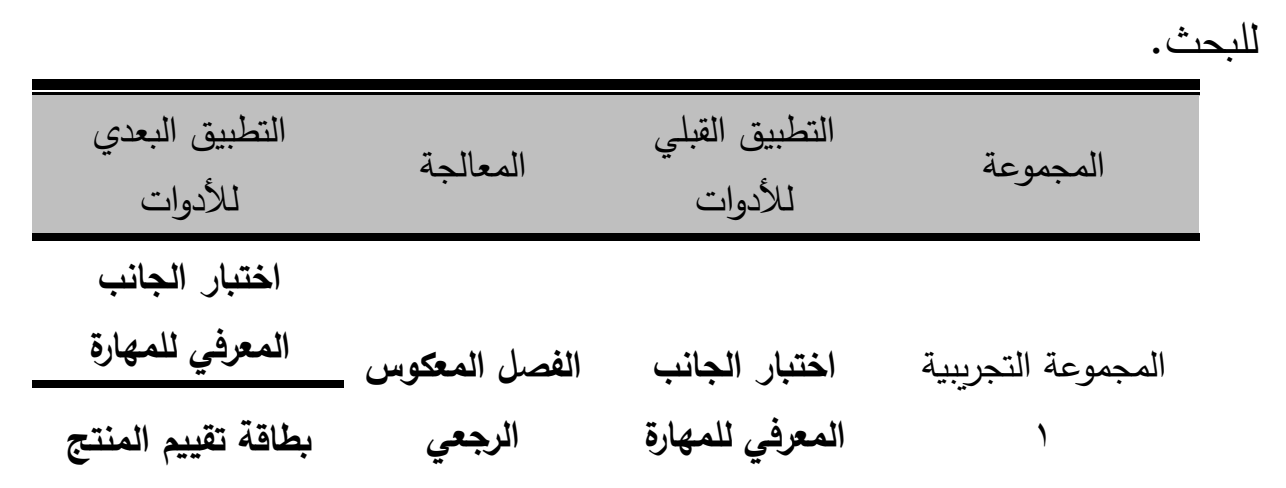


أثر استراتيجيتين للفصول المعكوسة التشاركية "التقدمية/الرجعية" أ.مني السيد العربي

\begin{tabular}{|c|c|c|c|}
\hline التطبيق البعدي & المعالجة & للنطبيق القبلي & المجموعة \\
\hline مقياس رضا عن & المعكوس التصدي & & المجموعة التجريبية \\
\hline
\end{tabular}

في ضوء اطلاع الباحثة على التعريفات التي وردت في عديد من الأدبيات التربوية والنفسية ذات العلاقة بمتغيرات البحث تم تحديد مصطلحات البحث إجرائيًا

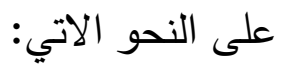
الفصل المعكوس

"يعرف بأنه نموذج تعليمي يهدف إلى تحويل المحتوى التعليمي إلى مقاطع فيديو حيث يقوم المعلم بإعدادها وإرسالها إلى المتعلم من خلال فصول جوجل التعليمية ليقوم الطالب بدراستها في المنزل، ويدون الملاحظات، في حين يخصص وقت المحاضرة للقيام بالأنشطة والمشاريع العملية التشاركية". التعلم التشاركي: يعرف بأنه "أسلوب للتعلم يعتمد على توزيع مهام النشاط الصفي بين أفراد المجموعة الواحدة، بحيث ينفذ كل طالب جزء من النشاط الصفي، فلا يحدث تبادل للأدوار في أداء النشاط الصفي، بل يحدث التعلم من خلال تطبيق كل طالب لجزء من النشاط بالممارسة الفعلية، أما بقية الأجزاء فيكون ناتج التعلم من الأقران. 


\section{بيئة الفصل المعكوب التقدمي:}

تعرف بأنها بيئة تعلم يتواصل فيها المتعلم إلكترونيًا مع المحتوى التعليمي المقدم

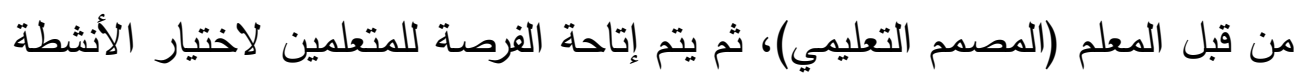
ونوعية المحتوى، والتحكم في توقيت التعلم لتحقيق الأهداف التعليمية المرجوة. بيئة الفصل المعكوس الرجعي:

تعرف بأنها بيئة تعلم يتواصل فيها المتعلم إلكترونيًا مع المحتوى التعليمي المقدم من قبل المعلم (المصمم التعليمي)، حيث تتضمن لقطات الفيديو والأنشطة المحدة مسبقًا من قبل المعلم (المصمم التعليمي) وفقًا لتحليل المحتوى وطبيعة المتعلمين

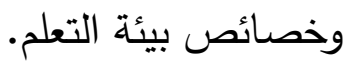

\section{مهارات تطوير المواقع التعليمية:}

تعرف بأنها قدرة المتعلم على تصميم وإنتاج المواقع التعليمية باستخدام موقع جوجل سايت Google Sites بحيث تتضمن هذه المواقع نصوص وصور ومقاطع فيديو لتحقيق الأهداف التعليمية المنشودة بدقة ومهارة. الإطار النظري

يتناول هذا الجزء المفاهيم والمحاور النظرية الأساسية للبحث والدراسات المرتبطة بها، حيث يشتمل على المحاور أساسية الاتية: المحور الأول: استراتيجيتي الفصول المعكوسة التشاركية (التقدمية /الرجعية) المحور الثاني: تتمية مهارات تطوير المواقع التعليمية. المحور الأول: استراتيجيتي الفصول المعكوبة التشاركية (التقدمية /الرجعية) Flipped-Classroom أولًا: الفصول المعكوسة الاول يعد الفصل المعكوس "مصطلح تم استحداثه مؤخرًا له جذور في التعليم، وأنه طريقة مبتكرة للتعليم والتعلم، تعتمد على القوة التعاونية للإنترنت، حيث يتم قلب الطرق التقليدية 


\section{أثر استراتيجيتين للفصول المعكوسة التشاركية "التقدمية/الرجعية" أ.مني السيد العربي}

في التدري، حيث يتم دراسة المحتوي في المنزل، في حين تتم المناقشات والأنشطة والتدريبات العملية داخل الفصول الدراسية"(المركز الوطني للتعلم الإلكتروني والتعلم عن لتعني

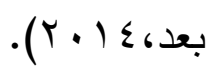

\section{مفهوم الفصل المعكوس}

الفصل المعكوس شكل من أشكال التعليم الدمجج ويعد منظومة تعليمية تساعد الطلاب على تعلم المحتوي التعليمي المحدد بأساليب مختلفة عديدة، كما تمكن المتعلم في التحكم في تعلمه كإعادة مقطع فيديو عدة مرات أو تسريع المقطع لتجاوز الأجزاء

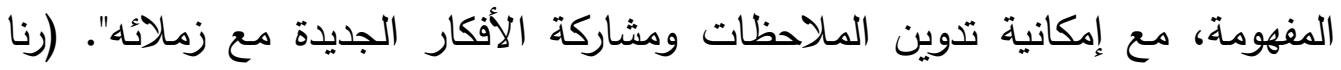

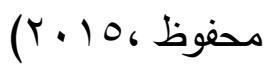

وفي هذا الإطار جاءت تعريفات الفصل المعكوس متقاربة في المضمون حيث أشار Marco المتعلم، حيث أن المتعلم يعتد على ذاته في عملية تعلمه فيقوم بالاطلاع على المحتوي التعليمي في المنزل ويدون الملاحظات بينما في الفصل الدراسي يتم مناقثة الملاحظات مع المعلم والقيام بالعديد من الأنثطة. وأثشار Brame (2013) إليه بأنه استراتيجية تدريس تساعد المعلم على إحداث التفاعل والمناقثة والحوار فيما بينه وبين الدتعلمين فتمكن المتعلم من تطبيق الأنثطة والتدريبات المختلفة حيث يقوم المتعلم بمشاهدة مقاطع الفيديو للمحاضرة في المنزل بينما في الفصل يتم التفاعل والمناقثة مع المعلم، ووفقا لتصنيف بلوم المعدل فإن المتعلم

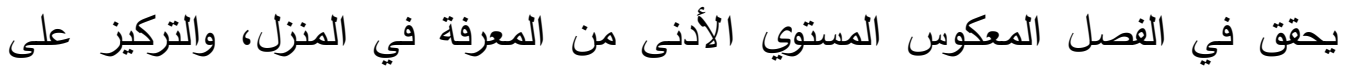
المستوي الأعلى من المعرفة (التطبيق، التحليل، التركيب، التقييم) في التعلم وجها لوجه. كما أوضح بيشوب Bishop (2013) أن الفصل المعكوس استراتيجية تعليمية

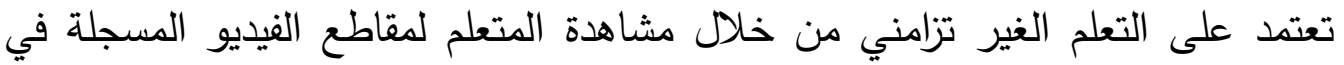


المنزل أما في الفصل الدراسي يخصص وقته للقيام بالأنشطة والتدريبات والمناقشات المختلفة، بالإضافة إلى المشاركة في حل المشكلات.

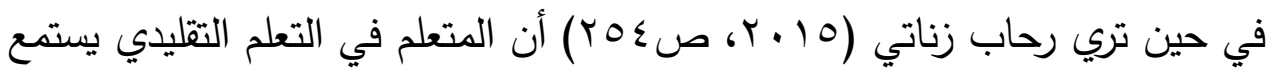
إلى شرح المعلم ويشاهد الأمثلة والتوضيحات ويحل بعض التدريبات، أما في الفصول المعكوسة فإن المعلم سيقوم بإعداد محاضرة فيديو لشرح الدرس يستمع إليها المتعلم في المنزل، ويري الأمثلة والتوضيحات ويحل بعض الأنشطة الإكترونية ويتلقى عليها التغذية الراجعة من خلال الوسائل المختلفة المعدة مسبقا من قبل المعلم وفي التعلم الصفي يقوم المتعلم بعمل التمارين والأنشطة المختلفة.

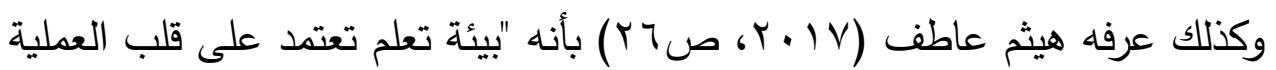
التعليمية (ما يحدث في الفصل الدراسي، مع ما يطلب من المتعلم من مهام وتكليفات في المنزل)، من خلال قيام المعلم بتسجيل الدروس ونشرها للطلاب في صورة مقاطع فيديو بحيث يمكن لكل طالب الاطلاع عليها من خلال حاسبه الشخصي أو هاتفه الذكي، بينما يخصص وقت الفصل الدراسي للمناقشات والتدريبات والأنشطة والمشاريع التعاونية. ومن التعريفات السابقة تلخص الباحثة مفهوم الفصل المعكوس في العناصر الأتية: أنه شكل من أشكال التعليم المدمج. هالفصل المعكوس منظومة تعليمية تمكن الطلاب من تلقي المفاهيم التعليمية بأساليب تعليمية مختلفة من مصادر مختلفة. الفصل المعكوس استراتيجية تربوية تتمركز حول الطالب بدلًا من المعلم. في الفصل المعكوس يقوم الطالب بمشاهدة فيديو للمحاضرة في المنزل بينما في الفصل يتم التفاعل والتدريب والمناقثة مع المعلم. 


\section{أثر استراتيجيتين للفصول المعكوسة التشاركية "التقدمية/الرجعية" أ.مني السيد العربي}

الأسس النظرية لاستخدام استراتيجية الفصول المعكوسة التشاركية:

في هذا الإطار نجد أن هناك عديد من نظريات التعلم التي تدعم استخدام

استراتيجية الفصول المعكوسة التثاركية في مجال تكنولوجيا التعليم من أهمها:

\section{النظرية البنائية}

ترتكز النظرية البنائية على أن المتعلم ييني المعني الخاص به من خلال وجهة نظره

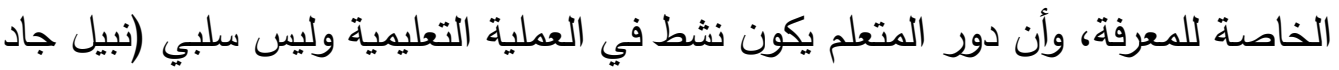

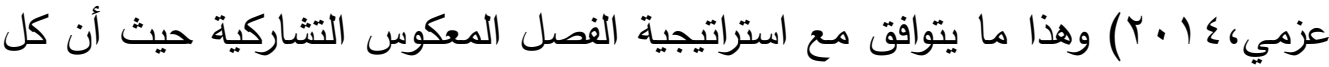
طالب يعتمد على ذاته في التعلم والمعلم يكون مشرف وموجه وميسر للعملية التعليمية. التعلم عملية بنائية نشطة ومستمرة وغرضية التوجه وأنها تتمركز حول المتعلم وما يقوم به من انشطه وتفاعلات لتحقيق الاهداف المنشودة وهذا ما يتوافق مع استراتيجية الفصول المعكوسة التشاركية حيث أنها تحول التعلم المتمركز حول المعلم إلى التعلم الدتمركز حول المتعلم، ففي الفصول المعكوسة المتعلم يتواصل مع المحتوي بذاته من الفن الفي

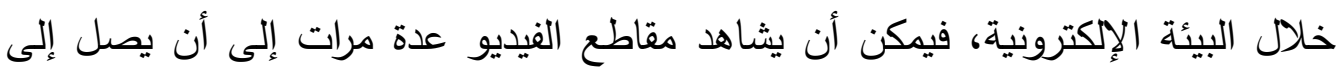
الأهداف المرجوة، وعند وجود صعوبات يستعين بالمعلم من خلال البيئة الصفية. بالإضافة إلي النظرية التواصلية حيث اهتمت هذه النظرية بالارتباط بين الفصل المعكوس وبيئات التعلم الإكتروني، فيمكن للمتعلم التواصل مع زملائه ومتابعة أدائهم

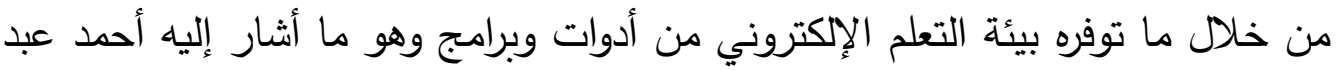

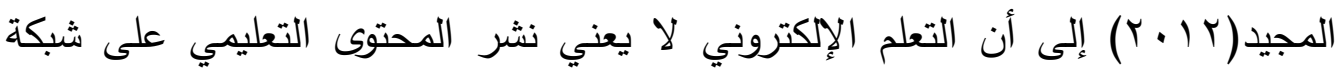
الانترنت، وإنما يعتمد في المقام الأول على تحويل دور المتعلم من متلقي سلبي

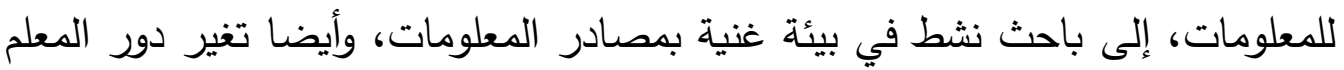

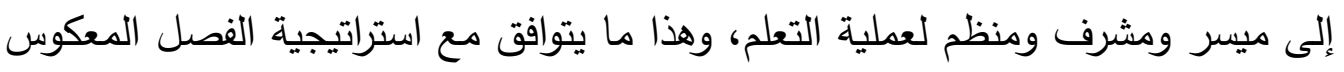

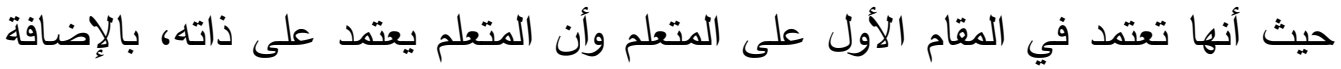


للاستفادة من التواصل المستمر مع زملائه من خلال أدوات البيئة الإلكترونية والتواصل وجها لوجه من خلال البيئة الصفية مما يعزز عملية التعلم •

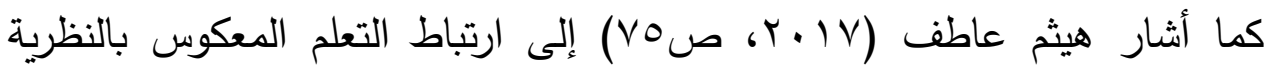
التواصلية للتعلم التي وضعهاSSiemens (0 . . ب) التي تعد نظرية تعلم ملائمة للعصر الرقمي وتثير هذه النظرية لمفهوم التعلم الثبكي حيث تتميز الشبكة بوجود عقد واتصال بين هذه العقد، فتمكن من تبادل المعرفة المتمثلة في (معلومات، بيانات، صور ، صوت، فيديو) وأن هذه النظرية تعتمد على الاتصال المستمر لتيسير التعلم، كما ان التعلم عملية اتصال تعتمد على تنوع الآراء.

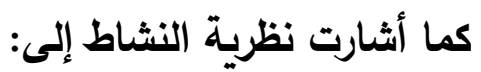

اتفاق الفصل المعكوس مع نظرية النشاط حيث ينقسم التعلم إلى جزئين الأول اكتساب المعلومات، والثاني تطبيق هذه المعلومات من خلال نشاط، وهذا ما يتوافق مع الفصل المعكوس التشاركي حيث أن اكتساب المعرفة يتم من خلال مشاهدة الفيديو في المنزل قبل وقت الحصة ثم تطبيق المعرفة من خلال القيام بالأنشطة المختلفة في الفصل الدراسي تحت إشراف المعلم تحقيقًا للأهداف المنشودة (Driscoll,2012؛ .(Mason,et.al,2013 مميزات الفصول المعكوسة

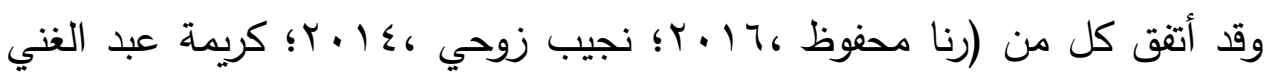

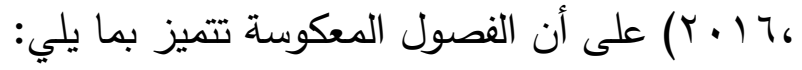
يتيح للمعلم استغلال وقت الحصة الاستغلال الأمثل في عمل الأنشطة والمناقثات والتدريب على المهارات. يراعي الفروق الفردية بين الطلاب حيث يمكن لكل طالب من إعادة الدرس أكتر من مرة حسب قدرته. 


\section{أثر استراتيجيتين للفصول المعكوسة التشاركية "التقدمية/الرجعية" أ.مني السيد العربي}

هقوي العلاقات بين الطلاب بعضهم البعض وبين المعلم.

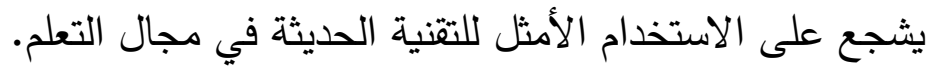

" يحول دور الطالب من متلقي سلبي إلى باحث نثط عن مصادر تعلمه.

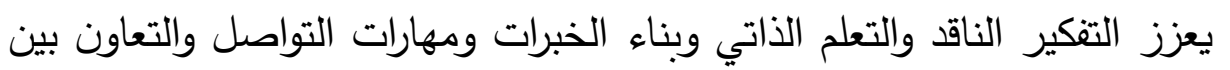

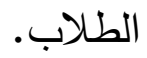

\section{التحديات التي تواجه تطبيق الفصول المعكوسة}

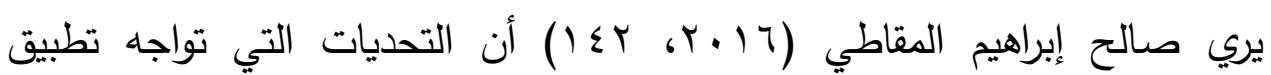
الفصول المعكوسة تتلخص في:

•وجود الكفاءة المطلوبة لدى المعلم لتوظيف تكنولوجيا التعليم ودمجها بعملية

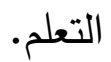

• تحليل المحتوى وإعادة بنائه بما يتتاسب مع متطلبات الموقف التعليمي الجديد. • تحويل المحتوى إلى مقاطع فيديو مناسبة وإرسالها إلى المتعلمين. • تصميم وبناء الأنثطة التعليمية والمهام الأدائية للطلاب. خطوات تنفيذ الفصول المعكوسة الخاصة بالمتعلم

يمكن تلخيص خطوات ومراحل تتفيذ الفصول المعكوسة الخاصة بالمتعلم كما أشار إليها (Bergman \&Sam,2014) كالتالي:

$$
\text { أ- أ- في المنزل }
$$

إشاهد المتعلم الفيديو التعليمي المرسل من قبل المعلم من خلال أدوات ووسائل التواصل الالكتروني المختلفة • يدون المتعلم الملاحظات المختلفة أثناء مشاهدته للفيديو، كما يمكن مشاهدة الفيديو عدة مرات، ثم يقوم بتطبيق النشاط المنزلي. 


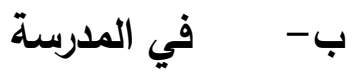

• يقوم المعلم بمناقشة الطلاب حول ملاحظاتهم المختلفة والإجابة على كافة التساؤلات والاستفسارات، ثم تكليف الطلاب بالنشاط الصفي بالتشارك فيما بينهم لتبادل الخبرات المختلفة. وهناك عديد من الدراسات التي أثبت فاعلية الفصول المعكوسة في العملية التعليمية ومنها ما يلي: أسفرت نتائج دراسة مروة إسماعيل (10 ب ب) عن فاعلية استخدام التعلم المعكوس في الجغرافيا لتنمية مهارات البحث الجغرافي لدي طلاب المرحلة الثانوية، كما أظهرت نتائج دراسة نبيل حسن (10 ب ب) فاعلية التعلم المعكوس القائم على التدوين المرئي في

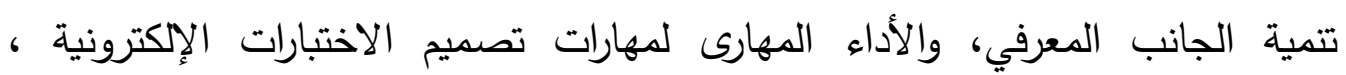
وأظهرت كذلك نتائج دراسة رباب البلاصي (10 • ب) أثر استراتيجية التعلم المقلوب Learning Flipped الإكترونية لطالبات دبلوم إدارة مراكز التعلم بجامعة حائل، وأوضحت نتائج دراسة رحاب زناتي (10 ب ب) فاعلية برنامج عبر الفصل الافتراضي المقلوب في التغلب على مشكلات

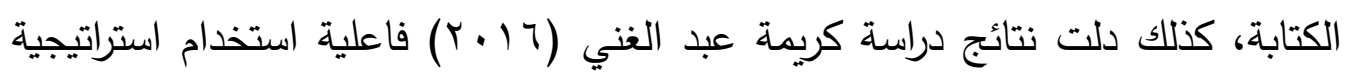
التعلم المقلوب على التحصيل وبقاء أثر التعلم في تدريس التاريخ لدى طلاب المرحلة الثانوية.

واتتقت دراسة كلا من صالح المقاطي (T ( • ب)؛ ودراسة ريم العبيكان ؛ودراسة مني

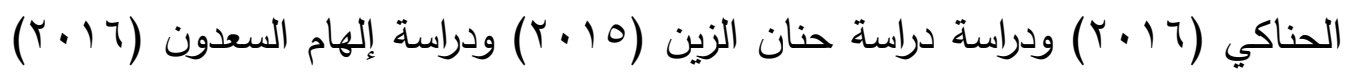

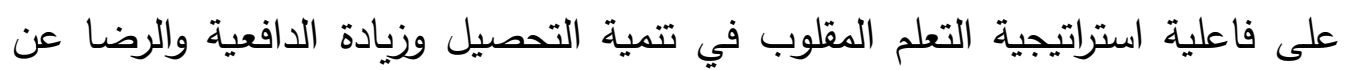
التعلم. 


\section{أثر استراتيجيتين للفصول المعكوسة التشاركية "التقدمية/الرجعية" أ.مني السيد العربي}

\section{Collaborative e-learning ثانيًا: التعلم التشاركي الإكتروني}

لقد أشار (Felt, et al 2012) إلي التعليم التشاركي بأنه أسلوب تعلم يشارك فيه

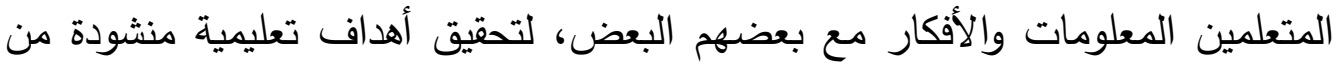
خلال التحفيز والإبداع. كما أثار Edman (2010, P101) إلى التعلم التثاركي بأنه نمط تعلم قائم علي التفاعل بين المتعلمين وبعضهم البعض، حيث يتشاركون من خلال مجموعات صغيرة

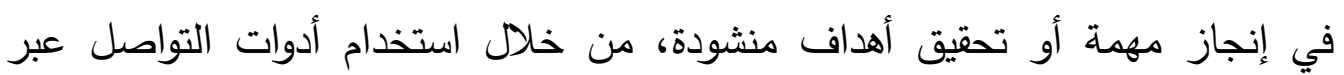
الويب، فيصبح التعلم متمركزًا حول المتعلم. وأسفرت نتائج عديد من الدراسات إلى فاعلية التعليم التشاركي في تحقيق نواتج

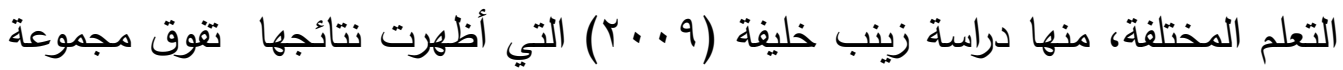
التعلم التثاركي على مجموعة التعلم بالوسائط المتعددة في تحصيل وأداء مهارات

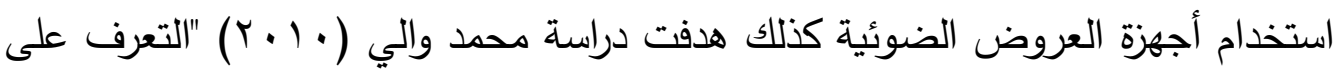
فاعلية برنامج تدريبي مقترح قائم على التعلم التشاركي بالويب في تتمية كفايات توظيف المعلمين لتكنولوجيات التعليم الإلكتروني في التدريس" إلى فاعلية البرنامج في التحصيل

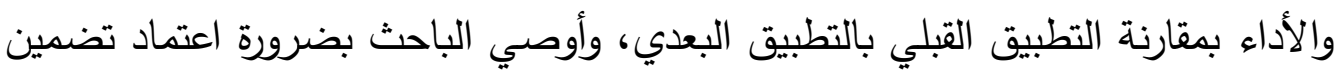

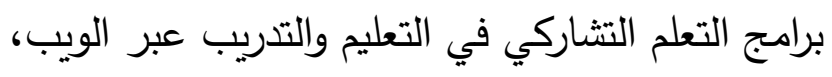
ودراسة التالتي استهدفت التعرف على فاعلية التعلم التشاركي في التحصيل المعرفي لطلاب الجامعة، وأثره على التحصيل المعرفي وأسفرت نتائجها على فاعلية التعلم التشاركي الإكتروني في تحصيل الطلاب. ثالثًا: التعلم التقدمي / الرجعي (Proactive /Reactive) يسعى البحث الحالي ضمن إلى المقارنة بين استراتيجيتين للفصول المعكوسة التثاركية ؛ استراتيجية التعلم المعكوس التقدمي "Proactive learning" وهي بيئة تعلم 
يتواصل فيها المتعلم إلكترونيًا مع المحتوى التعليمي المقدم من قبل المعلم (المصمم التعليمي)، ثم يتم إتاحة الفرصة للمتعلمين لاختيار الأنشطة ونوعية المحتوى، والتحكم في مقاي

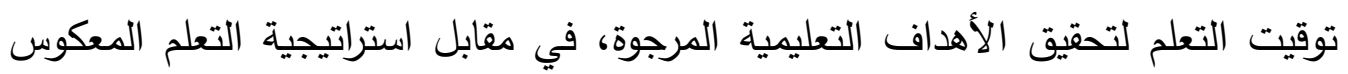
الرجعي "Reactive learning"وهي بيئة تعلم يتواصل فيها المتعلم إلكترونيًا مع المحتوى التعليمي المقدم من قبل المعلم (المصمم التعليمي)، حيث تتضمن لقطات الفيديو والأنشطة المحددة مسبقًا من قبل المعلم (المصمم التعليمي) وفقًا لتحليل المحتوى هي وطبيعة المتعلمين وخصائص بيئة التعلم.

ويمكن تفسير متغير البحث الحالي في ضوء أساليب التحكم على أساس أن بيئة التعلم المعكوس التقدمي تمنح الطالب القدرة على التحكم في اختيار الأنشطة والتطبيقات بينما تعتمد بيئة التعلم المعكوس الرجعي على تحكم المصمم التعليمي في اعداد خلطة محددة مسبقًا وفقًا لتحليل المحتوى وطبيعة الدارسين وقيود بيئة التعلم وخصائصها (وليد

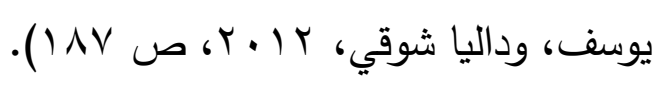

ومن خلا عديد من الدراسات التي تتاولت التحكم التعليمي فإن هناك عديد من المسميات للتحكم التعليمي فالبعض يطلق عليه استراتيجية تحكم مرتفع واستراتيجية تحكم متوسط، واستراتيجية تحكم منخفض وهنالك من يطلق عليه تحكم المتعلم بالبرنامج بدرجه كامله وتحكم البرنامج بدرجه جزئيه وتحكم المتعلم بالبرنامج بدرجه ذاتية، والبعض الاخر يطلق عليه تحكم المتعلم بالبرنامج وتحكم البرنامج بالمتعلم، وتحكم المتعلم مع الارشاد

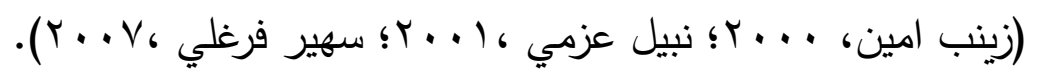
وهناك من أطلق عليه التحكم الرجعي والتحكم التقدمي والتحكم المتبادل حيث يثير مصطلح التحكم الرجعي إلى تحكم المتعلم أثر مثير ما في اتجاه خطي (تحكم خطي)، أما التحكم التقدمي فهو تحكم متعلم ولكن في وجود مساحة أكبر من التحكم الخطي

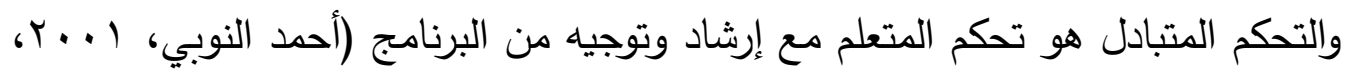




\section{أثر استراتيجيتين للفصول المعكوسة التشاركية "التقدمية/الرجعية" أ.مني السيد العربي}

وقد تبنت الدراسة الحالية مصطلح استراتيجية التعلم التقدمي Proactive blended

"learning" مقابل استراتيجية التعلم الرجعي "Reactive blended learning".

"Proactive learning" التعلم التقدمي

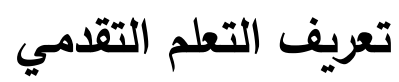

هناك من يري أن فكرة تحكم المتعلم بدأت بالفرص المتاحة للمتعلم لتتبع الأهداف

في المقرر التعليمي بالترتيب الذي يرغبه ثم توسع المفهوم ليتضمن الخطو والمحتوي

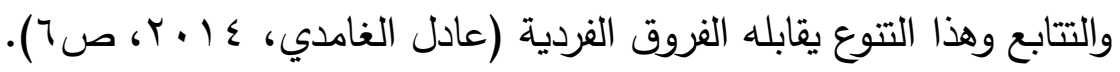

كما أن استخدام أسلوب تحكم المتعلم كمدخل لتصميم محتوي التعلم في بيئة التعلم الإلكتروني، يتيح للمتعلم أن يسير في تعلمه داخل بيئة التعلم الإكتروني وفقا لخطوه

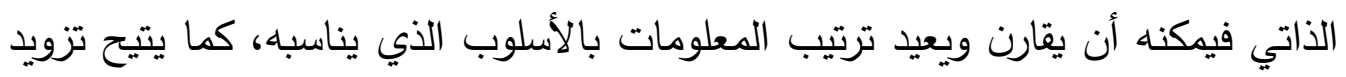

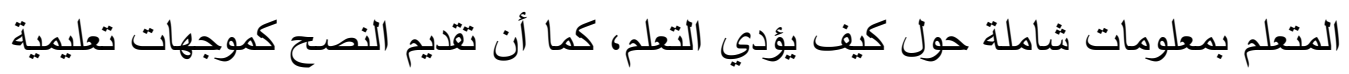

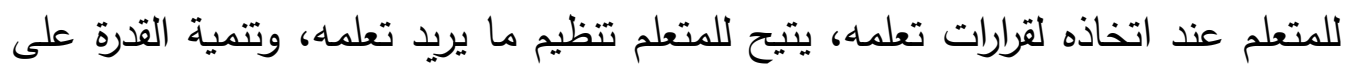

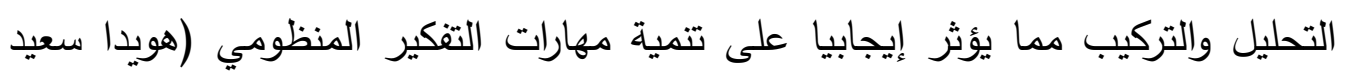

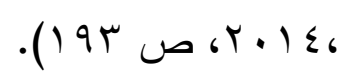

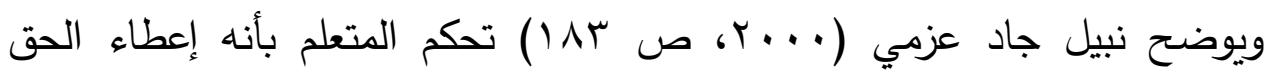

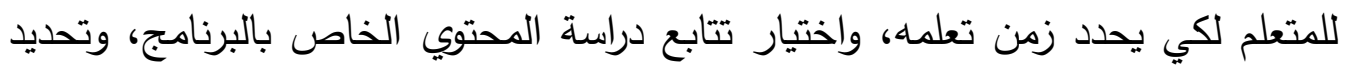

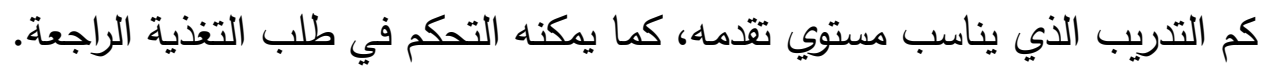

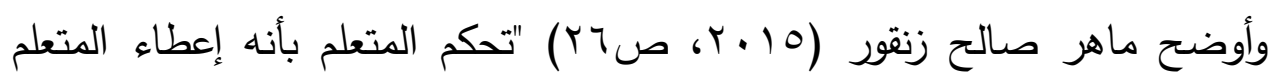

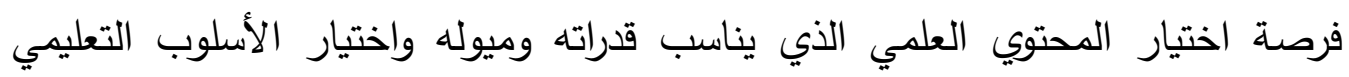
الذي يرغبه، والتحكم في التغذية الراجعة حيث يسير داخل البرنامج وفقا لقدراته الفردية". 
وفي هذا الإطار أشارت جودي كاي Judy Kay (2000) إلى أن تحكم المتعلم يعني أن يتحكم المتعلم في اختيار المحتوي والأنشطة وكذلك تحكمه في خطوات سير تعلمه بناءً على ميوله وقدراته.

الأسس النظرية الأعمة للفصل المعكوس التقدمي يري "جلاسر Glasser" أن "السلوك لا يصدر نتيجة الاستجابة لمثير خارجي ،

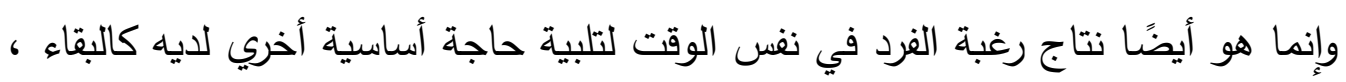
والحب ، والقوة ،والحرية حيث تتحكم كافة الكائنات الحية في سلوكياتها لتوسعة إشباع احتياجاتها" ، وبذلك فإنه طبقا لرأي "جلاسر " إذا لم يكن هناك دافع لدي المتعلم لأداء مهامه التعليمية ، فإنه يراها غير مناسبة لاحتياجاته الثخصية ؛ أي أنه لابد من ترك الحرية الكاملة للمتعلم لاتخاذ قراراته التعليمية بما يلائم احتياجاته ورغباته الفردية ، وبالتالي تزداد كل من قدراته على تحمل مسئولية تعلمه ودافعيته نحو استكمال مهام تعلمه (Funderstanding, 2006) ومن خلال الاطلاع على العديد من الدراسات والبحوث التي أوضحت النظريات

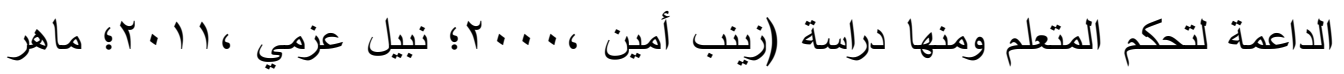

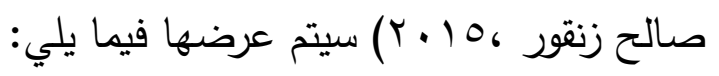
(1) نظرية معالجة المعلومات اقترح جانييه (Gagne,1985) فكرة أن عملية التعلم مستمرة ومتصلة، تبدأ من انتقال المعلومات من المستقبلات الحسية، وتمر خلال الذاكرة القصيرة المدى، وربما تصل للذاكرة الطويلة المدى حتى تتتهى أخيرًا باستجابة المتعلم، وأحد نتائج عملية ترميز المعلومات على المدى الطويل هو تكوين الخريطة المعرفية للمتعلم، والتي تعد الطريقة التي تتظم بها المعرفة في الذاكرة الطويلة المدى، ومن خلال هذه النظرية فإن أسلوب تحكم المتعلم يكون أكثر فاعلية في عملية التعلم عندما تكون الاختيارات التي يطلبها 


\section{أثر استراتيجيتين للفصول المعكوسة التشاركية "التقدمية/الرجعية" أ.مني السيد العربي}

المتعلم مرتبطة بدرجة كبيرة بالتنظيم المعرفي الداخلي له، وقد دعم "لوريلارد Laurillard, 1984 هذه الفكرة عندما أثار إلى أن اختيار المتعلم لمسارات معينة

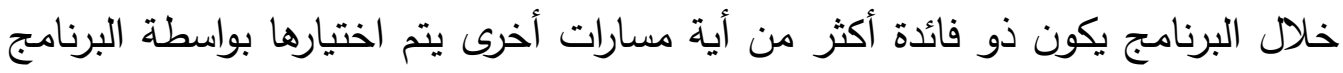

\section{"Motivation Theory" نظرية الدافعية (r)}

لقد أوضح كيلر (Keller, 1983) خلال مناقشة للدافعية، وخصائص عملية التعلم التي تدفع الطلاب إلى التعلم، أن هناك أربعة محددات تعليمية هي (الاهتمام، والمواءمة، والتوقع، والإثباع)، وهي تؤدى إلى مزيد من الدافعية، وبالتالي المزيد من التعلم، وهناك محددان من هذه المددات الأربعة يتعلقا بمفهوم تحكم المتعلم هما المواءمة، والتوقع. فالمواءمة كما يعرفها "كيلر" هي إدراك المتعلم للاحتياجات الثخصية خلال عملية

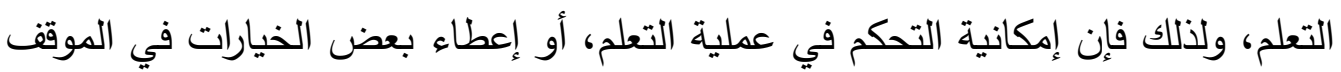

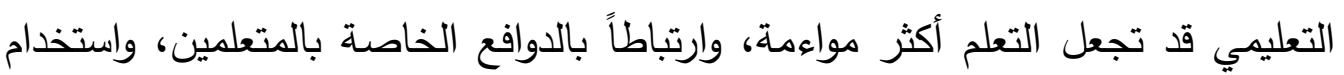
تحكم المتعلم قد يساعد في إثباع هذه الاحتياجات، وهذا يزيد من الدافعية، وهكذا يزداد

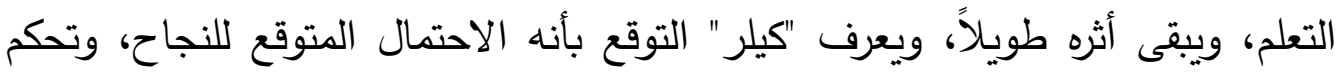

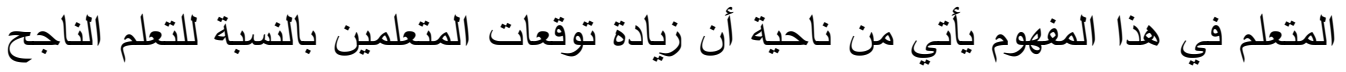
يرتبط لديهم بالتحكم الثخصي المبذول في عملية التعلم، لذلك فإن نظرية الدافعية

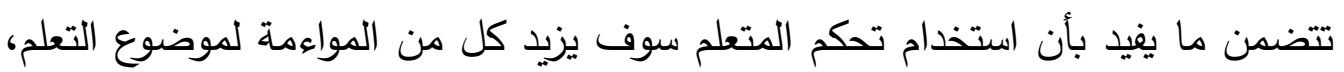
وأيضاً توقعات المتعلمين للنجاح. مميزات التعلم التقدمي لبيئة الفصل المعكوس التقدمي عديد من المميزات هى (ماهر زنقور ، 10.ب،

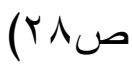
• إعطاء المتعلم حق اتخاذ القرارات التعليمية بثأن تعلمه. 
يترك للمتعلم حرية التحكم في سير عملية تعلمه. بنية منظوميه متعددة الأبعاد والمستويات. هتيح للمتعلم تحديد تسلسل وتتابع المحتوي وتحديد سرعة الخطو الذاتي في التعلم. هشاركة المتعلم في اتخاذ القرارات المتعلقة بعملية تعلمه الذاتي يساهم بالضرورة

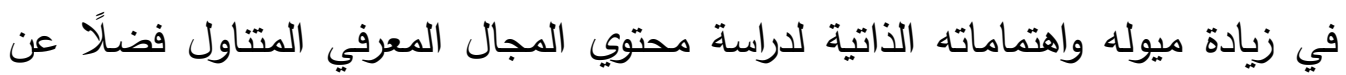
تعزيز وزيادة دافعيته للتعلم. عيوب التعلم التقدمي أشار نبيل جاد عزمي(1) (1) إلي وجود قصور في التعلم التقدمي رغم المميزات العديدة له والتي تتلخص فيما يلي: هناك بعض الدراسات تفسر التأثير المحدود لتحكم المتعلم على التحصيل بأنه ناتج عن نقص المقدرة على اتخاذ القرارات المناسبة بالنسبة للتعلم ومساره. وأيضا تؤكد الدراسات السابقة على أن المتعلمين ذوي التحصيل الضعيف ليست لديهم معلومات مسبقة كافية، وليست لديهم الدافعية المطلوبة لاتخاذ القرارات المناسبة بالنسبة للتعلم مثل كمية التدريب، الخطو الذاتي، التتابع الأمثل للمحتوي، لذلك فإن بعض الباحثين يقترحون تقديم إرشاد أو توجيه كحل بديل للاستخدام المطلق لتحكم المتعلم.

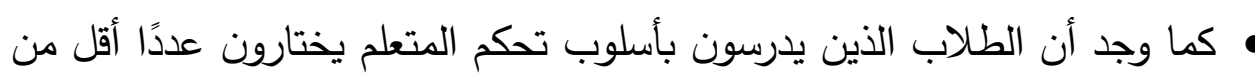

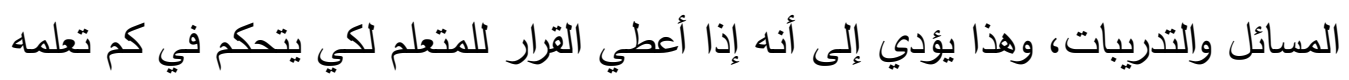
وتدربباته وأمثلته فقد ينهي تعلمه بسرعة قبل أن يتلقى تعلمًا كافيًا.

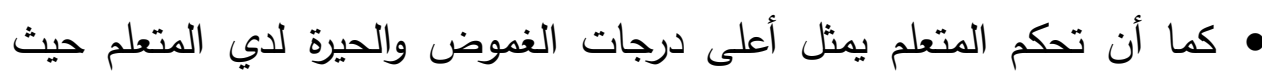
يكون مسئولًا عن جميع القرارات المتعلقة بتعلمه من البرنامج. 


\section{أثر استراتيجيتين للفصول المعكوسة التشاركية "التقدمية/الرجعية" أ.مني السيد العربي}

\section{Reactive learning التعلم الرجعي}

\section{تعريف التعلم الرجعي}

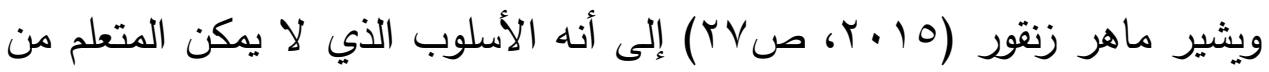
اختيار المحتوي العلمي الذي يناسب قدراته وميوله، حيث يسير المتعلم وفق نمط مفروض من قبل مصمم البرنامج، ويكون دور المتعلم تلقي للمعلومات التي يقوم البرنامج لئه

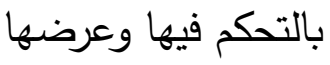

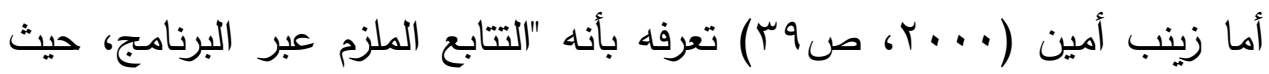
يستقبل المتعلم عناصر التعلم والمحتوي والتغذية الراجعة في بيئة التعلم".

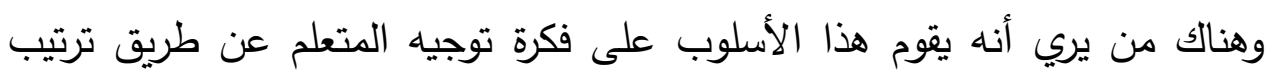

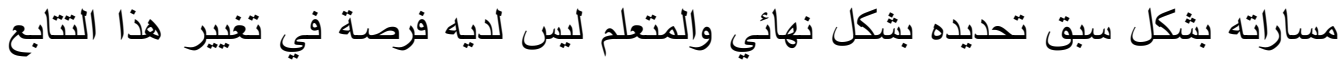

$$
\text { (محمد خليل منصور ، 10 م ب). }
$$

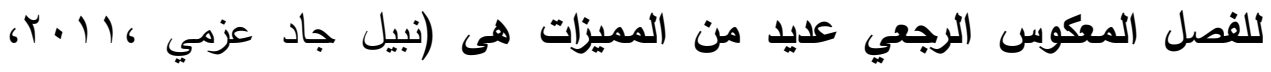
ص ـ ينتج عنه أقل مستويات للغموض والحيرة لدي المتعلم، فليس مطلوبا من المتعلم اتخاذ قرارات أثناء تعلمه من البرنامج، فيتنرغ لمهمة التعلم فقط وتزداد كفاءة التعلم.

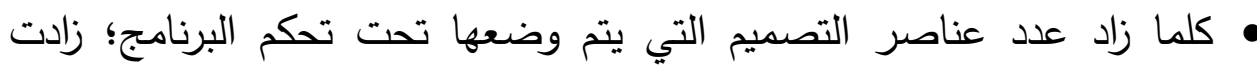

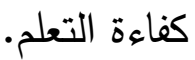
• تحكم البرنامج ينتج عنه زمن تعلم أقل. عيوب التعلم الرجعي لا يهتم بمراعاة الفروق الفردية بين المتعلمين. 
يحدد تتابع تعليمي واحد لكل الطلاب بغض النظر عن اهتماماتهم واحتياجاته

$$
\text { (نبيل عزمي ، ( + (ب). }
$$

هناك عديد من البحوث والدراسات السابقة والتي تتاولت التعلم التقدمي مقابل التعلم

$$
\text { الرجعي وفيما يلي يتم عرض نتائج هذه الدراسات والبحوث: }
$$

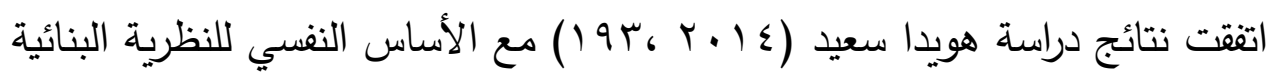
التي تري أن إخضاع المتعلم تحت تحكم البرنامج سيضع قيود على خبرة التعلم مما يؤدي إلى منع المتعلم من بناء نموذج عقلي من المعلومات ،وبدون هذا النموذج ستكون

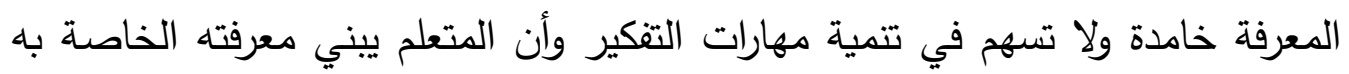
من خلا ما يتعلهه ، ويبتكر المتعلم أساليب جديدة لاستخدام المعرفة الجديدة التي يكتسبها ،ولحدوث ذلك ينبغي مراعاة طريقة عرض المعلومات والممارسة وتقييم المتعلم ، وأن التحكم ينتج عنه تعلم أكثر فاعلية وكفاءة وتتظيم داخلي، وكذلك كثفت دراسة عادل

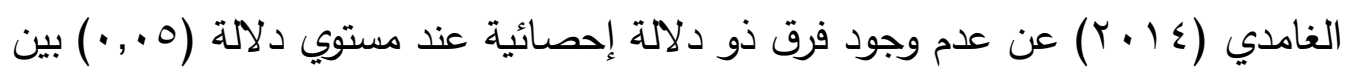
متوسطي درجات المجموعة التجريبية الأولي (تحكم البرنامج) والمجموعة التجريبية الثانية (تحكم المتعلم) في الاختبار التحصيلي وفي هذا الإطار هناك من يري أنه لا يوجد جدال حول ضرورة تحكم المتعلم في بيئة التعلم ولكن لابد من تحديد مستوي ودرجة التحكم الذي يجب ان يمارسه المتعلم في

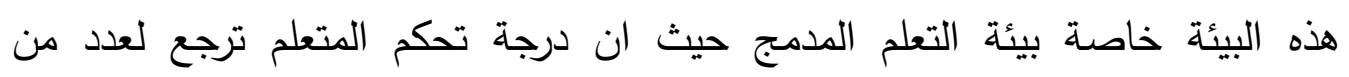
المتغيرات منها (عمر المتعلم، الخبرات السابقة للمتعلم، خطوات التعلم، درجه تعقيد المادة التعليمية، ودرجة ألفة المتعلم مع المادة المقدمة (وليد يوسف، داليا شوقي ، ب ا ب ). 


\section{أثر استراتيجيتين للفصول المعكوسة التشاركية "التقدمية/الرجعية" أ.مني السيد العربي}

المحور الثاني: مهارات تطوير المواقع التعليمية

\section{أولاً: مهارات تطوير المواقع التعليمية}

إن مصير أي مجتمع يسعي للتواجد العالمي يتحدد بمدي استجابته لمتغيرات

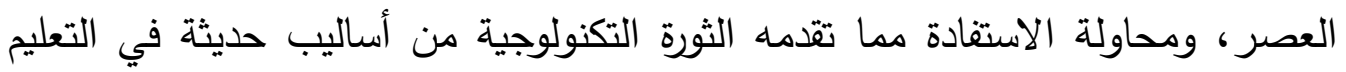
والتعلم، وبخاصة الأساليب التي تعتمد على تكنولوجيا الكمبيوتر والانترنت، والتي أكدت

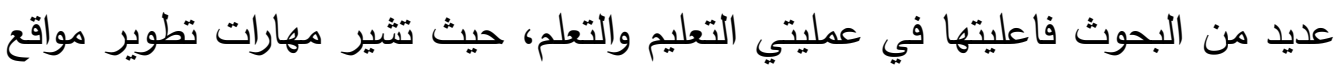

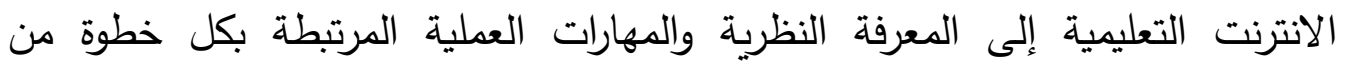

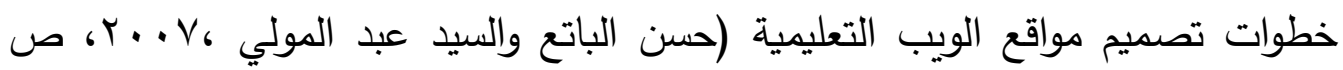
.$(104$

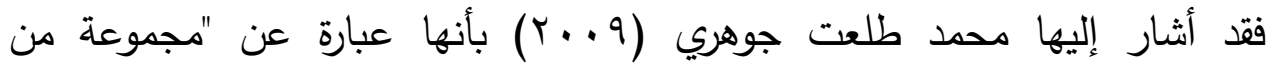
الإجراءات والخطوات التي يسلكها المتعلم من خلال البرنامج المحدد الذي يتسم بالدانة

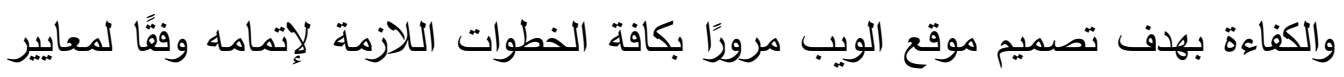

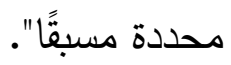

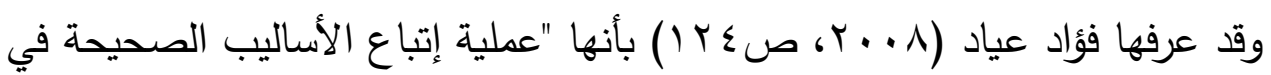
تصميم موقع ويب وإنتاجه للحصول على موقع ذي جودة عالية؛ وتشمل تلك العملية المهارات الست الرئيسية التالية: مهارة تصميم صفحات الموقع، مهارة استخدام الوسائط

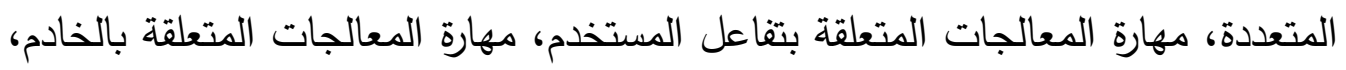
مهارة تحديد بنية الموقع، مهارة تطوير الموقع".

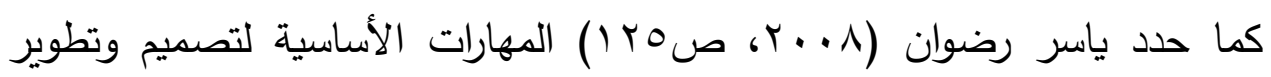

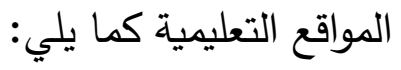

• تحديد الهفف من تصميم الموقع التعليمي. تصميم الصفحة الرئيسة للموقع وإنشاءها. 


$$
\text { • • إدراج الوسائط المتعددة في صفحات الموقع. }
$$

•إنشاء الارتباطات التشعبية في صفحات الموقع، والقدرة على تشغيلها والتعامل

نشر الموقع والقدرة على تشغيله والتعامل معه والتعديل على صفحاته.

\section{ثانيًا: المواقع التعليمية

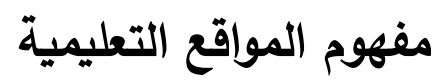

يعد استخدام مواقع الويب التعليمية أحد الإمكانيات التطبيقية لشبكة الإنترنت بما

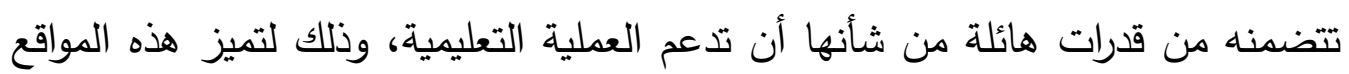
بعرض المعلومات باستخدام كافة أثكال الوسائط المتعددة، وما توفره من وسائل التفاعل

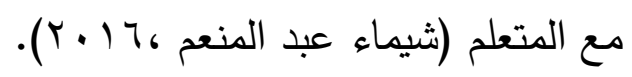
وهناك من أشار إليها بأنها عبارة عن مواقع إلكترونية تعليمية عبر شبكة الإنترنت، تتضمن المواد التدريسية أو التدريبية الممكنة، مع إمكانية تغيرها أو تطويرها بما يواكب التباه المتغيرات الحديثة بالمجال المعرفي والعلمي، وتتيح للمتعلم التفاعل مع هذه المواد وقتما

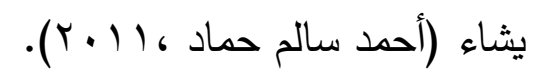
معاييز تصميم المواقع التعليمية أشار أحمد حماد (11 ـ Y، ص YO\&) إلى معايير تصميم المواقع بأنها: تفاعل المتدرب مع الموقع. إتاحة خيارات الاستكشاف. مراعاة الموقع للفروق الفردية بين المتعلمين. • إتاحة فرصة التعلم الذاتي. • يحتوي الموقع على تقويمات تجمعية ليحدد المتعلمين مستوي تقدم أدائهر. 


\section{أثر استراتيجيتين للفصول المعكوسة التشاركية "التقدمية/الرجعية" أ.مني السيد العربي}

• إمكانية وسهولة الإبحار والتتقل والتجول داخل الموقع بسهولة ويسر.

• توفير عنصر الإثارة والتشويق والمتعة أثناء التعلم.

العلاقة بين استراتيجيتي الفصول المعكوسة التشاركية (التقدمية/الرجعية) وتنمية مهارات تطوير المواقع التعليمية

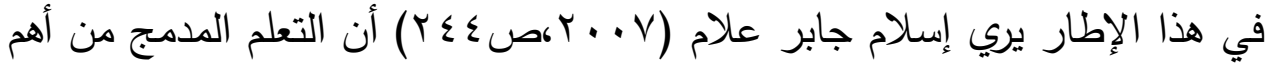
خصائصه تعدد مصادر التعلم للمحتوي، فيمكن الدتعلم من تلقي المعلومة بأثكال منال

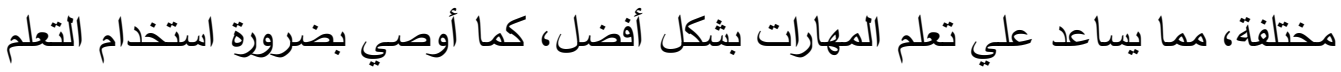
المدمج في تتمية المهارات الخاصة بتطبيقات تكنولوجيا التعليم بصفة عامة، ومهارات تصميم المواقع التعليمية بصفة خاصة، حيث أشارت نتائج دراسته إلى وجود فروق ذات دلالة إحصائية عند مستوى (0., •) بين المجموعتين التجريبية والضابطة في الاختبار التحصيلي وبطاقة الملاحظة لصالح المجموعة التجريبية.

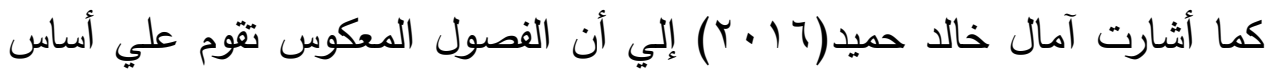

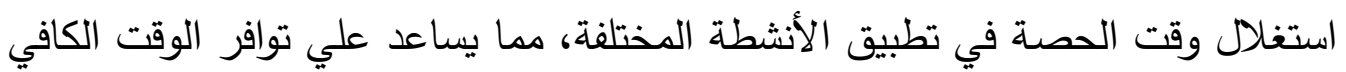
لاى الطلاب للتدريب على المهارات المختلفة، ومنها مهارات تصميم المواقع التعليمية،

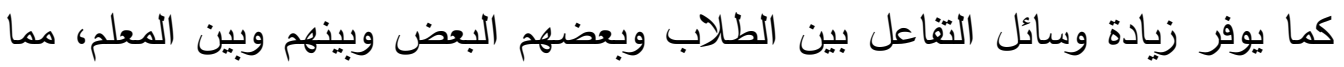

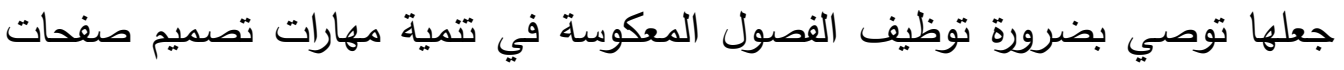

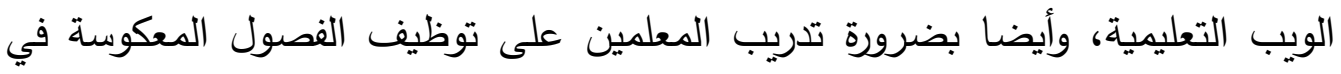
العملية التعليمية بإتقان، حيث أسفرت نتائج الدراسة عن وجود فروق ذابن ذات دلات دلالة إحصائية

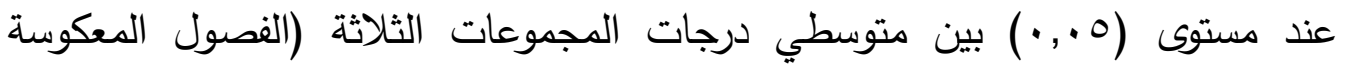
والمدمجة والتقليدية) في الاختبار التحصيلي وبطاقة الملاحظة لصالح مجموعة الفصول

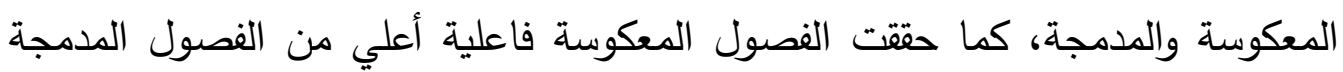
وفقا للكسب المعدل لبلاك. - الك. 
وأوصى حسن الباتع، والسيد عبد المولي (Y. . . . بضرورة استخدام التعلم المدمج في تدريس المهارات العملية، وبالأخص مهارات تصميم المواقع التعليمية، نظرًا لدورها الفعال في زيادة فاعلية العملية التعلمية، حيث أسفرت نتائج البحث عن تفوق المجموعتين التجريبيتين على المجموعة الضابطة في الجانب الأدائي لمهارات تصميم وإنتاج مواقع الويب التعليمية.

وأوضحت ميسر ناصر شرير(Y V P Y أن بيئة الصف المقلوب هي من متطلبات العصر ، وتعد لغة المتعلمين الحديثة؛ حيث أنها جعلت التعليم أكثر متعة وتشويقًا، كما وفرت لكل طالب إمكانية التعلم حسب سرعته الخاصة مما أدي إلي إتقانهم للمهارات،

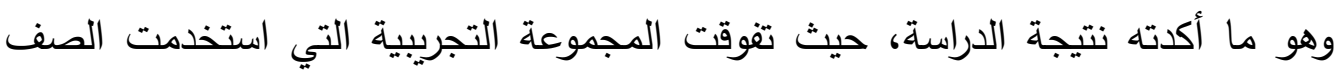
المقلوب علي المجموعة الضابطة في تتمية مهارات النحو. وأشار وليد يوسف وداليا شوقي(Y ( ا ب) إلى أن التعليم المدمج وانماطه المختلفة والتي منها الفصول المعكوسة، يستطيع معالجة قصور التدريس التقليدي للمفاهيم والمهارات؛ حيث أنه يوفر مزيدًا من التفاعل والتدريب والمشاركة في تطبيق الأنشطة التعليمية المختلفة، والتي تساعد على تتمية المهارات المختلفة ومنها مهارات التصميم التعليمي، كما أثار إلى أن إعطاء المتعلم مزيدًا من التحكم في تعلمه يساعده علي تعلم

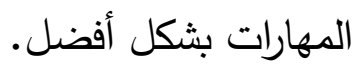

إجراءات بناء استراتيجيتي الفصول المعكوبة التشاركية (التقدمية ) الرجعية)، وتطبيق تجربة البحث: أولاًا: إعداد قائمة بالمعاييز الواجب توافرها في بيئة الفصول المعكوسة التثاركية. قامت الباحثة بإعداد قائمة المعايير في صورتها الأولية واشتملت مجالين رئيسيين و^ معايير فرعية وءr مؤشر، ومن ثم قامت بعرض قائمة المعايير على 


\section{أثر استراتيجيتين للفصول المعكوسة التشاركية "التقدمية/الرجعية" أ.مني السيد العربي}

مجموعة من المحكمين في مجال تكنولوجيا التعليم بلغ عددهم (^) محكمين لإبداء

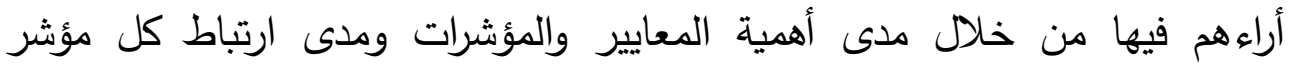

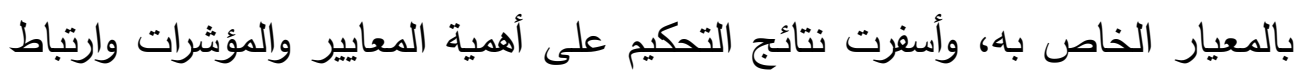

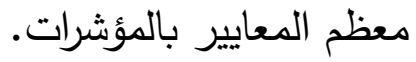

ثانيًا: التصميم التعليمي لبيئتي الفصول المعكوسة التشاركية

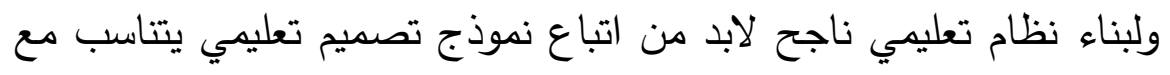
هذا النظام ولذلك قامت الباحثة بالاطلاع على عديد من نماذج التصميم التعليمي

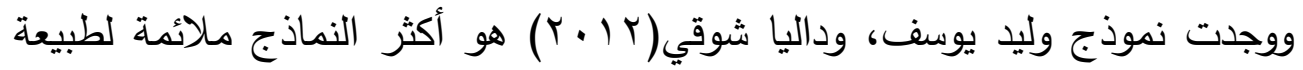

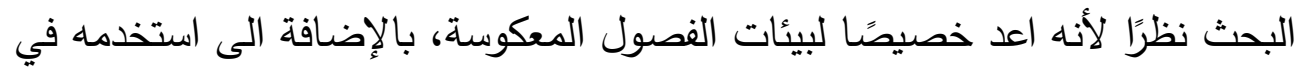
عديد من الدراسات والبحوث التي تضمنت ضمن إجراءاتها تصميم فصول معكوسة التهات

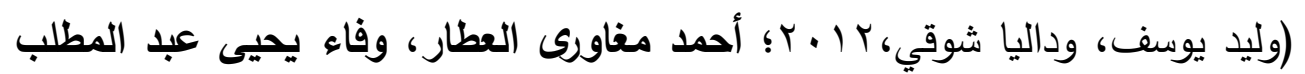

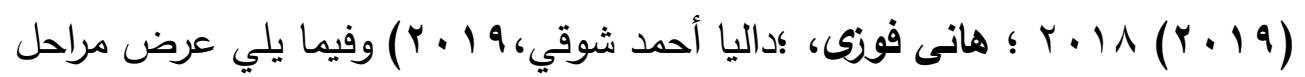
النموذج على تصميم البرنامج وتطويره المرحلة الأولي: التحليل أ- تحليل المشكلات وتقدير الحاجات

تم عرض المشكلة الواقعية التي دفعت الباحثة لاستخدام بيئة الفصل

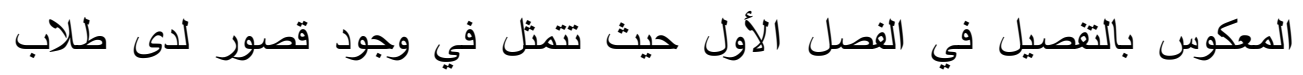

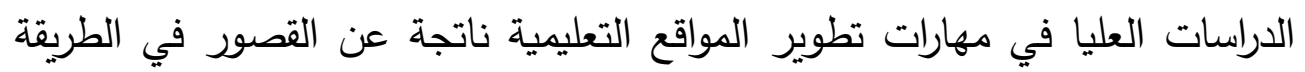
التقليدية للتدريس لعدم مراعاتها الفروق الفردية بين المتعلمين وعدم استخدام المستحدثات التكنولوجية المختلفة في العملية التدريسية وأيضًا عدم وجود الوقت التصنين الكافي لتطبيق المهارات العملية والأنثطة التعليمية المطلوبة التي من شأنها إثراء العملية التعليمية، هذا وبالإضافة إلى طبيعة عينة البحث (طلاب الدراسات العليا) 
كونهم غير متفرغين للدراسة واختلاف خصائصهم العمرية والفكرية والثقافية، مما جعل الباحثة تلجأ إلى الفصول المعكوسة التشاركية وهي أحد أنماط التعليم المدمج الذي يعد أنسب الطرق مع هذه الفئة.

\section{ب- تحليل خصائص المتعلمين وسلوكهم المدخلي}

- عينة البحث الحالي طلاب الدراسات العليا بقسم تكنولوجيا التعليم بكلية التربية النوعية جامعة عين شمس وجامعة بنها في الفصل الدراسي الثاني للعام

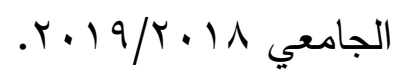
- سلوكهم المدخلي الخاص بتطوير المواقع التعليمية يكاد يكون متساويًا حيث أنهم لم يتعرضوا لدراسة المحتوى الموجود بهذا المقرر من قبل. - عدم تجانس عينة البحث من حيث اختلاف خصائصهم العمرية والفكرية والثقافية والاجتماعية.

- توفر مهارات استخدام الكمبيوتر والإنترنت لدي جميع الطلاب وهذا ما تأكدت منه الباحثة قبل البدء في التجربة. ج- تحليل بيئة التعلم

قامت الباحثة بتوفير جميع المستلزمات الإدارية والمالية والبشرية والمادية التي تخدم العملية التعليمية، حيث تأكدت من توفر معمل حاسب بقسم تكنولوجيا التعليم بالكلية، لكي يتم فيها اللقاء مع عينة البحث، حتى يتمكن كل طالب من التطبيق العملي لمهارات تطوير المواقع التعليمية وتطبيق الأنشطة الصفية التشاركية المختلفة. دـ تحديد الأهداف التعليمية العامة

الهدف العام من البرنامج المقترح هو إكساب طلاب الدراسات العليا بقسم تكنولوجيا التعليم بكلية التربية النوعية جامعتي عين شمس وبنها مهارات تطوير المواقع التعليمة بجانبيها الأدائي والمعرفي من خلال الفصول المعكوسة التشاركية وقياس مدي رضائهم عن هذه الفصول. 


\section{أثر استراتيجيتين للفصول المعكوسة التشاركية "التقدمية/الرجعية" أ.مني السيد العربي}

وقد قات الباحثة بوضع الأهداف العامة والإجرائية الخاصة بمقرر تطوير

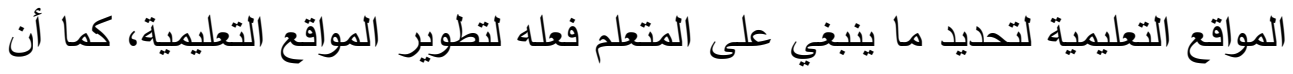

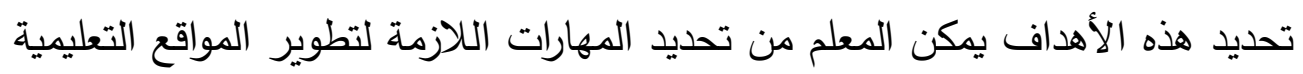

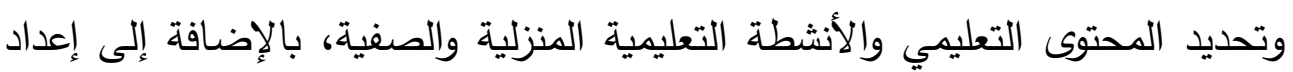

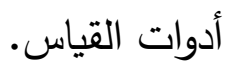

هـ - تحليل المهارات

قامت الباحثة بإعداد قائمة المهارات اللازمة لتطوير المواقع التعليمية، حيث

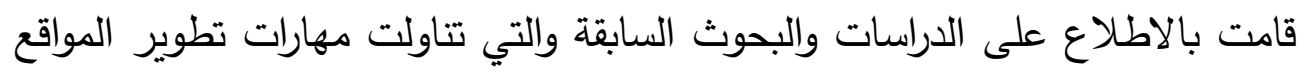

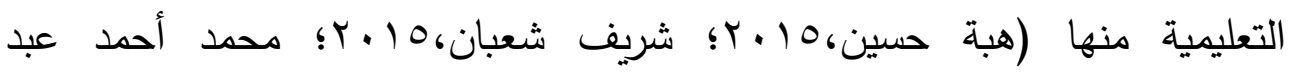

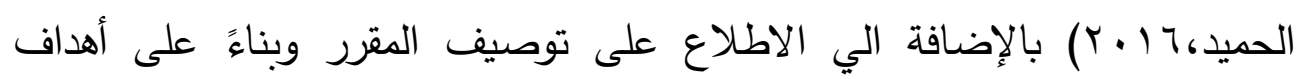

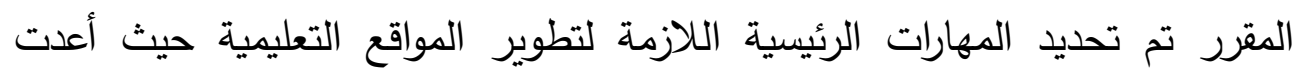

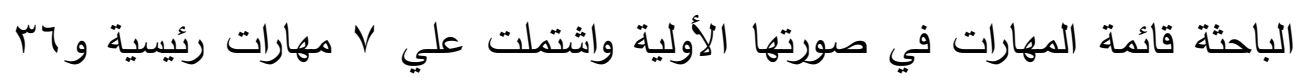
مهارة فرعية، وتم عرض قائمة المهارات على مجموعة من المحكمين في مجال

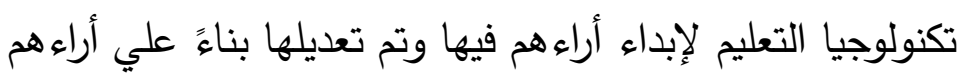

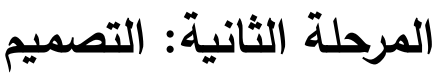

عملية التصميم تهدف إلي وضع الثروط والمواصفات الخاصة بمصادر التعلم وعملياته، فمن خلال تحديد الأهداف تحديدًا سليمًا، يمكن من تصميم محتوي

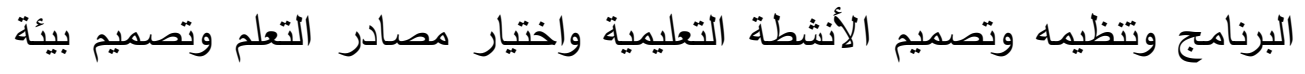
التعلم الإلكتروني وتصميم استراتيجيات التفاعلية والتحكم التعليمي وتصميم بيئة التعلم التئية وجهًا لوجه وتصميم أدوات التقويم والاستراتيجية التعليمية وأخيرا تصميم أنماط التعلم والسيناريو وفيما يلي شرح هذه الخطوات: 
تم تحديد الأهداف الإجرائية لتطوير المواقع التعليمية في ضوء الأهداف العامة السابق تحليلها، حيث قامت الباحثة بصياغة الأهداف الإجرائية على ضوء الأهداف العامة التي تم تحديدها وقد بلغت (^^) هدفًا في صورة أهداف سلوكية يمكن قياسها، وتصف سلوك المتعلم المتوقع فعله بدقة بعد الانتهاء من دراسة المحتوي التعليمي الخاص بمهارات تطوير المواقع التعليمية، ب- تصميم المحتوي التعليمي وتتظيمه وبناءً على الخطوة السابقة وهي تحديد الأهداف العامة والأهداف الإجرائية، وبالإضافة إلى إطلاع الباحثة للأدبيات والدراسات العلمية التي تتاولت هذا المحتوي تم إعداد قائمة خاصة بالمحتوي التعليمي، بالإضافة إلى الأهداف التعليمية، وتم عرض هذه القائمة على مجموعة من المحكمين عددهم (r I) في مجال تكنولوجيا التعليم.

\section{ج- تصميم الأنشطة التعليمية}

وأهتمت الباحثة في مرحلة تصميم الأنشطة بأن يكون النشاط المنزلي (الذي يتم تطبيقه في المنزل قبل الحضور للمحاضرة) فردي كل طالب علي حد للتأكد من مدي استيعاب كل طالب للمحتوي التعليمي، بينما يكون النشاط الصفي (الذي يتم تطبيقه

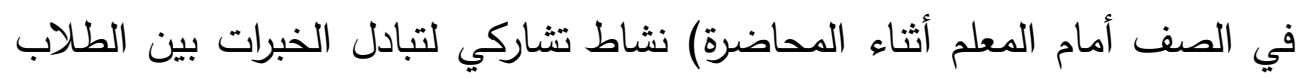
فيما بينهم.

د- اختيار مصادر التعلم

قامت الباحثة بإنتاج بيئتي للفصول المعكوسة التشاركية (التقدمية /الرجعية) من خلال فصول جوجل Google Classroom وذلك لقياس أثرهما على تتمية مهارات تطوير المواقع التعليمية لدى طلاب الدراسات العليا. 


\section{أثر استراتيجيتين للفصول المعكوسة التشاركية "التقدمية/الرجعية" أ.مني السيد العربي}

كما قامت الباحثة بعد تجميع المحتوي بتقسيمه إلى محاضرات وكان عددها (ع)

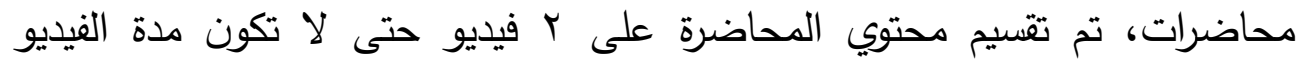
الواحد طويلة ويمل الطلاب، وبالاستعانة ببرامج تصوير سطح الككتب تم تسجيل

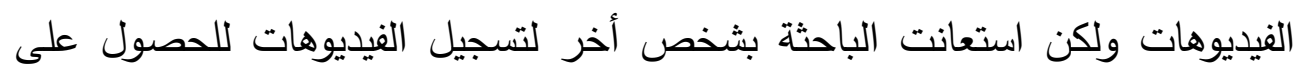
جودة عالية للصوت الخاص بالفيديو. هـ - تصميم بيئة التعلم الإكتروني بالئي

قامت الباحثة بتصميم بيئتي التعلم الإكتروني (التقدمية / الرجعية) من خلال فصول جوجل Google Classroom وهي بيئة جاهزة معدة مخصصًا للفصول المعكوسة، حيث قامت الباحثة بتقسيم عينة البحث إلى مجموعتين تجريبيتين كل مجموعة م. طالب ثم قامت بتصميم بيئة الفصل المعكوس التقدمي وتحتوي على التى

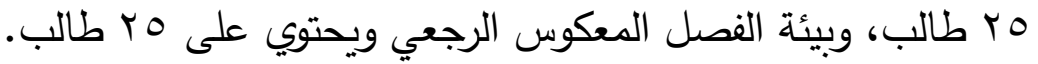
وقامت الباحثة بتصميم بيئتي التعلم على النحو التالي: بيئة الفصل المعكوس التقدمي

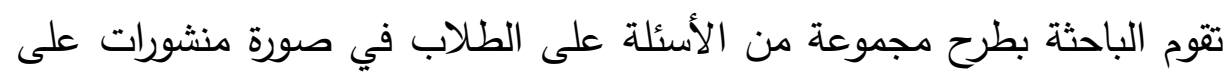
البيئة حيث يتم تقديم التعلم بناءً على إجابات هذه الأسئلة لطلاب الفصل المعكوس الفئل

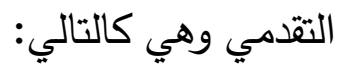

- هل تفضل تعلم المهارة فقط من الفيديو أم بالإضافة إلى ملف Pdf؟

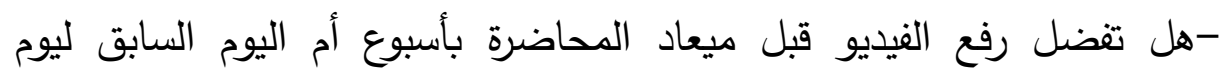
المحاضرة؟ - إن

• هل تفضل مشاهده زملائك للأنثطة المنزلية التي تقوم بها أم لا؟ هل تفضل طلب التغذية الراجعة أمام زملائك أم من المعلم عبر البريد

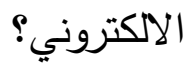


• هل تفضل ميعاد تسليم الأنشطة المنزلية يكون في نفس يوم رفع الفيديو أم

$$
\text { قبل ميعاد المحاضرة مباشرة؟ }
$$

• هل تفضل أن يسير التعلم بالتتابع المنطقي كما هو موضح بالأهداف

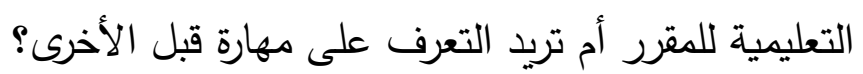

\section{بيئة الفصل المعكوس الرجعي}

أما في الفصل المعكوس الرجعي قامت الباحثة بتحديد كل النقاط السابقة دون اللجوء إلى طلاب العينة ولكن وفقًا لتحليل المحتوى وطبيعة المتعلمين وخصائص بيئة التعلم.

\section{و -تصميم التفاعل}

يتم التفاعل داخل بيئتي الفصول المعكوسة التشاركية (التقدمية /الرجعية) من

خلال:

\section{ا ـ التفاعل داخل البيئة الإلكترونية}

•التفاعل بين المتعلم والمحتوي: يتم ذلك من خلال تفاعل المتعلم مع الروابط الداخلية الخاصة بالمحتوى. التفاعل بين المتعمين والتفاعل بين المعلم والمتعلم: يتم من خلال طرق عدة للتفاعل، منها البريد الإلكتروني، التعليقات أسفل المنشورات الموجودة. التفاعل بين المتعلم وواجهة التفاعل. r ـ التفاعل داخل البيئة الصفية يتم التفاعل داخل البيئة الصفية من خلال عرض الطلاب لملاحظاتهم حول الفيديوهات والأجزاء الغير مفهومه، ومناقشتها بين الطلاب وبعضهم البعض وبين الطلاب والمعلم، وإعادة شرح بعض الأجزاء الغير المفهومة من خلال أجهزة العروض ولئ الضوئية، بالإضافة إلى التطبيق العملي للنشاط الصفي التشاركي أمام المعلم. 


\section{أثر استراتيجيتين للفصول المعكوسة التشاركية "التقدمية/الرجعية" أ.مني السيد العربي}

\section{تصميم بيئتي التعلم الصفية}

تم تجهيز معمل الحاسب بقسم تكنولوجيا التعليم بالكلية، من خلال تزويده بوصلات للإنترنت، كما يحتوي المعمل على عدد مناسب من أجهزة الكمبيوتر مما

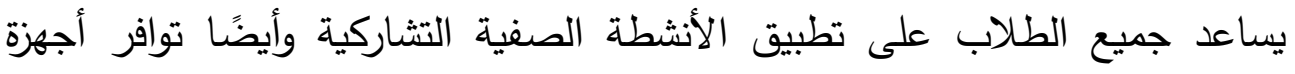

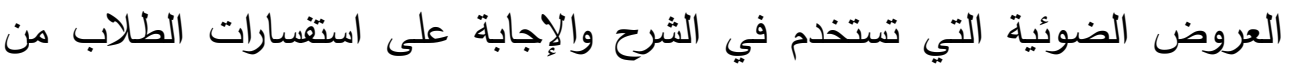

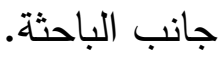

\section{تصميم استراتيجية التفذية الراجعة}

تم تقديم التغذية الراجعة من جانب الباحثة من خلال المناقشات والحوار بينها وبين الطلاب في البيئة الصفية ومن خلال متابعتها للطلاب في أثناء تطبيق الأنثطة

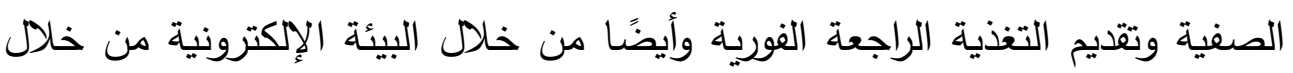

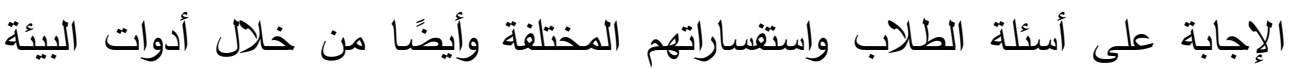

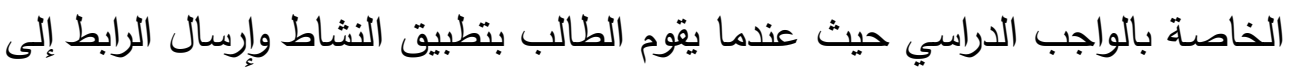

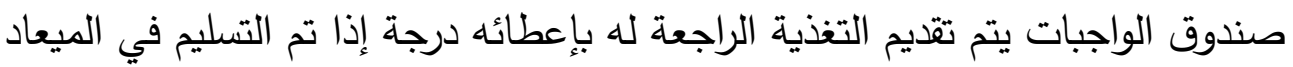
المحدد.

\section{تصميم الاستراتيجية التعليمية وأنماط التعلم}

الاستراتيجية التعليمية هي مجموعة من الإجراءات والتدابير الموضوعة مسبقًا من الإنيان

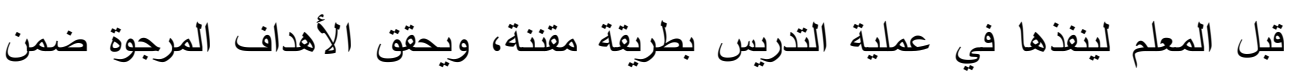
أبسط الإمكانيات والظروف وفيما يلي عرض خطوات سير الاستراتيجية التعليمية:

$$
\text { ا ب ت بديد الأهداف }
$$

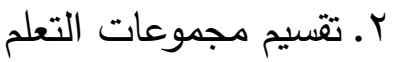

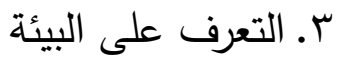

ع. ـ ت تطبيق الأدوات قبليًا 
ه تقسيم الطلاب إلى مجموعات تشاركية صغيرة داخل كل مجموعة تجريبية 7. تحديد نوعية التعلم داخل بيئة الفصل المعكوس التقدمي V. تحديد نوعية التعلم داخل بيئة الفصل المعكوس الرجعي

1. تقديم التعلم

9 . تنفيذ المنتج النهائي (تصميم موقع تعليمي):

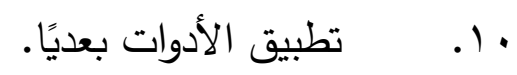

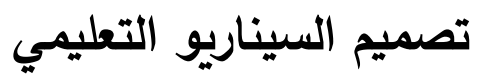

من خلال ما سبق من خطوات للتصميم، وبالرجوع إلى الأهداف التعليمية والمحتوي التعليمية تم تصميم السيناريو لاستراتيجيتي الفصول المعكوسة التشاركية

$$
\text { (التقدمية /الرجعية) حيث يحتوي على: }
$$

يعرض فيه كل ما يظهر على البيئة في هذا الإطار من نصوص، وصور وروابط.

$$
\text { المنشورات }
$$

يعرض فيها كل ما يعرض داخل الجانب المرئي من نصوص.

$$
\text { الوسائط المتعددة }
$$

يعرض فيها كل ما يعرض داخل الجانب المرئي من صور ورسوم

$$
\text { وفيديوهات. }
$$

$$
\text { عناصر الإبحار }
$$

تحتوي علي أسماء الروابط الموجودة داخل الجانب المرئي.

$$
\text { • أسلوب التعلم }
$$

يتم فيه تحديد الأسلوب الموجه إليه الجانب المرئي. 


\section{أثر استراتيجيتين للفصول المعكوسة التشاركية "التقدمية/الرجعية" أ.مني السيد العربي}

وبعد الانتهاء من صياغة السيناريو في صورته المبدئية، تم عرضه على

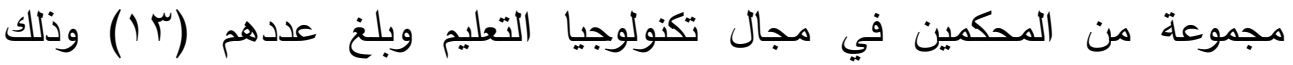

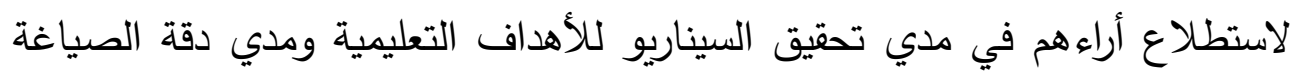

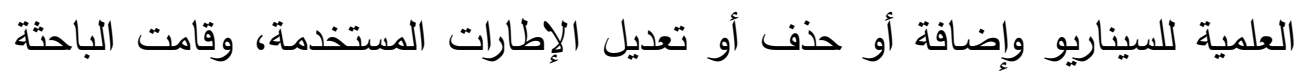
بإجراء التعديلات وفق ما اتقق عليه الدحكين حيث تم صياغة السيناريو في شكله

النهائي.

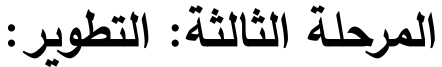

أ- التخطيط والتحضير لإنتاج بيئتي التعلم الالكتروني

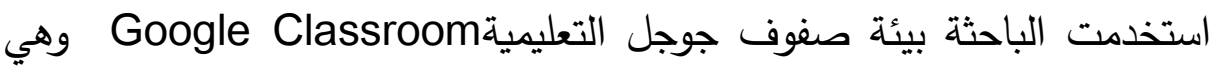

عبارة عن خدمة مجانية للمدارس والمؤسسات غير الربحية ويمكن لكل شخص لديه

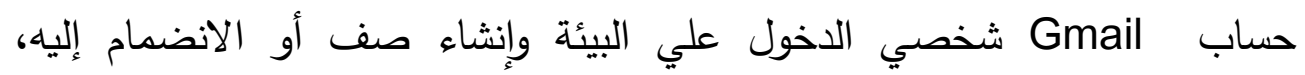

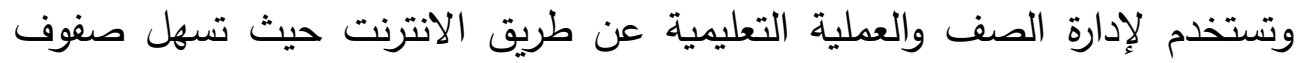
جوجل التعليمية للمتعلمين والمعلمين الاتصال داخل الددارس وخارجها لكي تتناسب

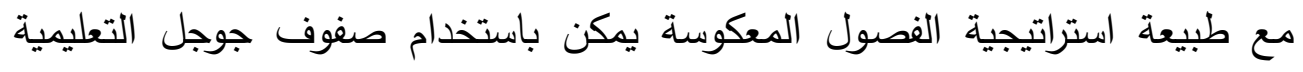

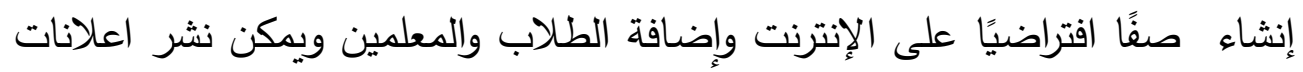
وإنشاء أسئلة ومهام للطلاب.

واستخدمت الباحثة في إعداد محتوي المقرر برنامج Word

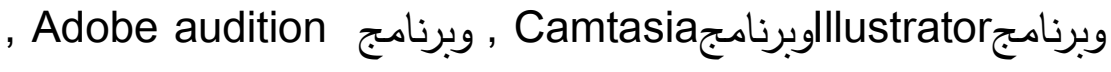

وبرنامج video scrib

ب-الإخراج المبائي لبيئتي التعلم

تم إعداد البيئة وإرسال رابط البيئة عن طريق وسائل التواصل الاجتماعي

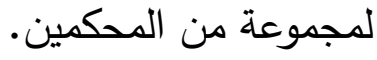




\section{ج-التقويم المبائي لبيئتي التعلم}

بعد الانتهاء من تصميم بيئتي التعلم تم عرضها على مجموعة من المحكمين في مجال تكنولوجيا التعليم، وذلك لإبداء أراءهم حول محتوي بيئتي التعلم، وأساليب التفاعل الموجودة وطرق التقويم المستخدمة، والأنشطة التي تستخدمها كل بيئة، ومدي

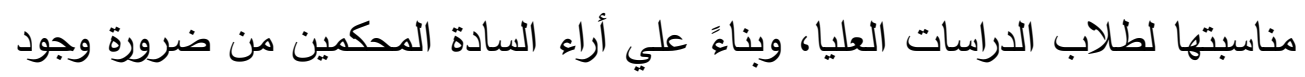
خطوات الفصل المعكوس بشكل ثابت أمام الطلاب، واختلاف طريقة التعلم في الفصل المعكوس عن البيئة التقليدية وضرورة وجود طرق للتفاعل إضافية، قامت الباحثة بإجراء التعديلات المناسبة، حتى أصبحت بيئتي التعلم في شكلهما النهائي صالحتين للتطبيق.

\section{د-التعديل والإخراج النهائي لبيئتي التعلم}

تم إعداد الصورة النهائية لبيئتي التعلم بعد إجراء تعديلات السادة المحكمين وإجراء التقويم النهائي، وتم إرسال رابط كل بيئة إلى الطلاب التابعين إليها حسب لهبء التصميم التجريبي، وذلك من خلال تطبيق الواتس(كوسيلة بديلة للتواصل)، حيث يقوم إنداء كل طالب بالدخول إلى البيئة الخاصة به من خلال الدخول على الرابط وكتابة رمز

\section{هـ - تطوير بيئتي التعلم الصفية}

وبناء علي أراء السادة المحكمين للبيئة، ومناقثة الباحثة في طبيعة البيئة الصفية، قامت الباحثة بالتأكد من تجهيزات البيئة الصفية، ووضع تصور للمشكلات التي قد تواجهها وكيفية مواجهتها، حتى يتسنى للباحثة إجراء التجربة بشكل صحيح،

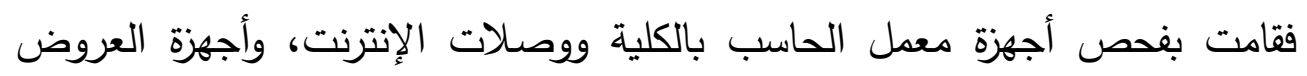
الضوئية. 
أثر استراتيجيتين للفصول المعكوسة التشاركية "التقدمية/الرجعية" أ.مني السيد العربي

\section{و -تنفيذ الاستراتيجية التعليمية المقترحة}

وقد تم تتفيذ الاستراتيجية التعليمية المقترحة على المجموعتين التجريبيتين خلال

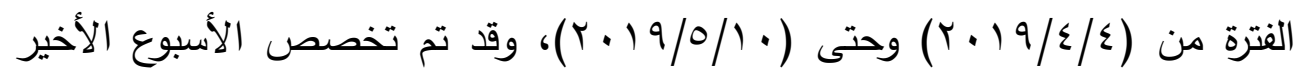
لاستلام المنتج النهائي من الطلاب (موقع تعليمي). المرحلة الرابعة: مرحلة التقويم

عملية منهجية، تقوم على أسس عملية، تستهدف إصدار الحكم بدقة وموضوعية

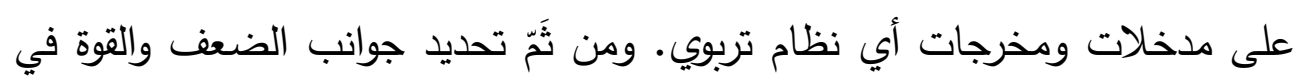
كل منها، تمهيذًا لاتخاذ القرارات المناسبة للإصلاح.

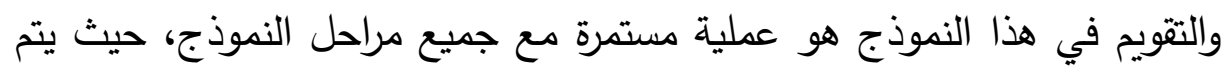
مراجعة خطوات كل مرحلة ومعالجة نقاط الضعف فيها وتعزيز نقاط القوة، وفي هذا النموذج تثمل مرحلة التقويم على إجراء التجربة الاستطلاعية وتطبيق التجربة الأساسية ورصد النتائج ومعالجتها إحصائيا وتحليل النتائج وتنعيرها. ثالثًا: إعداد أدوات البحث وردان

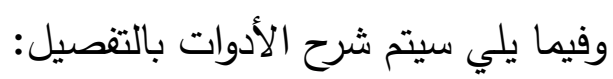
1- إعداد الاختبار التحصيلي

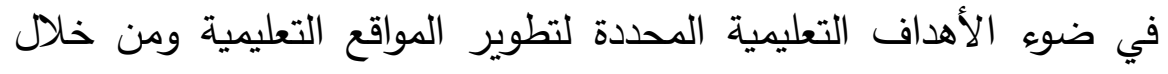

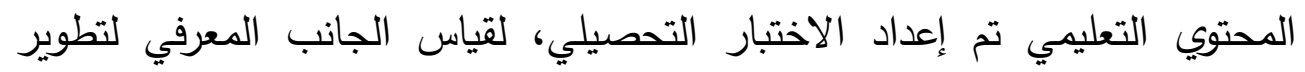
المواقع التعليمية ومعرفة أثر الفصول المعكوسة التثاركية (التقدمية مقابل الرجعية)

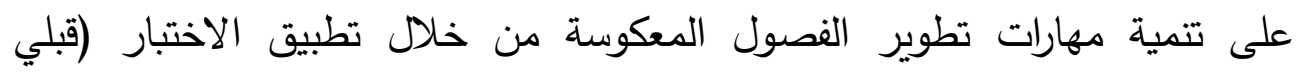

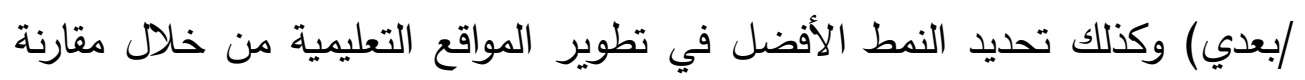
نتائج الاختبار لكلا الفصلين بعديًا. 
تم حساب صدق الاتساق الداخلي لاختبار التحصيل باستخدام معامل ارتباط سيبرمان وذلك عن طريق حساب معامل ارتباط درجة كل مفردة بالدرجة الكلية، وجدول التالي يوضح ذلك.

\begin{tabular}{|c|c|c|c|c|c|}
\hline الاتساق & r & الاتساق معامل & p & الاتساق & r \\
\hline$* * \cdot$, Vo & rq & $* *, Y l$ & 10 & $" *,, \vee \vee$ & 1 \\
\hline$* *, 77$ & $r$. & $* *, 09$ & 17 & $* *,, \vee 0$ & r \\
\hline$* * ., 00$ & $\mu_{1}$ & $* *, V 1$ & iv & $" *, v r$ & $r$ \\
\hline$* *, 79$ & rr & **. Tr & 11 & $* *, v r$ & $\varepsilon$ \\
\hline$* *, Y)$ & rr & $* *, \vee V)$ & 19 & $* *,, \wedge 1$ & 0 \\
\hline$" \cdot, v r$ & $r \varepsilon$ & $* * ., 09$ & r. & $* *,, \vee 0$ & 7 \\
\hline$" *, \wedge 1$ & ro & $* *, V 1$ & ri & $* *, v r$ & v \\
\hline$* * \cdot, 74$ & rq & **., 70 & rr & ***, & $\wedge$ \\
\hline$* * \cdot, V I$ & $r v$ & ***, Tr & rr & **, or & 9 \\
\hline$* *, V Y r$ & rᄉ & $* *, 71$ & $r \leq$ & $* *, 7 \wedge$ & 1. \\
\hline$* *$, , $\vee 0$ & $r q$ & $* *, \wedge$ & ro & $* *, \wedge$. & 11 \\
\hline$* *, 74$ & $\varepsilon$ & $* *, 70$ & Y & $* * \%$ & Ir \\
\hline$* *, Y)$ & $\leq 1$ & **, , Tr & $r v$ & $* *, V Y$ & Ir \\
\hline$* * ., 09$ & $\varepsilon r$ & **. & rA & $* *, 79$ & $1 \leq$ \\
\hline
\end{tabular}

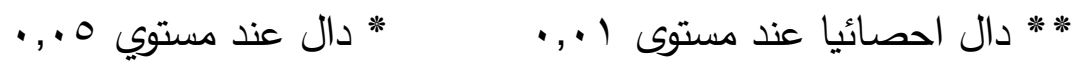




\section{أثر استراتيجيتين للفصول المعكوسة التشاركية "التقدمية/الرجعية" أ.مني السيد العربي}

يتضح من نتائج الجدول السابق أن مفردات اختبار التحصيل لها علاقة ارتباطية

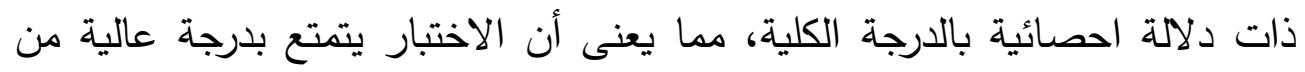

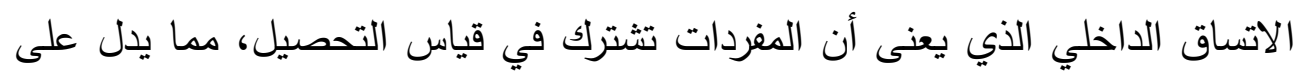

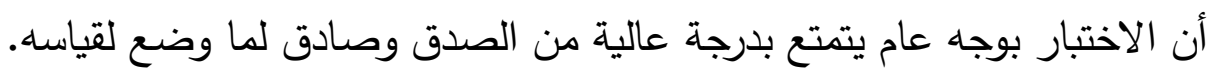

$$
\text { ب-حساب ثبات الاختبار }
$$

يقصد بثبات الاختبار أن يعطي نفس النتائج إذا ما أعيد تطبيقه علي نفس أفراد العينة في نفس الظروف بعد فترة زمنية محددة.

وتم حساب ثبات المقياس بطريقتين:

(1) (1) طريقة ألفا كرونباخ للثبات.

تم حساب الثبات بطريقة ألفا كرونباخ، حيث تم حساب ثبات الاختبار بطريقة ألفا كرونباخ وبلغ V9T, • وهي قيمة مرتغعة تعكس ثبات اختبار التحصيل المعرفي. جدول ثبات الاختبار بطريقة ألفا كرونباخ

\begin{tabular}{|c|c|c|c|c|c|}
\hline حذف ألفا كرونباخ عند & r & ألفا كرونباخ & م & ألفا كرونباخ عند & p \\
\hline$\cdot, V \cdot \Delta$ & $r q$ & . , v $q$ & 10 & $\cdot, \vee \wedge \wedge$ & 1 \\
\hline$\cdot, \vee 17$ & $\mu$ & •, & 17 & •, vqu & $r$ \\
\hline • , & r & • • & IV & $\cdot, \vee \wedge \vee$ & $r$ \\
\hline., $79 \varepsilon$ & $r r$ & •, Vrr & 11 &,,$\vee \circ \bullet$ & $\varepsilon$ \\
\hline$\cdot, v \cdot r$ & r & $\cdot, \vee \vee q$ & 19 & $\cdot, \vee \bullet \wedge$ & 0 \\
\hline$\cdot, V \cdot 7$ & q & •, & $r$ & $\cdot, v \bullet V$ & 7 \\
\hline$\cdot, \vee 01$ & ro & •, & rl & , , V०r & v \\
\hline., $79 \varepsilon$ & ry & $\cdot, \vee \vee q r$ & $r r$ &,,$\vee 70$ & $\Lambda$ \\
\hline$\cdot, v \cdot r$ & $r v$ &,,$\vee \vee q$ & rr & $\cdot, \vee \wedge \wedge$ & 9 \\
\hline
\end{tabular}




\begin{tabular}{|c|c|c|c|c|c|}
\hline$\cdot, V \cdot r$ & $r \Lambda$ & צ', & $r \leq$ & $\cdot, v \circ V$ & 1. \\
\hline$\cdot, \vee \vee q 1$ & $r q$ & $\cdot, V r \leq$ & ro & 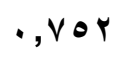 & 11 \\
\hline$\cdot, v \leqslant \wedge$ & $\varepsilon$. & $\cdot, \vee \vee$ & T & ., VOr & ir \\
\hline$\cdot, V q r$ & \& & $\cdot, \vee \vee \wedge$ & $r V$ & $\cdot, v \leq 0$ & ir \\
\hline$\cdot, \vee \vee q$. & $\varepsilon r$ & r, & $r \wedge$ & ., Vqr & $1 \leq$ \\
\hline
\end{tabular}

ويوضح الجدول أن معامل الثبات ينخفض عند حذف المفردة وهذا ما يعني ثبات الاختبار وأن حذف أي من المفردات يؤثر سلبا على درجة ثبات الاختبار وأن الاختبار يتمتع بدرجة عالية من الثبات.

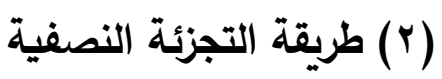
تم حساب الثبات بطريقة التجزئة النصفية، حيث تم تجزئة الاختبار الي نصفين (المفردات فردية الرتبة والمفردات زوجية الرتبة) ثم حساب معامل ارتباط سبيرمان بين درجات نصفي الاختبار وحساب معامل ثبات الاختبار ككل وبلغ VIN مرتفعة دالة احصائيًا مما يعني ثبات الاختبار وصلاحيته للتطبيق. حساب معامل الصعوبة والسهولة وإلتمييز لبنود الاختبار • وتدل القيمة العددية الناتجة على مدى اقتراب أو ابتعاد الفروق الفردية التي لهي يقيسها السؤال، وبما أن معاملات السهولة في صورتها المباشرة كسور عشرية، ومعاملات الصعوبة تمثل مكملات عشرية لها، لذلك فإن التباين يصل إلى نهايته العظمى عندما يساوى معامل السهولة (0, •)، وتكون النهاية العظمى لتباين السؤال (0, • ). ويبين الجدول التالي نتائج حساب معاملات الصعوبة والسهولة والتمييز

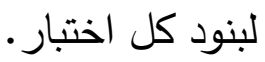




\section{أثر استراتيجيتين للفصول المعكوسة التشاركية "التقدمية/الرجعية" أ.مني السيد العربي}

جدول نتائج معاملات السهولة والتمييز لبنود الاختبار

\begin{tabular}{|c|c|c|c|c|c|c|c|c|}
\hline التمييز & السعهولة & رقم البند & التمييز & معامل & رقم البند & التمييز & السعهولة & رقم \\
\hline$\cdot, Y_{1}$ & $\cdot, V$ & $r q$ & $\cdot, Y_{1}$ & $\cdot, \mathrm{V}$ & 10 & $\cdot, Y_{1}$ & $\cdot, V$ & 1 \\
\hline$\cdot, Y_{1}$ & $\cdot, V$ & r. & $\cdot, Y_{1}$ & $\cdot, \mathrm{V}$ & 17 & $\cdot, Y_{1}$ & $\cdot, V$ & r \\
\hline$\cdot, Y_{1}$ & $\cdot, V$ & ו & $\cdot, Y_{1}$ & $\cdot, V$ & iv & $\cdot, r \leq$ & $\cdot, 7$ & $r$ \\
\hline$\cdot, Y_{1}$ & $\cdot, V$ & r & $\cdot, Y_{1}$ & $\cdot, V$ & 11 & $\cdot, Y_{1}$ & $\cdot, V$ & $\varepsilon$ \\
\hline$\cdot, Y_{1}$ & $\cdot, V$ & rr & $\cdot, 17$ & $\cdot, \wedge$ & 19 & $\cdot, Y_{1}$ & $\cdot, V$ & 0 \\
\hline$\cdot, Y_{I}$ & $\cdot, V$ & r & $\cdot, 17$ & $\cdot, \wedge$ & $r$. & $\cdot, Y_{I}$ & $\cdot, V$ & 7 \\
\hline$\cdot, Y_{1}$ & $\cdot, V$ & ro &., 17 & $\cdot, \wedge$ & YI & $\cdot, r \leq$ & $\cdot, 7$ & V \\
\hline$\cdot, Y_{1}$ & $\cdot, V$ & צמ & $\cdot, Y_{1}$ & $\cdot, V$ & rr & $\cdot, 17$ & $\cdot, \wedge$ & $\wedge$ \\
\hline$\cdot, Y_{l}$ & $\cdot, V$ & rv & $\cdot, Y_{1}$ & $\cdot, \mathrm{V}$ & rr & $\cdot, Y_{1}$ & $\cdot, V$ & 9 \\
\hline التمييز & السعهولة & رقم البند & التمييز & معامل & رقم البند & التمييز & السعهولة & رقم \\
\hline$\cdot, Y_{I}$ & $\cdot, V$ & r & $\cdot, Y_{1}$ & $\cdot, \mathrm{V}$ & $r \varepsilon$ & $\cdot, r \leq$ & $\cdot, 7$ & 1 \\
\hline$\cdot, Y_{I}$ & $\cdot, V$ & $r q$ & $\cdot, r \leq$ & $\cdot, 7$ & ro & $\cdot, r \leq$ & $\cdot, 7$ & 11 \\
\hline$\cdot$, YO & $\cdot, 0$ & $\varepsilon$. & $\cdot, Y_{1}$ & $\cdot, \mathrm{V}$ & $r t$ & $\cdot, Y_{1}$ & $\cdot, \mathrm{V}$ & Ir \\
\hline$\cdot, Y_{1}$ & $\cdot, V$ & $\varepsilon 1$ & • ro & $\cdot, 0$ & rV & $\cdot, Y_{1}$ & $\cdot, V$ & r \\
\hline$\cdot, Y)$ & $\cdot, V$ & $\varepsilon r$ & $\cdot, r \leq$ & $\cdot, 7$ & rA & $\cdot, Y_{1}$ & $\cdot, V$ & $1 \varepsilon$ \\
\hline
\end{tabular}

ويتبين من الجدول السابق أن قيم معاملات السهولة تقع في المدي من •0, • حتي

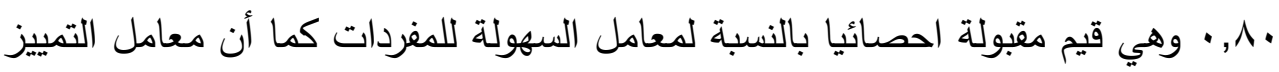

يتراوح ما بين 7 ا, · حتي 0ب, • وهي قيم مفبولة تعني قدرة المفردات علي التمييز. 


\section{r - ب - إعداد بطاقة تقييم المنتج}

تم إعداد بطاقة تقييم المنتج لقياس الجانب الأدائي لمهارات تطوير المواقع التعليمية

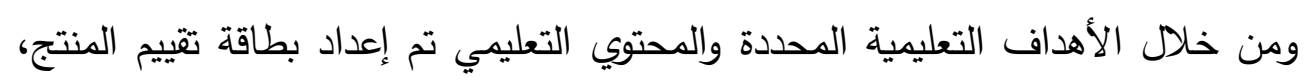
حيث تكونت من ع محاور رئيسية وتحتوي هذه المحاور على Y ع عبارة. وقامت الباحثة بتطبيق بطاقة تقييم المنتج بعديًا لتحديد أثر متغير البحث (الفصول المعكوسة التشاركية التقدمية/ الرجعية على المجموعتين التجريبيتين.

\begin{tabular}{|c|c|}
\hline العبارات & المحاور \\
\hline $1: \varepsilon$ & واجهة التفاعل \\
\hline$\Lambda: 0$ & الارتباط التشعبي \\
\hline$Y_{1}: 9$ & محتوي الموقع \\
\hline$r V: r r$ & الوسائط المتعددة \\
\hline TV & الاجمالي \\
\hline
\end{tabular}

• قامت الباحثة بإعداد البطاقة في صورتها النهائية حيث اشتمل على rV عبارة وتم تخصيص درجة لكل مفردة وبذلك تكون الدرجة الكلية للبطاقة الم درجة.

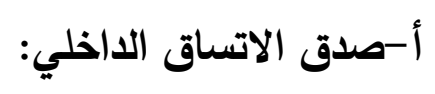
تم حساب صدق الاتساق الداخلي لبطاقة تقييم المنتج باستخدام معامل ارتباط سبيرمان وذلك عن طريق حساب معامل ارتباط درجة كل مغردة بدرجة البُعد الذي

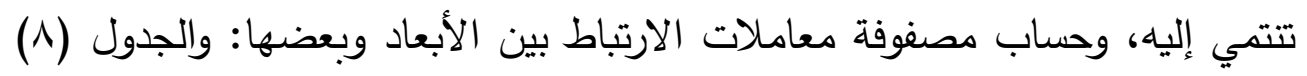
يوضح ذلك. جدول صدق الاتساق الداخلي لمفردات بطاقة تقييم المنتج 


\section{أثر استراتيجيتين للفصول المعكوسة التشاركية "التقدمية/الرجعية" أ.مني السيد العربي}

\begin{tabular}{|c|c|c|c|c|c|c|c|c|}
\hline الوسائط & r & محتوي & 5 & محتوي الموقع & s & الارتباط & واجهة & 5 \\
\hline$* *, \lambda Y r$ & Yr & $\begin{array}{r}\cdot, \vee \cdot \leq \\
* *\end{array}$ & 17 & **, , رץ。 & 9 & $* *, \wedge \circ \leq$ & $* *, \wedge \wedge 0$ & 1 \\
\hline$* *, \gamma \cdot q$ & rr & $\begin{array}{r}\cdot, \wedge 90 \\
* *\end{array}$ & iv & $* * \cdot, \wedge \cdot \vee$ & 1 & **, • & $* *,, \Lambda \vee Y$ & r \\
\hline ***, • フ & $r \leq$ & $\begin{array}{r}, \wedge 90 \\
* *\end{array}$ & 11 & $* *, \wedge 91$ & 11 & $* *, \vee \vee \neg \varepsilon$ & $* * \cdot, \wedge \cdot \wedge$ & r \\
\hline$* *, \wedge r q$ & ro & $\begin{array}{r}\cdot, \wedge \cdot 0 \\
\quad * *\end{array}$ & 19 & $* *, \wedge \cdot 0$ & IT & $* *, \wedge \circ \wedge$ & $* *,, \wedge \leq 0$ & $\varepsilon$ \\
\hline$* *, \Lambda \backslash r$ & rq & $\begin{array}{r}\text { • } \\
* \text { * }\end{array}$ & $r$. & $* *, \pi / \Gamma$ & Ir & & & \\
\hline **, • & rV & $\begin{array}{r}., 79 r \\
* *\end{array}$ & YI & ***, •, & 10 & & & \\
\hline
\end{tabular}

يتضح من نتائج الجدول السابق أن مغردات بطاقة تقييم المنتج لها علاقة ارتباطية ذات دلالة احصائية بدرجة البُعد التي تتنمي إليه، مما يعنى أن البطاقة تتمتع بدرجة عالية من الاتساق الداخلي الذي يعنى أن المفردات تشترك في تقييم المنتج، كما تم حساب معامل ارتباط درجة كل بُعد بالدرجة الكلية للبطاقة كما يبين

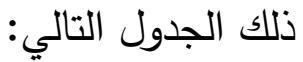


جدول مصفوفة علاقة الأبعاد لبطاقة تقييم المنتج

\begin{tabular}{|c|c|c|c|c|}
\hline المتعددة المسئ & الموقع & الارتباط & واجهة & الأبعاد \\
\hline$* *, \vee \vee \backslash \nearrow$ & $* *, \neg \wedge \varepsilon$ & $* *, \vee \vee \perp$ & $* *, \vee \backslash \wedge$ & بالدرجة الكلية \\
\hline
\end{tabular}

ويتضح من الجدول السابق أن معاملات الارتباط بين درجات الأبعاد والدرجة الكلية دالة عند مستوى (1 (., ) مما يدل على أن البطاقة بوجه عام تتمتع بدرجة عالية من الصدق لما وضعت لقياسه. ب-حساب ثبات البطاقة تم حساب ثبات البطاقة بطريقتين: (1) طريقة ألفا كرونباخ للثبات. تم حساب الثبات بطريقة ألفا كرونباخ، حيث تم حساب ثبات الأبعاد الفرعية وحساب ثبات البطاقة ككل؛ ويوضح جدول التالي الثبات بطريقة ألفا كرونباخ. جدول ثبات البطاقة بطريقة ألفا كرونباخ

\begin{tabular}{|c|c|c|c|c|c|c|c|c|c|}
\hline \multirow{5}{*}{ كرونباخ } & & ألفا & & ألفا & & ألفا & & ألفا & \multirow{5}{*}{ مفردة } \\
\hline & امفردة & كرونباخ & مفردة & كرونباخ & امفرد; & كرونبا & امفردة & كرونباخ & \\
\hline & & عند & & عند & & عذا & & عند & \\
\hline & & حذف & & حذف & & حذف & & حذف & \\
\hline & & المفردة & & المفردة & & المفردة & & المفردة & \\
\hline \multirow[t]{2}{*}{$\cdot, 7 \diamond \wedge$} & Yr & • & 17 & $\cdot, 7 \varepsilon$ & 9 & $\cdot, 7$ & 0 & $\cdot, V_{1}$ & \multirow[t]{2}{*}{1} \\
\hline & & $\mu$ & & 9 & & 71 & & 1 & \\
\hline., 771 & $r r$ &., 70 & IV &., 70 & 1. & $\cdot, 7$ & 7 & $\cdot, V$. & $r$ \\
\hline
\end{tabular}


أثر استراتيجيتين للفصول المعكوسة التشاركية "التقدمية/الرجعية" أ.مني السيد العربي

\begin{tabular}{|c|c|c|c|c|c|c|c|c|c|}
\hline \multirow{5}{*}{ كرونباخ ألفا } & & ألفا & & ألفا & & ألفا & & ألفا & \multirow{5}{*}{ مفردة } \\
\hline & امفردة & كرونباخ & مفردة & كرونباخ & امفرد & كرونبا & امفردة & كرونباخ & \\
\hline & & عذد & & عند & & خ عند & & عند & \\
\hline & & حذف & & هنف & & حذف & & حظف & \\
\hline & & المفردة & & لمفردة & & المفردة & & المفردة & \\
\hline \multirow{3}{*}{ צד , • } & & 9 & & r & & Tr & & 9 & \\
\hline & $Y \xi$ & • & 11 & D & 11 & . 7 & V & $\cdot, \mathrm{V}$. & $r$ \\
\hline & & 9 & & 1 & & 09 & & 。 & \\
\hline \multirow[t]{2}{*}{$\cdot, T \leq Y$} & ro & ., vo & 19 & D & Ir & . 7 & $\wedge$ & $\cdot, v_{1}$ & $\varepsilon$ \\
\hline & & r & & $\varepsilon$ & & 90 & & 9 & \\
\hline \multirow[t]{2}{*}{.,$Y \circ V$} & Y & 0,7 & $r$. & 0 & ir & & & & \\
\hline & & $v$ & & 1 & & & & & \\
\hline \multirow[t]{4}{*}{ ודצד, } & $r V$ & . & rI & צ T, • & $1 \varepsilon$ & & & & \\
\hline & & 7 & & 9 & & & & & \\
\hline & & & & \& & 10 & & & & \\
\hline & & & & $\wedge$ & & & & & \\
\hline$=$ & & $=$ & & & & $=$ & & $=$ & الفا \\
\hline \multirow[t]{2}{*}{ r, } & & • & & & & •, 7 & & $\cdot, V_{1}$ & للعامل \\
\hline & & 9 & & & & 97 & & 9 & \\
\hline
\end{tabular}

ويوضح الجدول السابق أن معامل الثبات للأبعاد ينخفض عند حذف المفردة وهذا ما يعني ثبات الأبعاد الفرعية للبطاقة وأن حذف أي من المفردات يؤثر سلبا على درجة ثبات البطاقة وتم حساب معامل الثبات لأبعاد البطاقة والثبات للبطاقة ككل

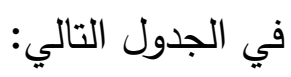


جدول معامل ألفا كرونباخ لأبعاد البطاقة وللبطاقة ككل

\begin{tabular}{|c|c|c|}
\hline ألفارقم المفردة & كرونباخ & الأبعاد \\
\hline$\varepsilon-1$ & $\cdot, \vee 19$ & واجهة التفاعل \\
\hline $1-0$ & • & الارتباط التشعبي \\
\hline r) -9 &., 709 & محتوي الموقع \\
\hline \multirow[t]{2}{*}{$r V-r Y$} & •, & الوسائط المتعددة \\
\hline & $\cdot, V Y$. & بطاقة تقييم المنتج ككل \\
\hline
\end{tabular}

يتضح من الجدول السابق أن البطاقة تتمتع بدرجة عالية من الثبات. (r) طريقة التجزئة النصفية.

تم حساب الثبات بطريقة التجزئة النصفية، حيث تم تجزئة البطاقة الي نصفين (المفردات فردية الرتبة والمفردات زوجية الرتبة) لكل بعد على حدة ثم حساب معامل ارتباط سبيرمان بين درجات نصفي البطاقة وحساب معامل ثبات البطاقة ككل كما يوضحه الجدول التالي:

جدول معامل الثبات بطريقة التجزئة النصفية

\begin{tabular}{|c|c|}
\hline جتمان & الأبعاد \\
\hline$\cdot, \times \backslash 1$ & واجهة التفاعل \\
\hline$\cdot, \vee \cdot O$ & الارتباط التشعبي \\
\hline$\cdot, V T r$ & محتوي الموقع \\
\hline$\cdot, \wedge \cdot 1$ & الوسائط المتعددة \\
\hline$\cdot, \vee>70$ & بطاقة تقييم المنتج ككل \\
\hline
\end{tabular}

وهي قيم مرتقعة الدالة احصائيًا مما يعني ثبات البطاقة وصـلاحيتها للتطبيق. 


\section{أثر استراتيجيتين للفصول المعكوسة التشاركية "التقدمية/الرجعية" أ.مني السيد العربي}

\section{رابعًا: إجراء التجربة الاستطلاعية للبحث}

هدف الباحثة من تطبيق التجربة الاستطلاعية هو تجريب بيئتي الفصول المعكوسة علي العينة الاستطلاعية من طلاب الدراسات العليا قسم تكنولوجيا التعليم

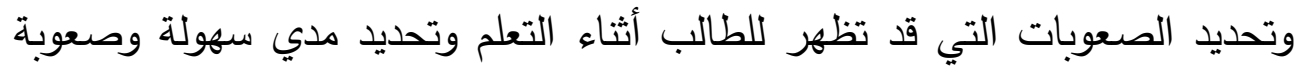

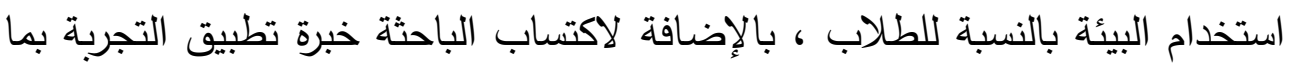

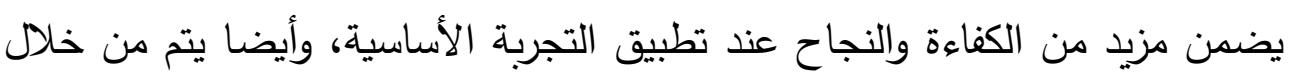
تطبيق التجربة الاستطلاعية قياس مدي صدق وثبات النبات أدوات البحث ومدي سهولة

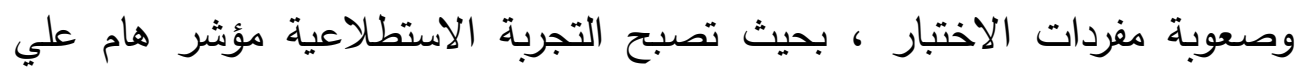
صلاحية تطبيق أدوات البحث علي العينة التجريبية.

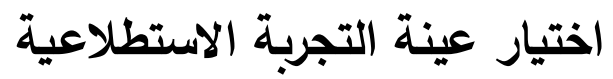
قامت الباحثة باختيار طلاب العينة الاستطلاعية بطريقة عشوائية من مجتمع الاسته

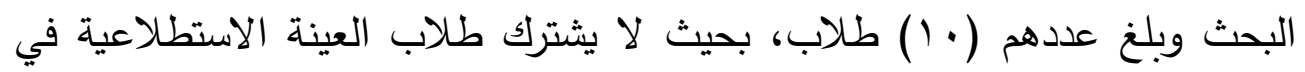
تطبيق العينة الأساسية. نتائج التجربة الاستطلاعية التينة أسفرت نتائج التجربة الاستطلاعية للبحث علي: أ- اتفاق معظم الطلاب على وضوح أهداف المقرر، وجودة الاستطلاعلئ الفيديوهات

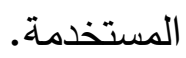

ب- إعجاب معظم الطلاب بالتجربة ومحاولة الاستفادة منها. ج- التعرف على أسس الفصول المعكوسة وكيفية استخدامها والتعرف على بيئة فصول جوجل من جانب بعض الطلاب للاستفادة منها في تدريس بعض المواد

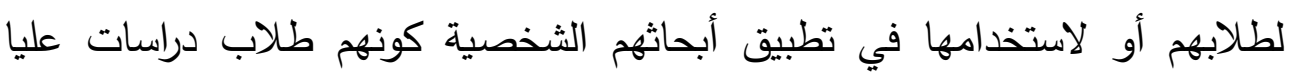
وبعضهم معلمين في مدارس. 
د- كما أسفرت النتائج عن صدق وثبات أداة الاختبار التحصيلي. هـ - وصدق وثبات أداة مقياس الرضا، وارتباط المحاور الرئيسية بالمقياس. و - وأيضا صدق وثبات بطاقة تقييم المنتج. ز - صلاحية بيئة Google Classroom للتطبيق. ح- تحديد زمن الاختبار التحصيلي. ط- التوصل إلى ملاحظات ومقترحات تفيد الباحثة عند تطبيق العينة الأساسية. خامسًا: تطبيق التجربة الأساسية للبحث بعد الانتهاء من إجراء التجربة الاستطلاعية والتأكد من صلاحية أدوات البحث والمعالجة التجرببية والبيئة للتطبيق، قامت الباحثة بالبدء في إجراء التجربة الأساسية. وقامت الباحثة باختيار طلاب العينة الأساسية بطريقة عشوائية من مجتمع البحث وبلغ عددهم (1) طالب من طلاب الدراسات العليا، تم تقسيم الطلاب إلى مجموعتين تجريبيتين وفقا للتصميم التجريبي بحيث تشمل كل مجموعة على طالب، وأعدت الباحثة بيئتي للتعلم هما بيئة الفصل المعكوس التقدمي وبيئة الفصل المعكوس الرجعي.

سادسًا: تكافؤ المجموعتين التجريبيتين للتحقق من تكافؤ مجموعتي البحث، تم استبعاد آثار المتغيرات الضابطة في متغيرات البحث وذلك بالتحكم في هذه المتغيرات وضبطها أو عزل أثرها في نتائج البحث البعدية، ومن هذه المتغيرات ما يلي:

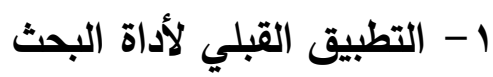

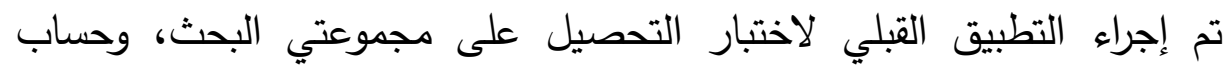
مستوي الدلالة الإحصائية لقيمة اختبار ت للفرق بين درجات مجموعتي البحث، ويوضح ذلك الجدول التالي: 


\section{أثر استراتيجيتين للفصول المعكوسة التشاركية "التقدمية/الرجعية" أ.مني السيد العربي}

جدول نتائج اختبار " ت " للفرق بين متوسطي درجات المجموعتين في التحصيل

\begin{tabular}{|c|c|c|c|c|c|c|}
\hline مستوي & الحرجة & قيمة & الانحراف & الحستوسط & العدد & المجموعة \\
\hline غير دالة & & & $\{, 09$ & $9, \wedge 7$ & $r_{1}$ & تقدمي \\
\hline احصائيا & rq & $1, \times 71$ & $0, V_{1}$ & Ir,V. & $r$. & رجعي \\
\hline
\end{tabular}

يتضح من الجدول السابق عدم وجود فروق ذات دلالة إحصائية بين متوسطات درجات المجموعتين في التطبيق القبلي، مما يعتبر مؤشراً على تكافؤ مجموعتي

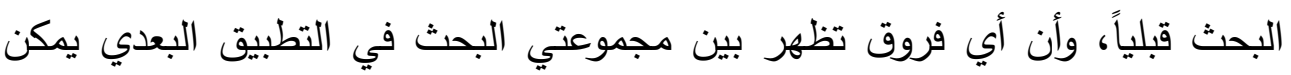
ارجاعها الي اختلاف المعالجة التدريسية. نتائج الاراسة وتفسيرها النتائج المتعلقة بالفرض الاول قامت بالتحقق من صحة الفرض الأول والذي ينص على: لا يوجد فرق دال إحصائيًا عند مستوى ج 0., • بين متوسطي درجات الكسب لطلاب المجموعتين التجريبيتين في أداء مهارات تطوير المواقع التعليمية عند الدراسة باستخدام بيئة

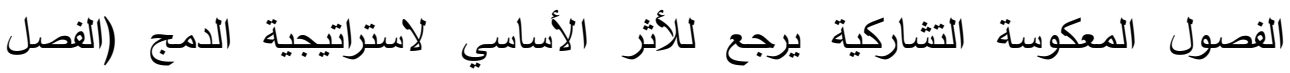
المعكوس التقدمي مقابل الفصل المعكوس الرجعي). ولاختبار صحة هذا الفرض قامت الباحثة بوصف وتحديد درجات المجموعتين

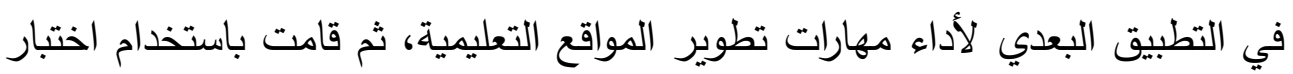
(ت) المجموعتين المستقلتين غير المتساويتين في عدد الأفراد، وبتطبيق اختبار(ت) لفرق المتوسطين، لقياس مقدار دلالة الفرق بين متوسطي درجات مجموعتي البحث اتضح ما يلي: 
جدول نتائج اختبار " ت " للفرق بين متوسطي درجات المجموعتين التجربيتين في بطاقة تقييم المنتج

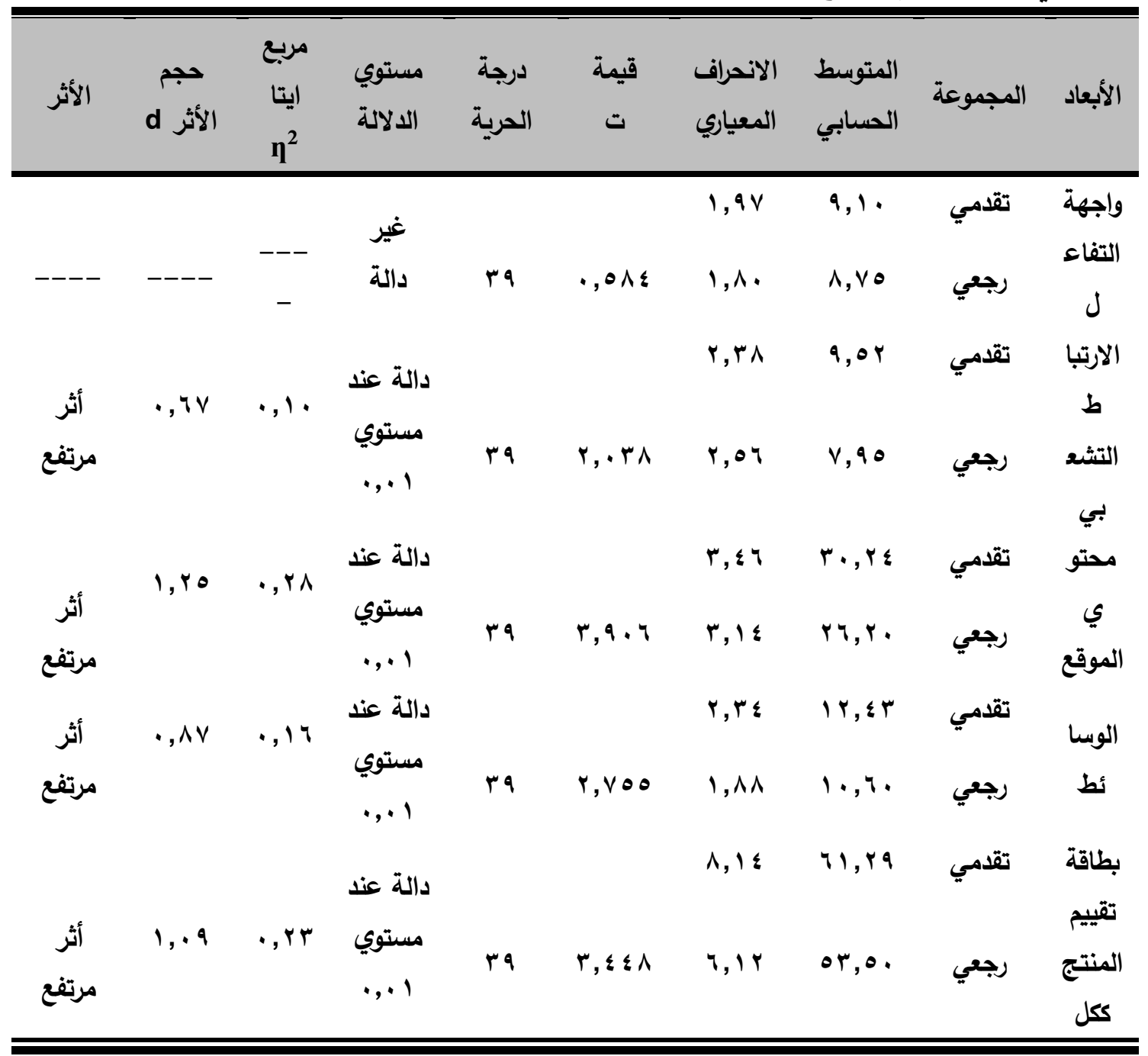

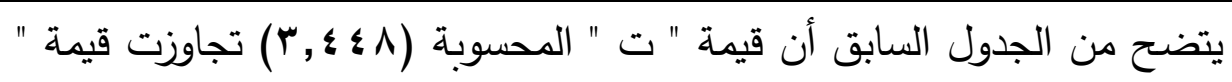
ت " الجدولية عند درجة حرية (q ) ) ومستوى دلالة (1 (., ) مما يدل على وجود فرق حقيقي بين متوسطي درجات المجموعتين في التطبيق البعدي لصالح مجموعة 


\section{أثر استراتيجيتين للفصول المعكوسة التشاركية "التقدمية/الرجعية" أ.مني السيد العربي}

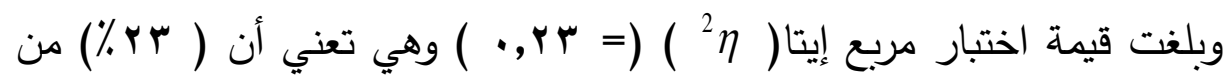

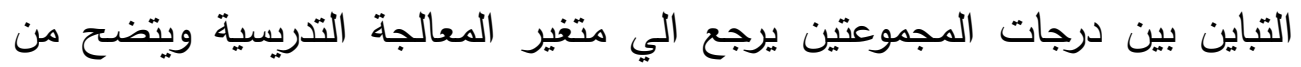

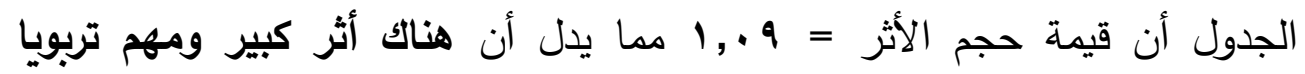
لاستخام استراتيجية الفصول المعكوسة التشاركية التقدمية في تنمية الأداء لمهارات تطوير المواقع التعليمية. ويتضح مما سبق وجود فروق واضحة بين درجات مجموعتي البحث في التطبيق

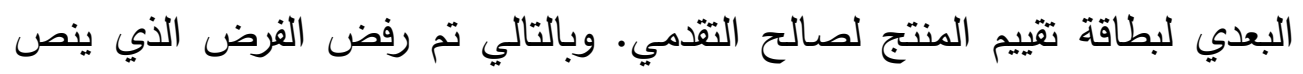

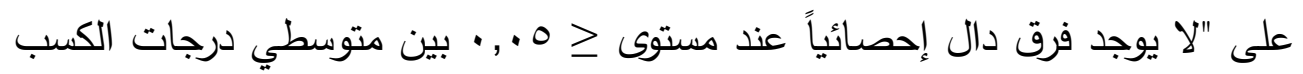

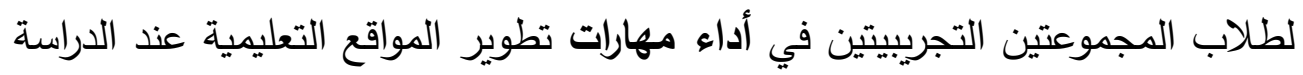

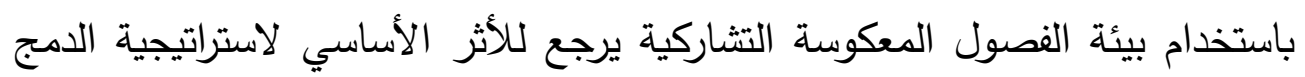
(الفصل المعكوس التقدمي مقابل الفصل المعكوس الرجعي). النتائج المتعلقة بالفرض الثاني

قامت بالتحقق من صحة الفرض الثاني والذي ينص على : لا يوجد فرق دال

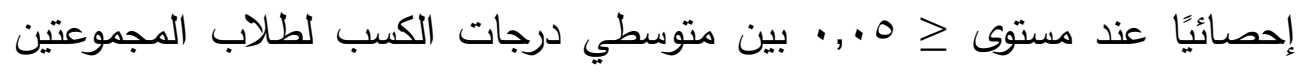
التجريبيتين في اختبار التحصيل المعرفي المرتبط بمهارات تطوير المواقع التعليمية بندية

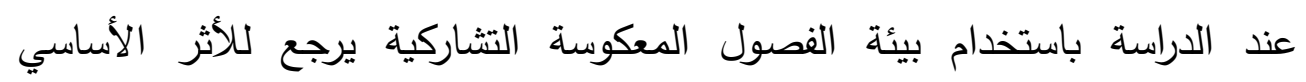
لاستراتيجية الدمج (الفصل المعكوس التقدمي مقابل الفصل المعكوس الرجعي). ولاختبار صحة هذا الفرض قامت الباحثة بوصف وتحديد درجات المجموعتين

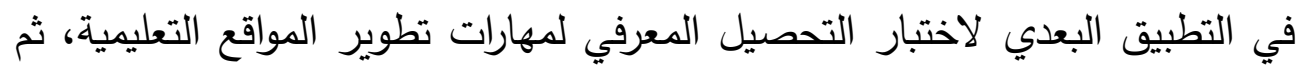

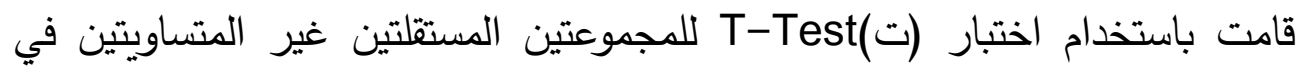
عدد الأفراد، وبتطبيق اختبار (ت) لفرق المتوسطين لقياس مقدار دلالة الفرق بين متوسطي درجات مجموعتي البحث اتضح ما يلي: 
جدول نتائج اختبار " ت " للفرق بين متوسطي درجات المجموعتين التجريبيتين

في الاختبار التحصيلي

\begin{tabular}{|c|c|c|c|c|c|c|c|c|}
\hline الأثر & $\begin{array}{l}\text { الأثر } \\
\text { d }\end{array}$ & $\begin{array}{l}\text { مربتا } \\
\text { "2 }\end{array}$ & مستوي & الحرية & قيمة & الانعراف & الحسابي & المجموء \\
\hline أثث & & & دالة عند & & & 7,90 & $r \varepsilon, T V$ & تقدمي \\
\hline كبير & $\cdot, 9 \leqslant$ & $\cdot, 1 \wedge$ & مستوي & rq & $\begin{array}{c}r, \wedge q \\
\vee\end{array}$ & $\{, \leqslant\rceil$ & rq, ro & رجعي \\
\hline
\end{tabular}

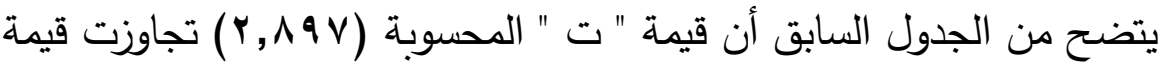

" ت " الجدولية عند درجة حرية (q ب) ومستوى دلالة (1 (.,·) مما يدل على وجود فرق حقيقي بين متوسطي درجات المجموعتين في التطبيق البعدي لصالح الفصل المعكوس التقدمي (ذو المتوسط الأكبر) .

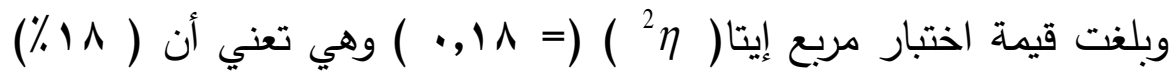
من التباين بين درجات المجموعتين يرجع الي متغير المعالجة التدريسية ويتضح من الجدول أن قيمة حجم الأثر = ؟ 9, • مما يدل علي أن مستوي الأثر كبير ، وأن هناك أثر كبير ومهم تربويًا لاستخدام استراتيجية الفصول المعكوسة التشاركية التقدمية في تنمية التحصيل المعرفي لمهارات تطوير المواقع التعليمية. ويتضح مما سبق وجود فروق واضحة بين درجات مجموعتي البحث في التطبيق البعدي لاختبار التحصيل المعرفي لمهارات تطوير المواقع التعليمية، وبالتالي تم رفض الفرض الذي ينص على" لا يوجد فرق دال إحصائياً عند مستوي ا ب,. ب بين متوسطي درجات طلاب المجموعتين في التطبيق البعدي لاختبار التحصيل المعرفي لمهارات تطوير المواقع التعليمية لصالح الفصل المعكوس التقدمي. 


\section{أثر استراتيجيتين للفصول المعكوسة التشاركية "التقدمية/الرجعية" أ.مني السيد العربي}

\section{خامسًا: نتائج البحث}

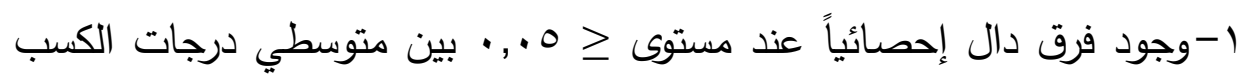

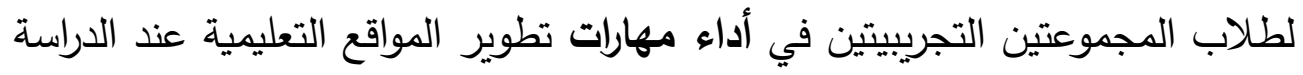
باستخدام بيئة الفصول المعكوسة التشاركي لصالح الفصل المعكوس التقدمي.

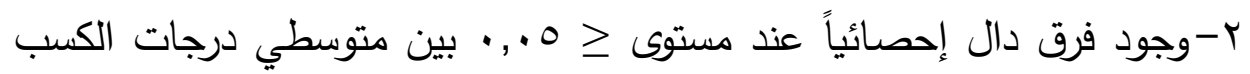

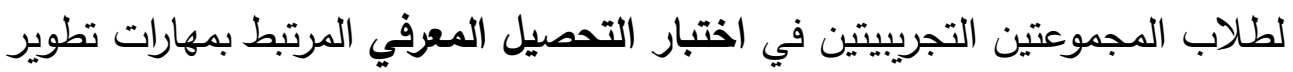
المواقع التعليمية عند الدراسة باستخدام بيئة الفصول المعكوسة التشاركية لصالح التصيل الفصل المعكوس التقدمي. سادسًا: مناقشثة النتائج 1-تفسير النتيجة الأولي والثانية الخاصة ببطاقة تقييم المنتج والاختبار

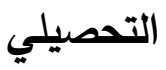

استخدام بيئة الفصل المعكوس التثاركي التقدمي ساعدت كل طالب علي

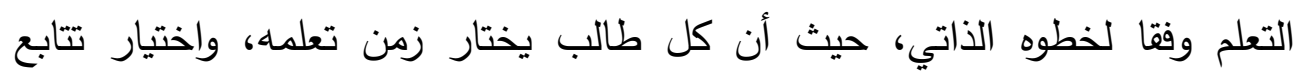

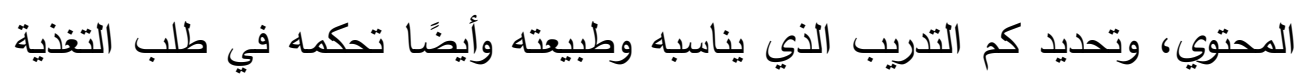

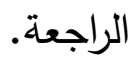

• كما ساعد الفصل المعكوس التشاركي التقدمي على تحول دور المتعلم من تلفي

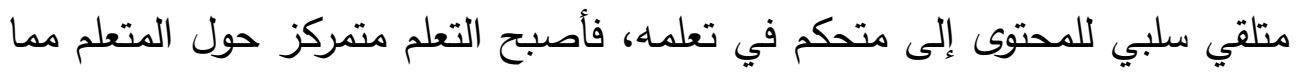
جعل ناتج تعلمه أفضل. " كما أن بيئة الفصل المعكوس التشاركي التقدمي تمكن المتعلم من تعلم

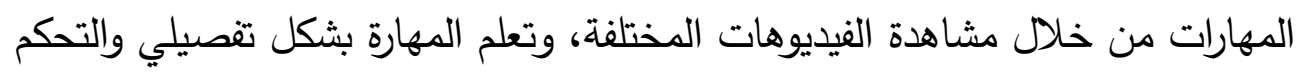
في الفيديو بالإيقاف أو التثغيل عدة مرات حسب قدرته على الفيلى الاستيعاب، بالإضافة إلى وجود ملفات نصية تثمل محتوي الفيديو مما يدعم تعلم المهارة. 
تري الباحثة أن بيئة الفصل المعكوس التشاركي التقدمي تتيح مصادر للتعلم بأثكال مختلفة ومتنوعة، مما جعل بيئة التعلم تتتاسب مع احتياجات جميع الطلاب، وأتاح الفرصة بشكل أكبر أمام المتعلم لتعلم المزيد من الجوانب المعرفية الخاصة بالمهارات، حيث يتم التعلم من خلال الفيديوهات بالإضافة إلى ملفات النصوص

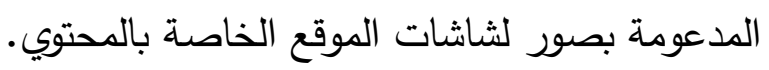

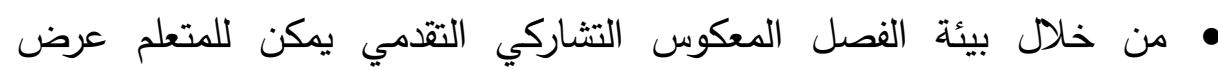
الأنثطة الخاصة به على زملائه وبالتالي يحدث تبادل في الخبرات بين الطلاب وبعضهم البعض، واستفادة المتعلم من مميزات وأخطاء زملائه، مما زاد من كفاءة المنتج النهائي. لاحظت الباحثة وجود شعور بالارتياح النفسي لدى طلاب الفصل التقدمي، عندما تركت لهم حرية تحديد طريقة تعلمه، حيث أن كل متعلم يثعر أنه محور العملية التعليمية، من خلال تلبية احتياجاتهم التعليمية.

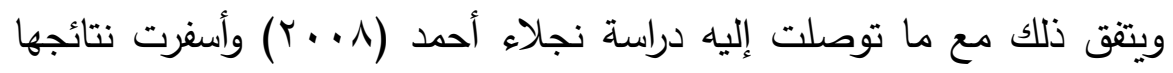
عن وجود فرق دال إحصائيا عند مستوي > 0 .,. ب بين المجموعتين التجريبيتين (النشط مقابل العادي Reactive) لصالح النشط في الأداء المهارى لاستخدام شبكة الإنترنت.

ويتفق أيضا مع ما توصلت إليه دراسة ماهر زنقور (10 ب. (10) حيث أسفرت نتائجها على وجود فروق دالة إحصائيا عند مستوي( ( . · ) بين متوسطي درجات طلاب المجموعتين التجريبيتين تحكم المتعلم مقابل تحكم البرنامج في (أنماط التعلم المفضلة، تتمية مهارات معالجة المعلومات، مستويات تجهير المعلومات، وتتمية مهارات التفكير المستقبلي) لصالح تحكم المتعلم فيما عدا مستويات تجهيز المعلومات في المستوي الهامشي والمتوسط لصالح تحكم البرنامج بينما المستوي العميق لصالح تحكم المتعلم. ويتفق ذلك مع ما توصلت إليه دراسة كلا من (الطيب الناشري، r ا ــ؟؛ هويدا

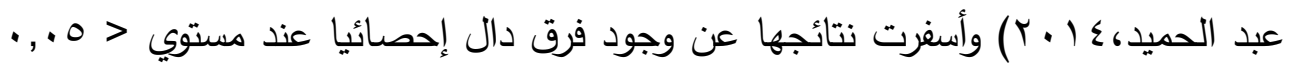
rwV 


\section{أثر استراتيجيتين للفصول المعكوسة التشاركية "التقدمية/الرجعية" أ.مني السيد العربي}

بين المجموعتين التجريبيتين (تحكم المتعلم مقابل تحكم البرنامج) لصالح مجموعة تحكم

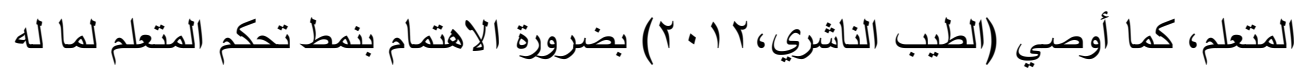
من تأثير فعال بالنسبة للتحصيل الدراسي.

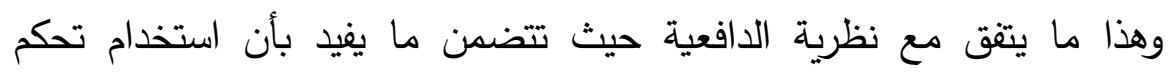

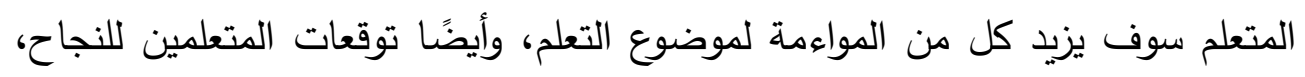

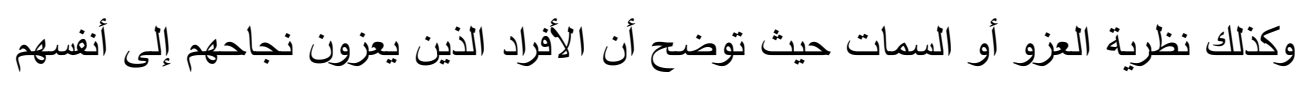

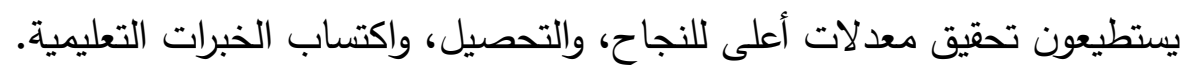

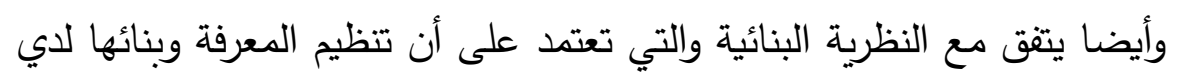

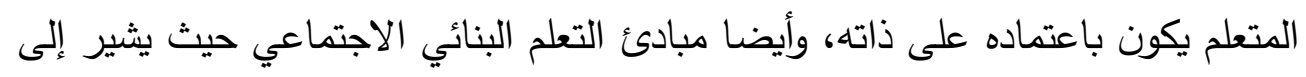

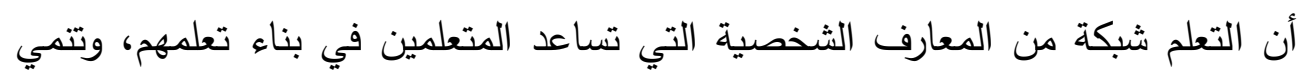

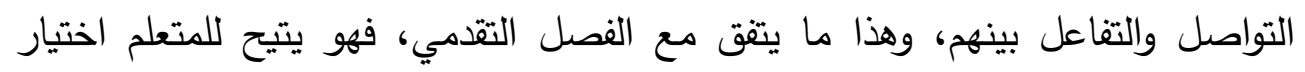

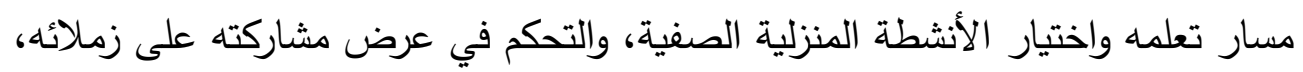
مما نتج عنه زيادة التحصيل والأداء المهارى.

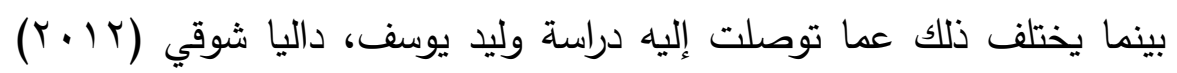
والتي هدفت إلى قياس أثر استراتيجيتي التعلم المدمج (التقدمي / الرجعي) في إكساب التبات

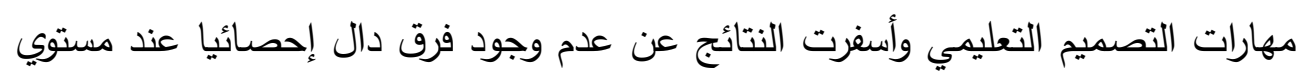

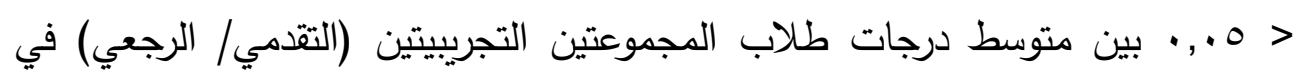

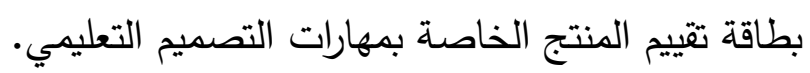

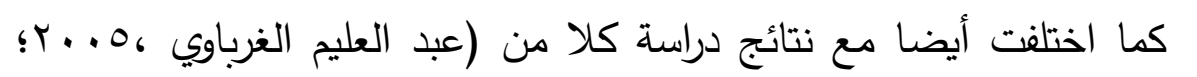

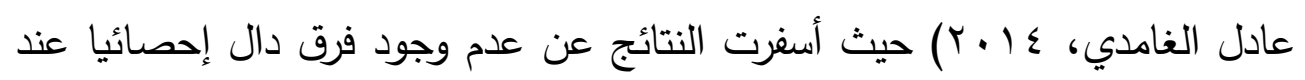
مستوي دلالة > ه., • بين متوسطي درجات طلاب المجموعتين التجريبيتين (تحكم

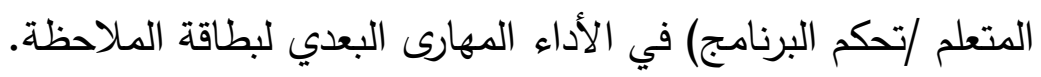


وتختلف مع ما توصلت إليه دراسة كلا من (خالد عبد العال، 1 ( ـ ؟؛ عادل

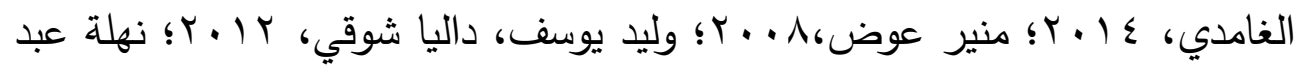

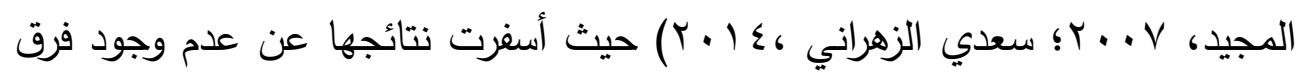
دال إحصائيا عند مستوي (0. . •) بين المجموعتين التجربييتين (تحكم المتعلم مقابل

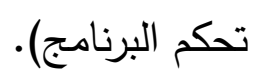

\section{سابعًا: توصيات البحث}

ا. ضرورة الاهتمام بتطبيق استراتيجية الفصل المعكوس في مواد دراسية

مختلفة.

r. السعي نحو تصميم كافة المقررات بشكل إلكتروني مما يسهل علي المعلم

استخدامها دون تحمل أعباء إنتاج المحتوي الالكتروني.

r. تشجيع المعلمين على استخدام الاستراتيجيات التعليمية الحديثة في التعليم

ومن بينها استراتيجية الفصول المعكوسة

ع. ضرورة الاهتمام بتمية مهارات تطوير المواقع التعليمية لدي الطلاب من

خلال المستحدثات التكنولوجية الحديثة.

0. تطبيق استراتيجية الفصول المعكوسة في مراحل التعليم الجامعي لكونها

مناسبة لخصائص هذه الفئة. ثامنًا: مقترحات البحث

قياس أثر استراتيجيتي الفصول المعكوسة التثاركية والفردية (التقدمية/ الرجعية) على نواتج مختلفة.

قياس فاعلية التعلم النقال المعتمد على استراتيجية الفصول المعكوسة في تتمية مهارات مختلفة.

• أثر الفصول المعكوسة في زيادة دافعية الإنجاز لدي المتعلمين. 
أثر استراتيجيتين للفصول المعكوسة التشاركية "التقدمية/الرجعية" أ.مني السيد العربي

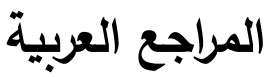

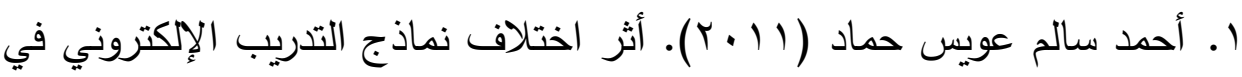

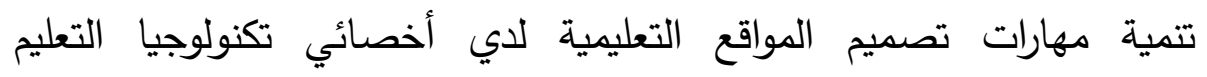

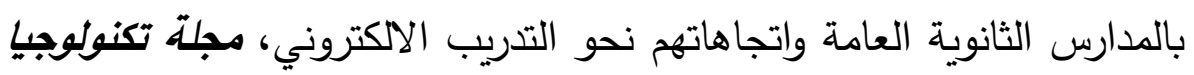

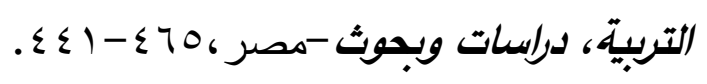

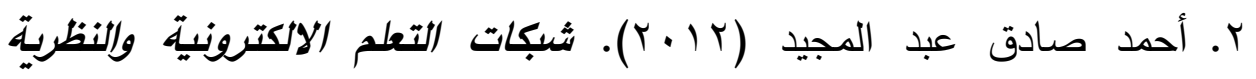

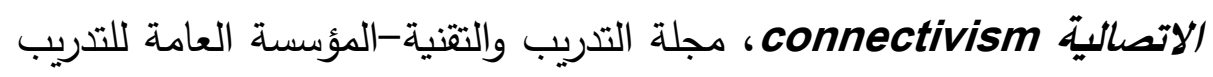

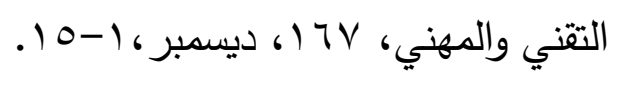

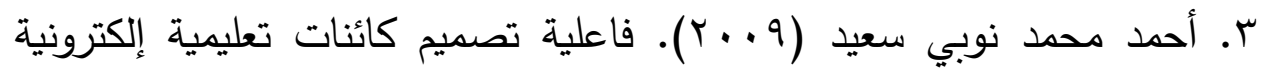

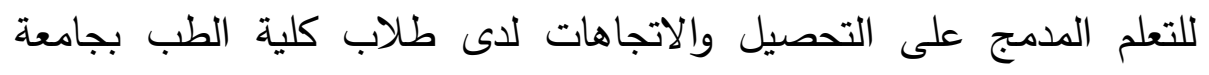

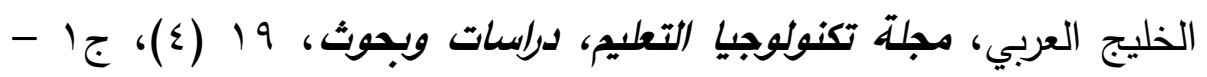
أكتوبر .

ع. اسلام جابر علام(10 • ب). أنماط التشارك عبر محررات الويب التشاركية

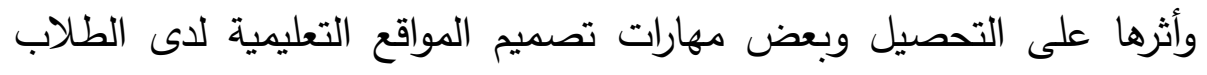

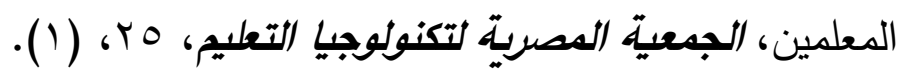

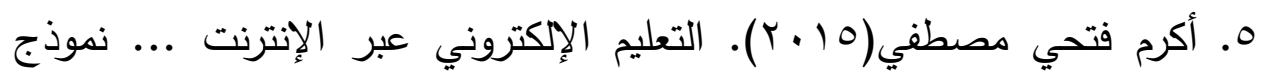

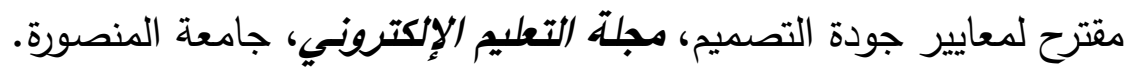

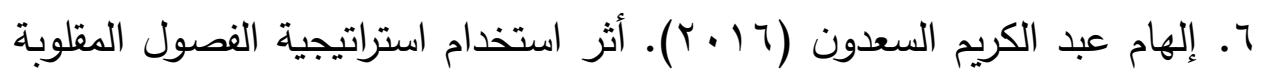

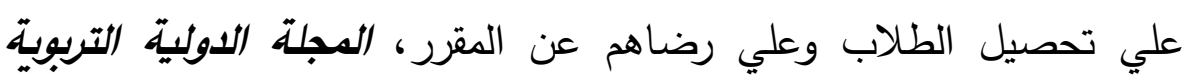

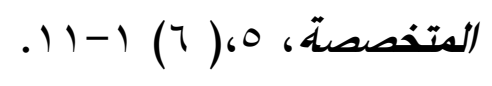

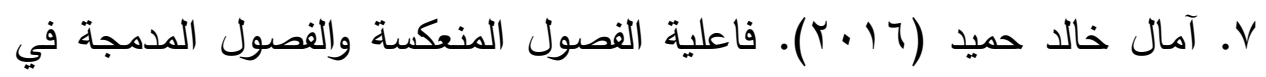

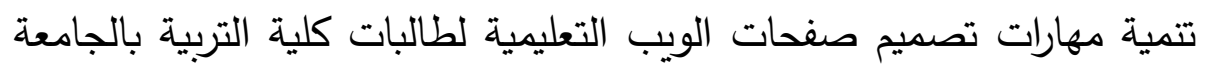


الإسلامية بغزة، رسالة ماجستير منشور، كلية التربية، الجامعة الإسلامية

بغزة.

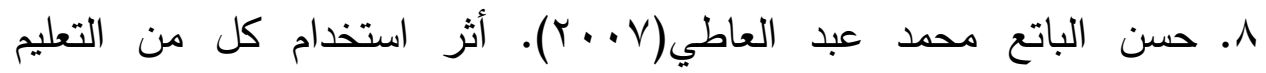

الإكتروني والتعليم المدمج في تتمية مهارات تصميم وإنتاج مواقع الويب التعليمية لدى طلاب الدبلوم المهنية واتجاهاتهم نحو تكنولوجيا التعليم الإلكتروني، المؤتمر العلمي الثالث للجمعية العربية لتكنولوجيا التربية بالاثتراك مع معق الدراسات التربوبية - جامعة القاهة، تكنولوجيا التعليم

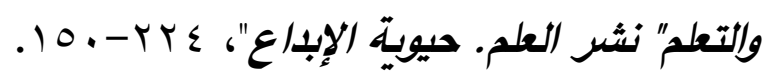

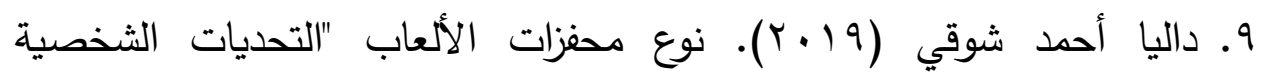

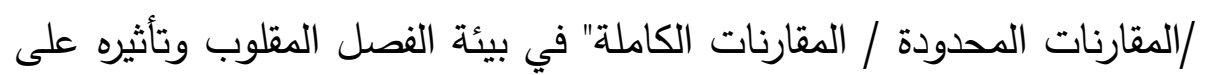
تتمية التحصيل ومهارات تصميم خدمات المعلومات الرقمية وتقديمها والانخراط في بيئة التعلم لدي طلاب شعبة تكنولوجيا التعليم، المجلة التربويةّ، جامعة

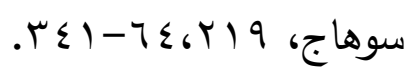

• 1. رباب عبد المقصود البلاصي (10 • ( ). أثر استراتيجية التعلم المقلوب Learning Flipped

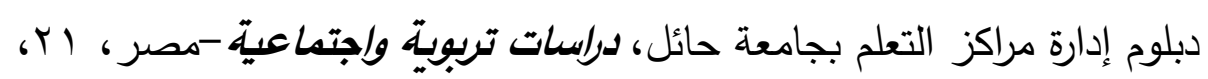

11. رحاب زناتي(10 ( ب). برنامج للتغلب على صعوبات الكتابة التي تواجه المبتدئين الناطقين بغير العربية باستخدام الفصل المقلوب الافتراضي المعتمد

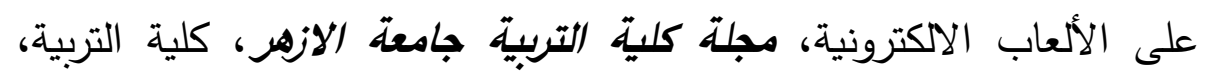

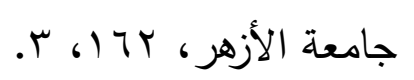

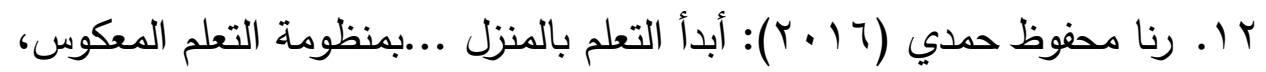
مجلة التعليم الإكترونسي، جامعة المنصورة. 


\section{أثر استراتيجيتين للفصول المعكوسة التشاركية "التقدمية/الرجعية" أ.مني السيد العربي}

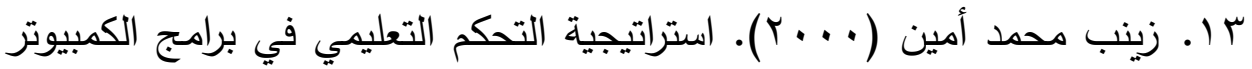
ووجهة الضبط وعلاقتهما بالتحصيل ودقة التعلم لدي طلاب كلية التربية

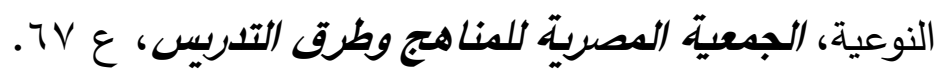

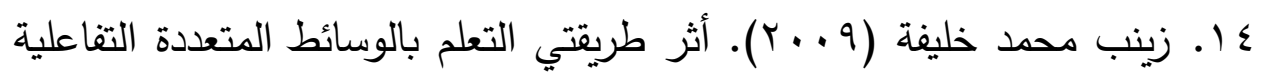
والتعلم الاكتروني التثاركي عبر الانترنت في اكساب مهارات استخدام أجهزة

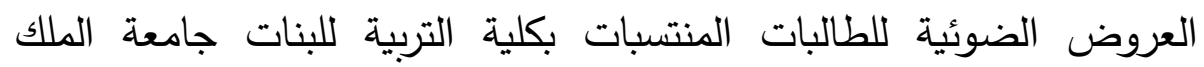

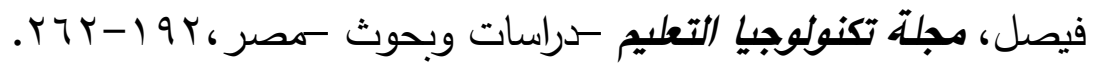

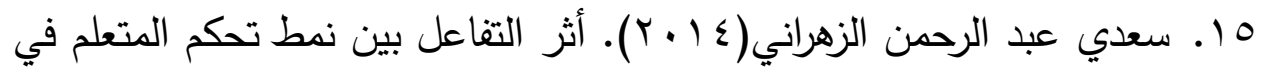
برمجية الوسائط المتعددة والأسلوب المعرفي في التحصيل في مقرر الكيمياء لطالبات المرحلة الثانوية، رسالة ماجستير منشورة ، جامعة الباحة-السعودية. 1 1 ـ شريف شعبان ابراهيم (10 • ب). أثر اختلاف نمط التفاعل في الوسائط الفائقة

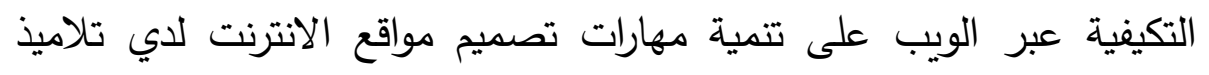

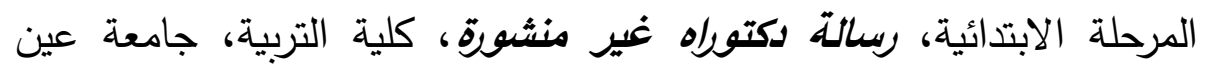

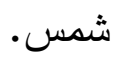

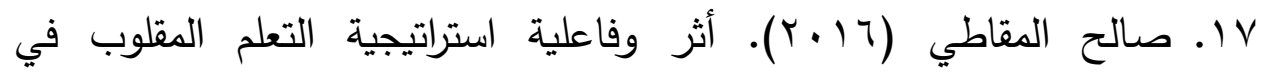
التحصيل الدراسي لطلاب المستوي الرابع في مقرر الدذخل للتدريس لكلية

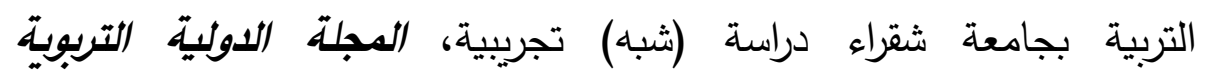

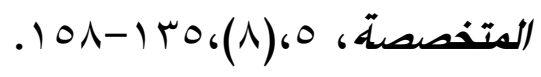

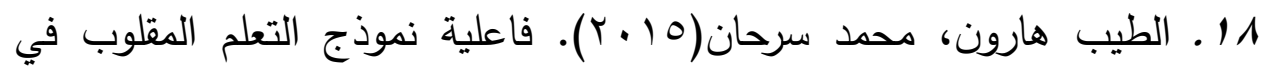

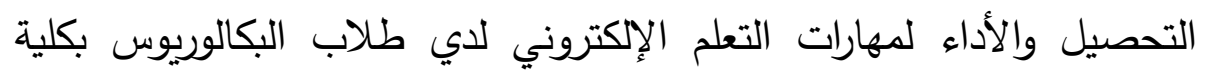

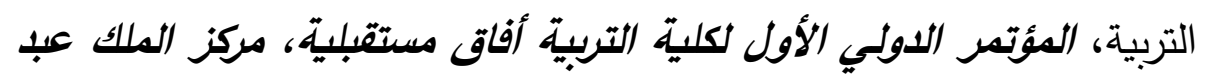

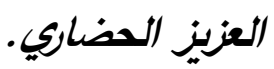


9 1. . عادل محمد أحمد الغامدي (ع ( ب). أثر التفاعل بين نمط التحكم التعليمي في برمجية الوسائط المتعددة والأسلوب المعرفي للمتعلم على مهارات البرمجة لطلاب المرحلة الثانوية، رسالة ماجستير منشورة، كلية التربية، جامعة الباحة -السعودية.

• r. عبد الرؤوف محمد إسماعيل (YV) . Y. اثر التفاعل بين أسلوب الضبط والتحكم (التقدمي/الرجعي) للتعلم المدمج المقلوب في تتمية مهارات التفاعل والتشارك الاككتروني وتعديل توجهات المسؤولية التحصيلية لدى التلاميذ

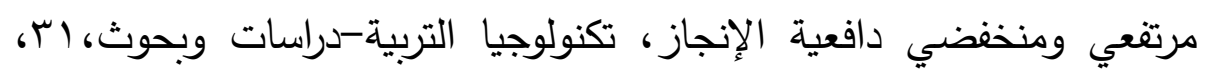
.1 rq-ror

اY. عبد العليم أحمد عبد العليم الغرباوي (0 . . ب). فاعلية اختلاف بعض أساليب التحكم ووجهة الضبط في برنامج كمبيوتري مقترح لتتمية مهارات تدريس لهـي الكمبيوتر لطلاب شعبة تكنولوجيا التعليم بكلية التربية، رسالة ماجستير، كلية

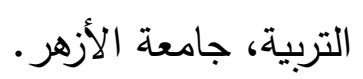

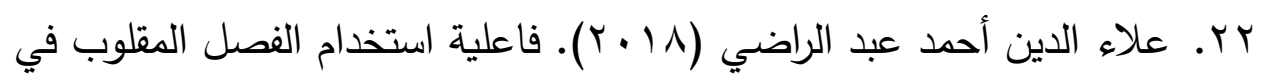
الدراسات الاجتماعية لتتمية مهارات التفكير التاريخي لدي تلاميذ المرحلة

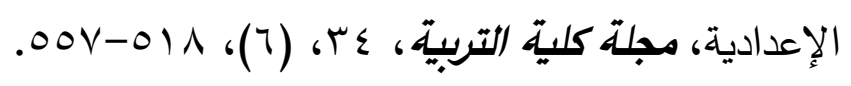

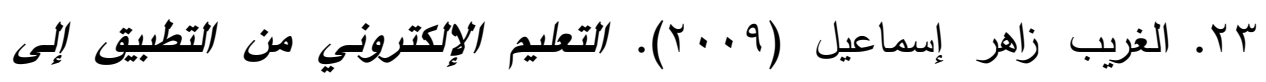
الاحتراف والجودة، القاهرة، عالم الكتب. צr. فؤاد إسماعيل عياد (1 . . r). مستوي توافر مهارات تطوير مواقع الويب لدي طلبة برنامج الماجستير في تخصص تكنولوجيا التعليم، مجلة الجمعية

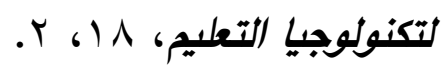




\section{أثر استراتيجيتين للفصول المعكوسة التشاركية "التقدمية/الرجعية" أ.مني السيد العربي}

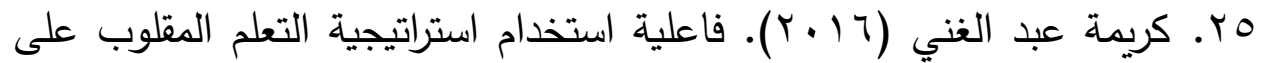
التحصيل وبقاء أثر التعلم في تدريس التاريخ لدي طلاب المرحلة الثانوية،

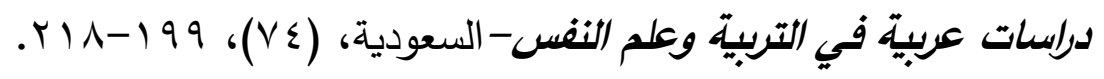

Tr. ماهر محمد صالح زنقور (10 • (Y). أثر الاختلاف بين نمطي التحكم " تحكم

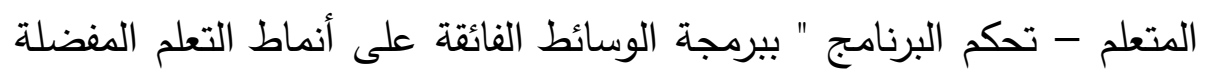
ومهارات معالجة المعلومات ومستويات تجهيزها والتفكير المستقبلي في

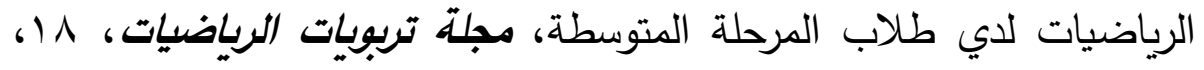

$$
.10 \leqslant-7 ،(0)
$$

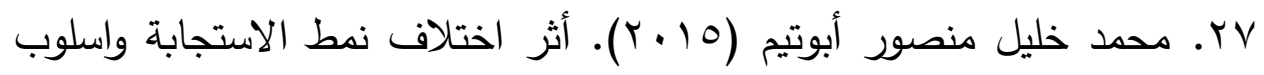
التحكم في زمن الاستجابة بالاختبارات الإلكترونية في خفض قلق الاختبار لدي

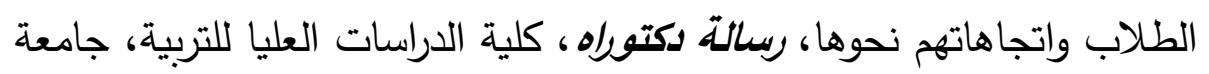
القاهرة.

^r. محمد طلعت جوهري محمد (9 . . ب).أثر استخدام بعض استراتيجيات التعلم النشط في تتمية مهارات تصميم المواقع الإلكترونية لدي تلاميذ الصف الإعدادي، رسالتة ماجستير ، معهد الدراسات التربوية، جامعة القاهرة. 9. . محمد عطية خميس (T . . Y). عمليات تكنولوجيا التعليم، القاهرة، مكتبة دار الكلمة.

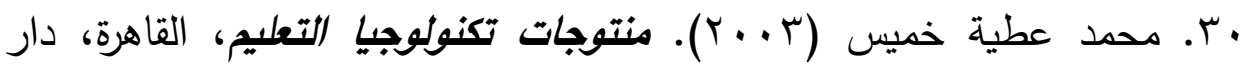
الحكمة. اب. محمد عنتر محمد (Y Y (Y). فاعلية برنامج مقترح قائم على التعلم المدمج في إكساب طلاب تكنولوجيا التعليم مهارات توظيف بيئات التعلم غير النمطية وتنمية اتجاهاتهم نحوها، رسالة دكتورله، جامعة عين شمس، كلية التربية. 
r.r. محمد فوزي والي ( • • ( ). فعالية برنامج تدريبي قائم على التعلم التشاركي عبر الويب في تتمية كفايات توظيف المعلمين لتكنولوجيا التعليم الإلكتروني في التدري، رسالة دكتوراه منشورة ، جامعة الإسكندرية، كلية التربية.

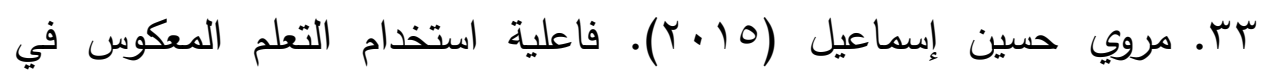
الجغرافيا لتنمية مهارات البحث الجغرافي لدي طلاب المرحلة الثانوية، مجلة

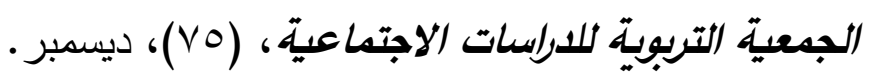

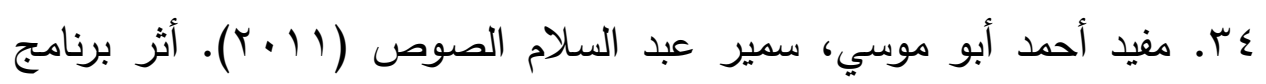
تدريبي قائم على التعلم المزيج (Blended Learning) في قدرة المعلمين على تصميم وإنتاج الوسائط المتعددة التعليمية. المؤتمر السنوي الثالث للمدارس الخاصة بعنوان: آفاق الثراكة بين قطاعي التعليم العام والخاص). الاردن: طيف للخدمات التعليمية. هr. منير سعيد علي عوض (1 . . r). أثر التقاعل بيم مستويات التحكم التعليمي ووجهة الضبط عند تصميم برامج الكمبيوتر متعدد الوسائط على تتمية التحصيل في مادة التكنولوجيا، حولية كلية البنات للآد/ب والثعلوم وإلتربية، لروبة

بT. ميسر ناصر عيد (Y V V V). فاعلية توظيف بيئة تعليمية قائمة علي الصف المقلوب في تتمية النحو والاتجاه نحوه لدى طالبات الصف التاسع الأساسي بغزة، سسالة ماجستير منشورة، كلية التربية، الجامعة الإسلامية بغزة.

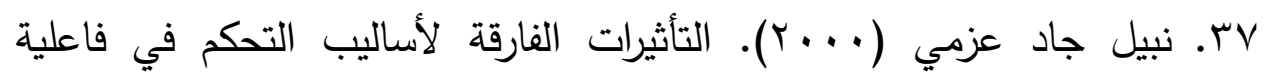
عناصر تصميم برامج الكمبيوتر التعليمية، رسالة دكتوراه، كلية التربية، جامعة حلوان.

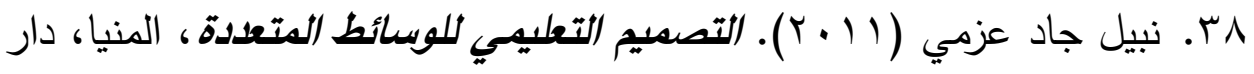
الهدي للنشر والتوزيع، طب. 


\section{أثر استراتيجيتين للفصول المعكوسة التشاركية "التقدمية/الرجعية" أ.مني السيد العربي}

qr. نبيل جاد عزمي (ع ا بr). بيئات التعلم التفاعلية، القاهة: دار الفكر

$$
\text { العربي. }
$$

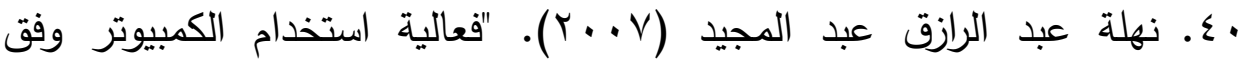

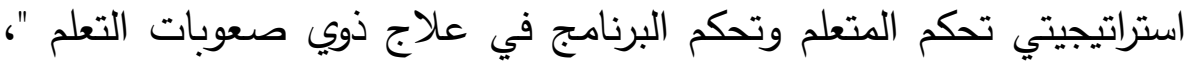
المؤتمر العلمي الأول لثباب الثباحثين، كلية التربية، جامعة أسيوط.

اء. نورة الذويخ (ع ( ب). أثر تطبيق مفهوم الصف المقلوب على نمو مهارات

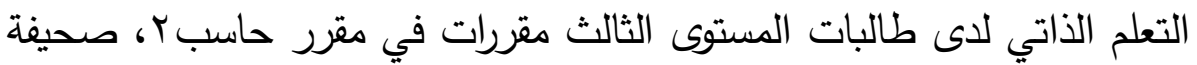

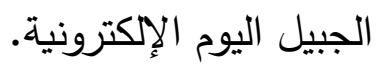

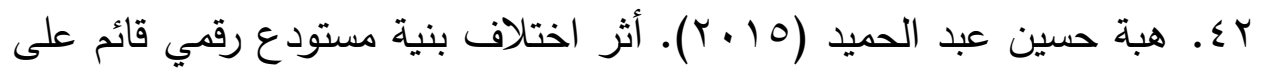

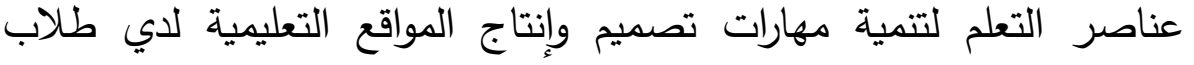

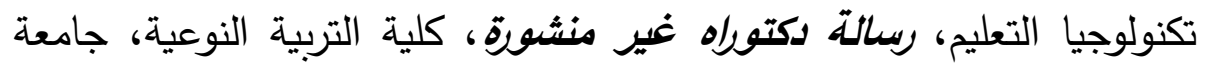
عين شمس.

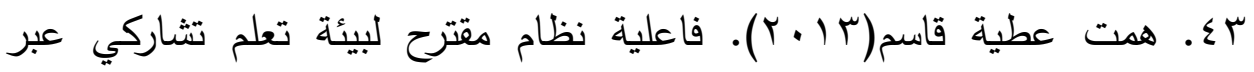
الإنترنت في تتمية مهارات حل المشكلات والاتجاهات نحو بيئة التعلم لدي طلاب تكنولوجيا التعليم، سالة دكتوراه، كلية التربية، جامعة عين شمس.

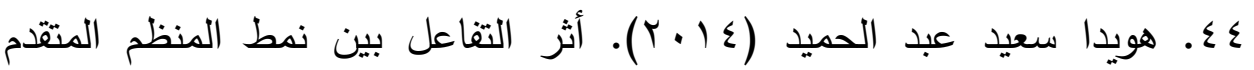

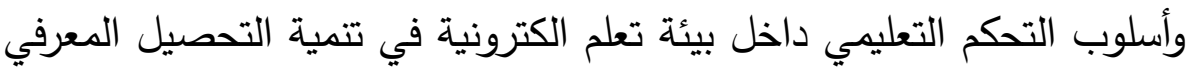

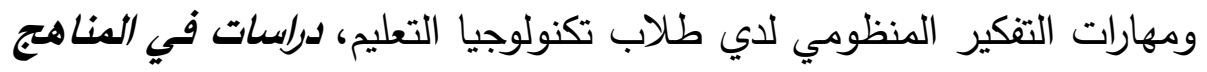

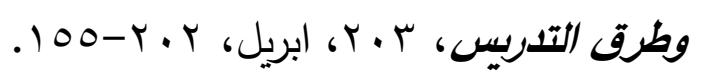

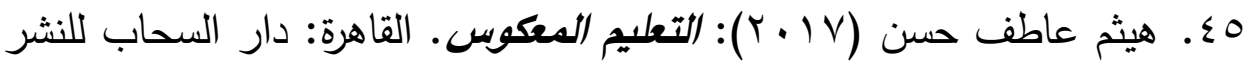
والتوزيع.

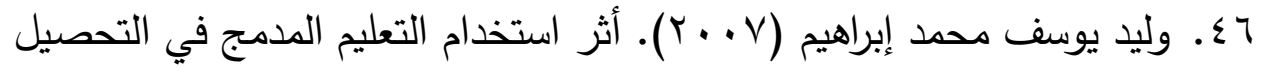

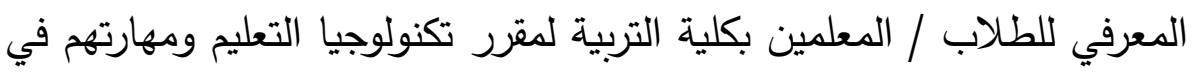


توظيف الوسائل التعليمية واتجاهاتهم نحو المستحدثات التكنولوجية التعليمية.

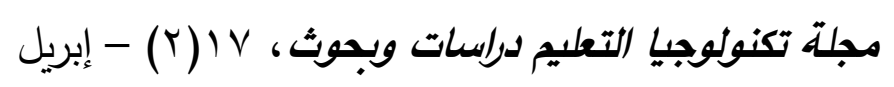

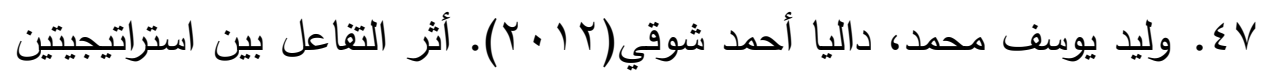

للتعلم المدمج التقدمي والرجعي ووجهتي الضبط في اكساب مهارات التصميم التعليمي للطلاب /المعلمين بكلية التربية وانخراطهم في بيئة التعلم المدمج،

$$
\text { دراسات عربية في التربية وعلم النفس،السعودية، (rV)، جr. }
$$

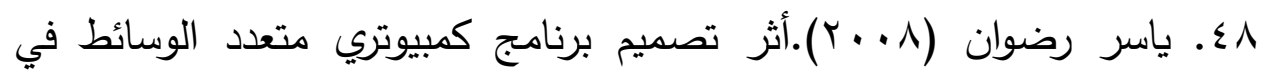

تتمية مهارات استخدام تكنولوجيا المعلومات والتحصيل والاتجاه نحوها لدي هيئة التدري بكلية فلسطين التقنية، رسالة ماجستير منشورة، غزة: برنامج الدراسات العليا المشترك بين جامعة الأقصى وجامعة عين شمس.

\section{المراجع الأجنبية}

1. Alekse, J. \& Chris, P. (2004): Reflections on the use of blended learning, the university of Sanford.

2. Alvaraez, Brenda.(2011)flipping theclassroom: Homework in class ,lessons at Home.national educational association.

3. Alvarez,B (2012). "Flipping the Classroom : Homework in Class, Lessons at Home", National Education Association , $77(8)$.

4. Aly.M , Elen.J (2005): Learner-Control Vs. ProgramControl Instructional Multimedia: A Comparison Of Two 


\section{أثر استراتيجيتين للفصول المعكوسة التشاركية "التقدمية/الرجعية" أ.مني السيد العربي}

Interactions When Teaching Principles Of Orthodontic Appliances - European Journal Of Dental Education Volume 9.

5. Barkley, A. (2015). Flipping the College Classroom for Enhanced Student Learning ,NACTA Journal,59(3),240.

6. Bergman, J. \& Sams, A. (2012): Flip your classroom: Reach every student in every class every day. Washington, DC: International Society for Technology in Education.

7. Bernatek, B \& et al. (2012). Blended Learning in Practice:Case Studies from Leading Schools . Retrieved from http://5a03f68e230384a218e0938ec019df699e606c950a5614b999bd.r33.cf2.rackcdn.co m/Blended_Learning_Kipp_083012.pdf. KIPP Empower Academy.

8. Bishop, J. and Averleger,M (2013). The Flipped classroom : A survey of the research 120th ASEE annual conference and exposition,American Society for Engineering Education.

9. Bliuc,AM,Goodyear,P,\&Ellis,RA.(2007)Research focus and methodlogical choices in studies into students experiences of blended learning in higher education Internet and Higher Education ,10,231-244. 
10. Brame, Cynthia J. (2013). “ Flipping theclassroom"Vanderbilt University forTeaching,

11. Bryan,Hopkins(2005).Learning Strategies, available at : http://www .bryanhopkins.co.ukllearningdesignltotorials.

12. Chehayeb, A. (2015). New in Classroom: saving time while grading. Retrieved from: http://googleforeducation.blogspot.com/2015/12/new -in-Classroom-saving-time-while-grading.html

13. Edman, Elaina (2010).Implementation of formative assessment in the classroom .A thesis submitted to fulfillment of the requirement for the tor, Saint Louis University.

14. Enfield, J. (2013). Looking at the impact of the flipped classroom model of instruction on undergraduate multimedia students at CSUN. TechTrends: Linking Research \& Practice to Improve Learning, 57(6), 14-27

15. Fallon, Jessi. (2015). GOOGLE CLASSROOM FOR THIRD GRADE WRITING. Rerieved from: http://rdw.rowan.edu/cgi/viewcontent.cgi?article $=157$ $6 \&$ context $=$ etd

16. Fulton,K (2012). Upside Down and Inside Out : Flip Your Classroom to Improve Student Learing . Learning \& Leading with Technology,39(8),June.12-17. 


\section{أثر استراتيجيتين للفصول المعكوسة التشاركية "التقدمية/الرجعية" أ.مني السيد العربي}

17. Graham, C. R. (2009). Blended Learning Models. In M. Khosrow-Pour, Encyclopedia of Information Science and Technology (pp. 375-382). IGI Global. Retrieved from http://ebooks.narotama.ac.id/files/Encyclopedia\%20of\%201 nformation $\% 20$ Science $\% 20$ and $\% 20$ Technology $\% 20$ (2nd\%2 0Edition)/Blended\%20Learning\%20Models.pdf

18. Hamadan ,N,et(2013).Areview of flipped learning Net work.

19. Horn, M. B., \& Staker, H. (2011). The Rise of K-12 Blended Learning. New York: Innosight Institute.Retrieved from www.innosightinstitute.org

20. https://www.uwosh.edu/training/ training-manuals/titanapps/TitanAppsforTeaching.pdf.

21. Iftakhar, Shampa. (2016). GOOGLE CLASSROOM: WHAT WORKS AND HOW? Retrieved from: http://jesoc.com/wpcontent/uploads/2016/03/KC3_35.pdf

22. Jeremy F. Strayer(2012): How learning in an inverted classroom influences cooperation, innovation and task orientation, Department of Mathematical Sciences, Middle Tennessee State University . 
23. Jong, S, D (2006): Learner Vs. System Control In Using Online Support For Simulation- Based Discovery Learning Springer, Learning Environments, Research 4(3).

24. Kathleen M. D. (2016) . The effects of Google Classroom on teaching social studies for students with learning disabilities, Rowan Digital Works ,Rowan University.

25. Klemm W.R.(2010):"Using a Formal Collaborative Learning Paradigm for Veterinary Medical Education",Texas A\&M University, DLA Ejournal.

26. lee\& wong (2008) : Cognition And Learner Control: A Literature Review, Journal Of Computer Based Instruction, 16.

27. Marco, Ronchetti. (2010): Using video lectures to make teaching more interactive. International Journal of Emerging Technologies in Learning (IJET),5(2),P.45-48.

28. Marshall, H. W. (2013). Three reasons to flip your classroom.

29. Mason,G. S, Shuman, T. R \& Cook, T. E. (2013). Comparing The Effectiveness of an Inverted Classroom to a Traditional Classroom in an Upper-division Engineering Course Education, leee Transactions,56(4),430-435. 


\section{أثر استراتيجيتين للفصول المعكوسة التشاركية "التقدمية/الرجعية" أ.مني السيد العربي}

30. Mendez, J, A \& Gonzalez, J, G(2010) A reactive blended learning proposal for an introductory control engineering course,Computers \& Education, 54, 856-865

31. Siemens.G (2005): Connectivism A Learning Theory for the Digital Age, International Journal of Instructional Technology and Distance Learning.

32. Singh, H. (2003,). Building Effective Blended Learning Programs. Journal of Educational Technology , 43 (6), December, pp. 51-54. Retrieved from http://asianvu.com/digital-library/elearning/blendedlearning-by_Singh.pdf

33. Vaughan, N.; Garrison, R. (2006). How Blended Learning Can Support A Faculty Development Community of Inquiry, Journal of Asynchronous Learning, Retrieved from:org/publications/jaln/v10n4/v10n4vaughan.asp.

34. Walne, M. B. (2012). EMERGING BLENDED-LEARNING MODELS AND SCHOOL PROFILES. Community Foundation.Retrieved from http://www.innosightinstitute.org/mediaroom/publications/blended-learning/blended-learningprofiles-all-profiles/ 